Prepared for the U.S. Department of Energy

Under Contract DE-AC05-76RL01830

\title{
Evaluation of Ultrasonic Measurement Variation in the Double-Shell Tank Integrity Project
}

AF Pardini

DR Weier

SL Crawford

JT Munley

January 2010

Pacific Northwest

NATIONAL LABORATORY

Proudly Operated by Battelle Since 1965 


\title{
DISCLAIMER
}

This report was prepared as an account of work sponsored by an agency of the United States Government. Neither the United States Government nor any agency thereof, nor Battelle Memorial Institute, nor any of their employees, makes any warranty, express or implied, or assumes any legal liability or responsibility for the accuracy, completeness, or usefulness of any information, apparatus, product, or process disclosed, or represents that its use would not infringe privately owned rights. Reference herein to any specific commercial product, process, or service by trade name, trademark, manufacturer, or otherwise does not necessarily constitute or imply its endorsement, recommendation, or favoring by the United States Government or any agency thereof, or Battelle Memorial Institute. The views and opinions of authors expressed herein do not necessarily state or reflect those of the United States Government or any agency thereof.

\author{
PACIFIC NORTHWEST NATIONAL LABORATORY \\ operated by \\ BATTELLE \\ for the \\ UNITED STATES DEPARTMENT OF ENERGY \\ under Contract DE-AC05-76RL01830
}

Printed in the United States of America

Available to DOE and DOE contractors from the

Office of Scientific and Technical Information,

P.O. Box 62, Oak Ridge, TN 37831-0062;

ph: (865) 576-8401

fax: $(865) 576-5728$

email: reports@adonis.osti.gov

\footnotetext{
Available to the public from the National Technical Information Service,

U.S. Department of Commerce, 5285 Port Royal Rd., Springfield, VA 22161

ph: (800) 553-6847

fax: (703) 605-6900

email: orders@ntis.fedworld.gov

online ordering: http://www.ntis.gov/ordering.htm
}

This document was printed on recycled paper.

(9/2003) 


\title{
Evaluation of Ultrasonic Measurement Variation in the Double-Shell Tank Integrity Project
}

\author{
AF Pardini \\ DR Weier \\ SL Crawford \\ JT Munley
}

January 2010

Prepared for

the U.S. Department of Energy

under Contract DE-AC05-76RL01830

Pacific Northwest National Laboratory

Richland, Washington 99352 



\section{Executive Summary}

Washington River Protection Solutions (WRPS) under contract from the U.S. Department of Energy (DOE) is responsible for assessing the condition of the double-shell tanks (DST) on the Hanford nuclear site. WRPS has contracted with AREVA Federal Services LLC (AFS) to perform ultrasonic testing (UT) inspections of the 28 DSTs to assess the condition of the tanks, judge the effects of past corrosion control practices, and satisfy a regulatory requirement to periodically assess the integrity of the tanks.

Since measurement inception in 1997, nine waste tanks have been examined twice through Fiscal Year (FY) 2009 providing UT data that can now be compared over specific areas. During initial reviews of these two comparable data sets, average UT wall-thickness measurement reductions were noted in most of the tanks. It is unknown whether such differences could be a result of actual wall thinning occurring on the waste-tanks walls or rather due to some unexplained anomaly resulting from measurement error due to causes such as the then-current measurement procedures, operator setup, or equipment differences. WRPS contracted with the Pacific Northwest National Laboratory (PNNL) to assist in understanding why this variation exists and where it stems from.

Several different studies were conducted with results then presented in this report. The following provides a summary of the conclusions for the topics addressed in this evaluation. The first three conclusions are more general, but they are supported by the latter conclusions associated with the specific studies.

General conclusions:

- Precision: The UT measurement process is likely more precise (repeatable) than it's been given credit for, at least in the short term under consistent temperature conditions. Variability studies described in this report with multiple operators, instruments, and transducers, and thus multiple setups and calibrations, indicated that measurement results are repeatable within a two-sigma range to about \pm 5 mil.

- Accuracy: If UT measurement images are analyzed computationally from raw data, lift-off, primarily in one scanner direction, can cause overestimation of wall thickness, but the visual analysis method currently used is minimally impacted by this. An altered fixture should reduce such lift-off. However, temperature differences between couplant, tank wall, and calibration block can significantly impact measurement bias, even within the currently required differentials of no more than 25 degrees. Former analysis methods that used peak/edge analysis show this impact while a newly proposed multiple-echo method shows much less sensitivity to such temperature differentials.

- Corrosion conclusions: Comparing old to new inspections to determine wall corrosion for a particular tank is somewhat risky because specific and respective temperature conditions under the old and new inspections are unknown. For example, a hot-summer old inspection and cold-winter new inspection, or conversely, might have resulted in differing couplant, tank wall, and calibration block temperature relationships between the two inspections and thus altered accuracy characteristics. These differences would in turn lead to poor wall-thickness change estimates for the peak/edge analysis methods currently used. Using instead multiple-echo analysis, currently under investigation, in subsequent consecutive inspections would appear to mostly eliminate such problems, thereby facilitating improved old to new comparisons. 


\section{Specific conclusions:}

- Peak, Edge, and Peak/Edge analysis of UT inspection scans for various tanks demonstrated how the particular type of analysis used for old inspections could be deduced. Measurement differences between the analysis methods are shown to be up to about 4.5 mils on the average. Such measurement differences should be used to adjust "old-minus-new" differences for tanks where different analysis methods were used in the old and new inspections. Peak/Edge is now the preferred approach and has been used consistently since about the 2002 timeframe. (Section 3.3)

- Baseline measurements were made on the two mockups used in these studies. Flat-barrel and pointbarrel micrometer measurements are maximum values over the size of the barrel tip, so point-barrel measurements were about 2.5 mils smaller on the average. No difference was indicated between PNNL and AFS point-barrel measurements. The manual UT values taken on the same mockup areas were in between micrometer values. The manual micrometer values averaged about 1.1 mils greater than the point-barrel measurements and about 1.4 mils less than the flat-barrel measurements. (Section 4.1)

- A wall-cleaning study on a mockup that scanned un-cleaned areas and areas cleaned using wire brush or flapper wheel showed no significant difference in UT image averages before and after cleaning. (Section 4.2) Therefore, the cleaning method did not introduce actual wall thickness or thickness measurement changes.

When mockup plates' baseline measurements using micrometers and manual UT were compared to subsequent scan measurements in the wall-cleaning and variability studies, the scan thickness measurements were about 12 mils less than the baseline measurements. (Section 4.2.2) While the specific cause of this difference was not identified, it could potentially be due to the manual UT and micrometer measurements being relatively unaffected by differing couplant, mockup, and calibration block temperatures. Such temperature differences can influence the UT scan measurements as described in the following bullets.

- A temperature study was conducted (Section 4.3) that kept the test block and couplant temperatures close together, but varied them in different combinations with varying calibration block temperatures. Results showed that having test block/water couplant temperature lower than the calibration block temperature led to under-estimating wall thickness. Conversely, having calibration block temperature lower than block/water couplant temperature led to over-estimating wall thickness. Having temperatures the same led instead to generally unbiased thickness measurement.

Under the operational requirement that tank wall and calibration block temperature be within $25^{\circ} \mathrm{F}$ of each other, the under-/over-estimation of wall thickness could still be as great as \pm 14 mils for UT image averages. Such temperature variation is, therefore, indicated to be a considerably larger contributor to UT measurement variability and/or bias than the measurement factors in the previous bullet. Based on these results, differing temperature combinations from old to new inspections could be a very significant source of measured wall-thickness differences, so keeping the calibration block/tank wall/couplant temperatures even closer together than the $25^{\circ} \mathrm{F}$ requirement is certainly desirable, if not essential, for meaningful comparisons of old and new inspection results.

- A second temperature study (Section 4.4) was conducted that kept the test block and calibration block temperatures close together but varied them in different combinations with varying couplant temperatures. Results showed that having couplant temperature less than the test block/calibration block temperature led to under-estimating wall thickness by as much as 35 mils, again a significant 
source of potential bias/variability. Conversely, having the test block/calibration block temperature less than couplant temperature, or having the temperatures the same, led to unbiased thickness estimation. Thus, couplant temperature should be kept at least as high as the tank wall and calibration block temperatures.

A more comprehensive study that varies all three temperatures independently (test block, calibration block, and couplant), as in the operator/transducer/instrument study, would be useful.

- The previous temperature study results were obtained using peak/edge analysis as is currently used in field inspections. An alternative multiple-echo analysis approach was also used to evaluate the UT measurements from these temperature studies (Sections 4.3.4 and 4.4.4). This alternative approach resulted in more than an order of magnitude reduction in the thickness changes observed. Thus the multiple-echo approach showed much less sensitivity to such temperature changes. This alternative analysis approach should be investigated for field use.

- Other studies performed on mockups, including spring tension of transducer holders (Section 4.5), cable length (Section 4.6), and dual-element versus single-element transducers (Section 4.7), concluded that modifications of these components within the parameters analyzed would have little impact on the measurement values.

- Point studies were performed on a mockup plate and in Tanks 241-AW-103 and 241-AW-105 (Section 5.1). Three-inch-square areas of the plate and tank walls were examined using subsets of the usual scan pixel measurements. Nine fixed points were then measured from within the 3-inch areas with the scanner stationary. When the $7000+$ pixels were examined for the 3-inch areas, persistent measurement difference patterns were observed for the tank and mockup scans, which were caused by transducer lift-off and scanner raster/step settings.

Subsequent discussion with inspection personnel indicated their awareness of such patterns. The inspection personnel explained how they account for the lift-off so that patterns do not have influence on the measurement analyses. In particular, the lift-off phenomenon from the scanner changing directions has dramatic effect on measurements, with generally every other row of pixel measurements being biased quite high. Again, this lift-off bias does not impact the current visual analysis approach used by the Level III inspectors. If personnel actually do computations on the pixel measurements, the impact of the lift-off phenomenon needs to be considered.

For the mockup plate, the average bias between the scan measurement of the centered 3-inch areas and the nine stationary points was 4.6 mils when all pixels were used, but reduced to 1.3 mils when the lift-off rows of pixels were not included. Due to rougher walls, the lift-off phenomenon was considerably greater in Tank 241-AW-105. The average bias for the 3-inch areas was then 11.4 mils with only 0.9 mils for Tank 241-AW-103. The corrected values obtained by omitting the lift-off pixels were not computed for these latter two cases. The observed biases would be even greater for the entire 12-inch $\times 15$-inch images than for the 3-inch squares. Without the lift-off pixels included, little difference is expected between the scan and stationary measurements. Fixture re-design is being performed that would reduce or eliminate the lift-off phenomenon.

- UT image measurement variability studies on operators, instruments, and transducers were performed through repeated scans of a mockup plate and Tank AW-103 (Section 5.2). In the tank study, the primary source of variation was between tank locations while this was a minimal source of variability for the mockup plate. Among the measurement factors, for the mockup, the primary contributor to variability was the operator followed by the transducer with essentially no variability between 
instruments. However, in the tank study, the most variability was due to transducer, followed by instrument, with essentially none due to operator. The differing results are rather surprising. When only the measurement factors are considered and not the location differences, a combined one standard deviation variability for the mockup plate was 2.7 mils and for the tank 2.5 mils, so slightly less measurement variability was demonstrated in the tank study. Two-sigma ranges for these three combined measurement factors are thus about \pm 5 mils. 


\section{Acknowledgments}

The authors would like to acknowledge the support provided by AREVA Federal Services LLC inspectors Wesley H. Nelson, William D. Purdy, Jeffery S. Pintler, and Laura A. Sepich. Their assistance in data acquisition and analysis provided the basis for the information presented in this report.

The authors would also like to acknowledge the guidance and direction provided by Washington River Protection Solutions management team of Jim L. Castleberry and Kayle D. Boomer and technical and administrative assistance from Timothy J. Peters and Kay E. Hass of the Pacific Northwest National Laboratory. 


\section{Acronyms and Abbreviations}

AFS

DOE

DST

GE

HAZ

PNNL

UT

WRPS
AREVA Federal Services LLC

U.S. Department of Energy

double-shell tanks

General Electric

heat-affected zone

Pacific Northwest National Laboratory

ultrasonic testing

Washington River Protection Solutions 


\section{Contents}

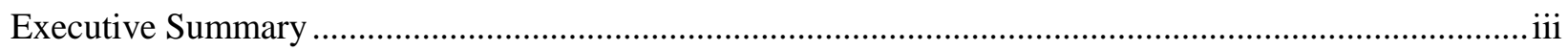

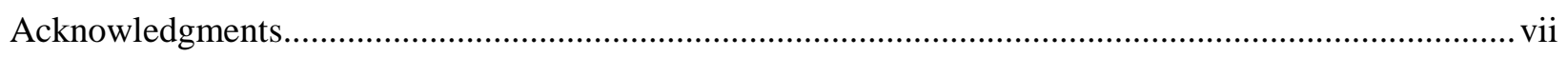

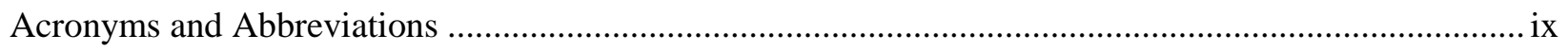

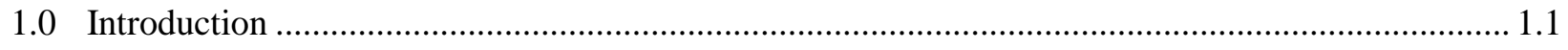

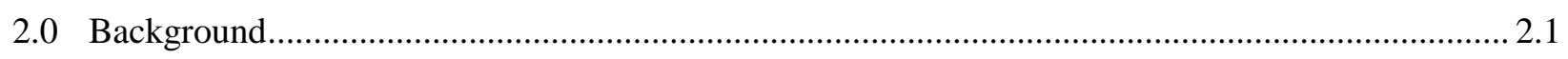

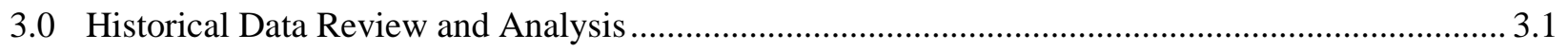

3.1 Background on UT Data Acquisition and Analysis .......................................................... 3.1

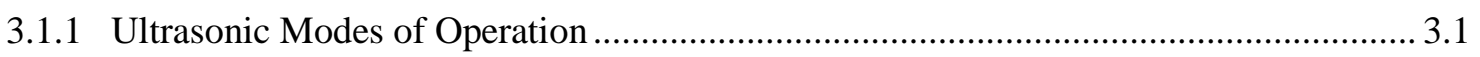

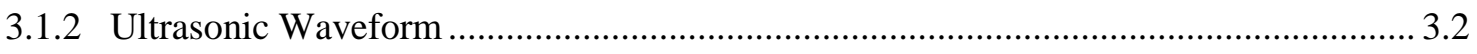

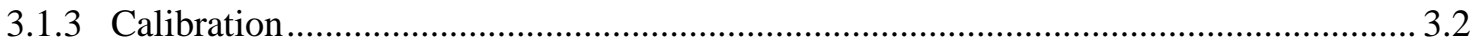

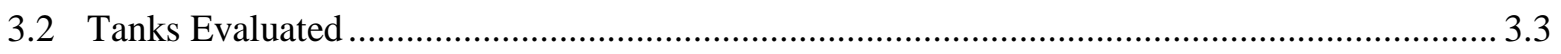

3.3 Data Evaluation and Impact on Wall-Thickness Measurements............................................ 3.3

3.3.1 Inspection Method Evaluation.................................................................................. 3.7

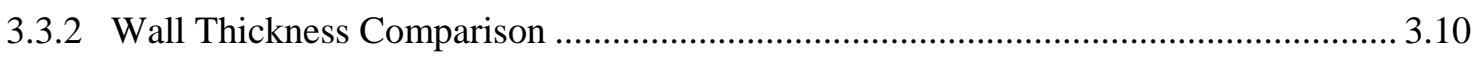

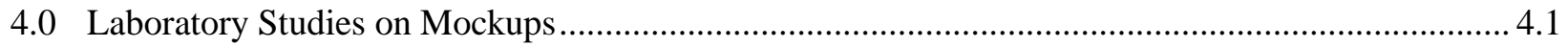

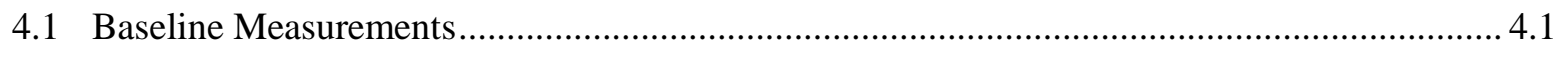

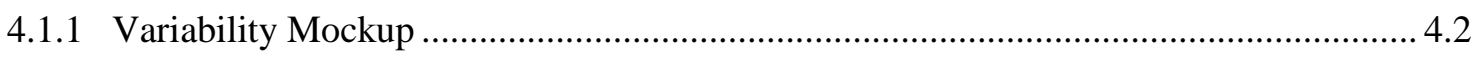

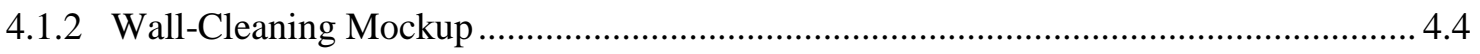

4.1.3 Summary of Wall Thickness …..................................................................................... 4.5

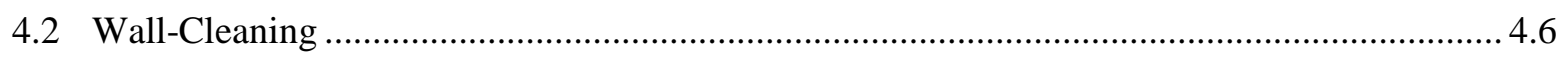

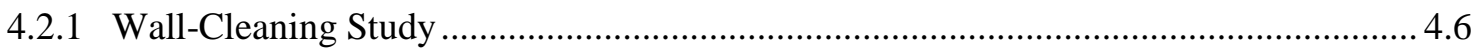

4.2.2 Data Acquisition Methods and Evaluation of Data ................................................... 4.8

4.3 Calibration Block and Test Block/Couplant Temperature Variations .................................. 4.11

4.3.1 Temperature Study ................................................................................................ 4.11

4.3.2 Data Acquisition Methods and Evaluation of Data .................................................. 4.12

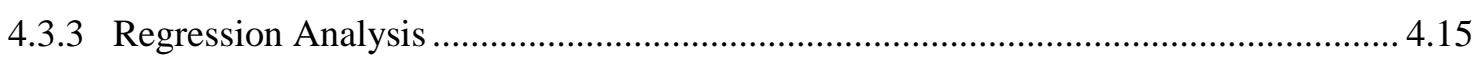

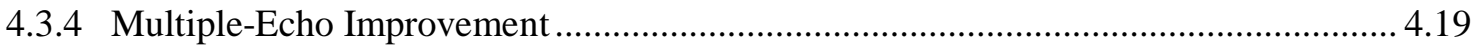

4.4 Couplant and Test Block/Calibration Block Temperature Variations .................................. 4.20

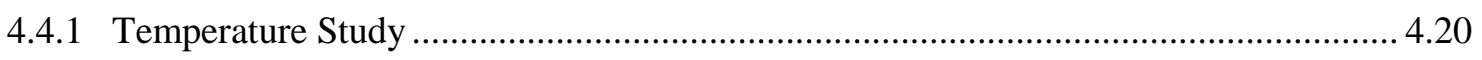

4.4.2 Data Acquisition Methods and Evaluation of Data .................................................... 4.20

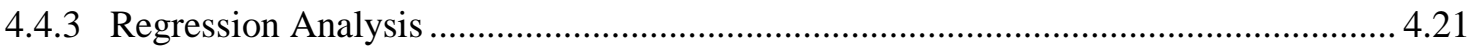

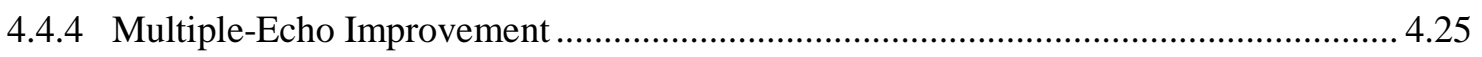

4.5 Spring Tension of the Transducer Holders......................................................................... 4.26

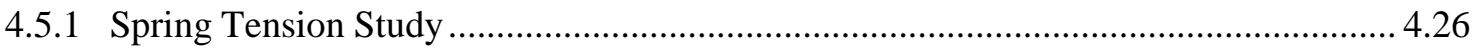

4.5.2 Data Acquisition Methods and Evaluation of Data ............................................... 4.26 


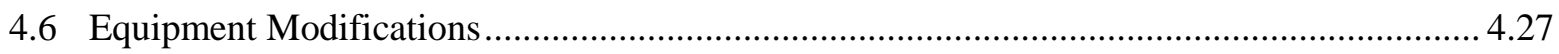

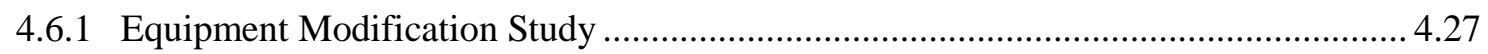

4.6.2 Data Acquisition Methods and Evaluation of Data...................................................... 4.27

4.7 Dual Element Transducers versus Single Element............................................................. 4.28

4.7.1 Dual Element Transducer versus Single Element Study .......................................... 4.28

4.7.2 Data Acquisition Methods and Evaluation of Data................................................... 4.29

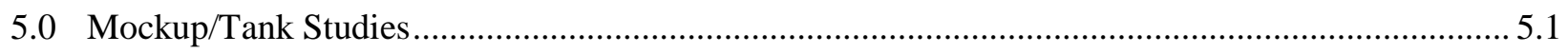

5.1 Mockup/Tank Point Studies ............................................................................................ 5.1

5.1.1 Data Acquisition Methods and Evaluation of Data...................................................... 5.1

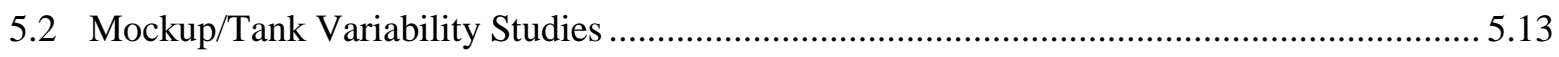

5.2.1 Data Acquisition Methods and Evaluation of Data ..................................................... 5.13

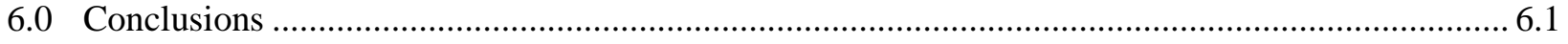

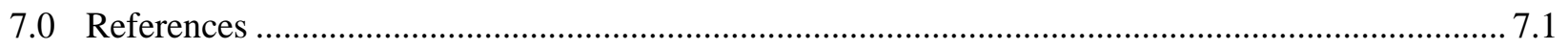




\section{Figures}

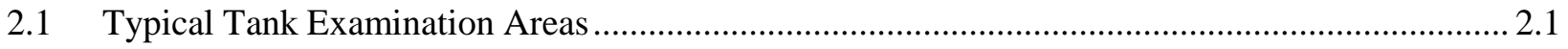

3.1 Ultrasonic Scanning System Used on Hanford Waste Tanks.................................................... 3.1

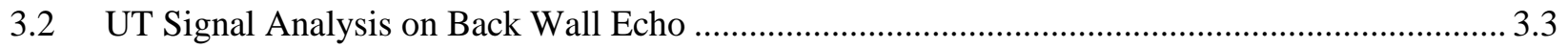

3.3 Tanks AN-102 and AN-107 Average Wall over Nominal by Elevation in Inches ....................... 3.5

3.4 Tanks AP-108 and AZ-101 Average Wall over Nominal by Elevation in Inches ........................ 3.6

3.5 Tanks AN-102 and AN-107 Thickness over Nominal Original Method versus Peak/Edge/

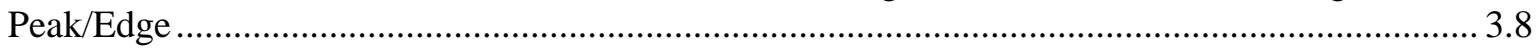

3.6 Tanks AP-108 and AZ-101 Thickness over Nominal Original Method versus Peak/Edge/

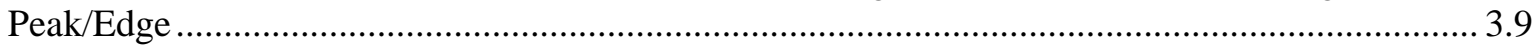

3.7 Tanks AN-106 and AY-102 Thickness over Nominal Original Method versus Peak/Edge/

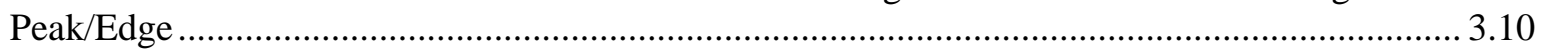

3.8 Tanks AN-102, AP-108, AN-107, AZ-101, AN-106, and AY-102 Average Wall over Nominal by Elevation.............................................................................................................. 3.14

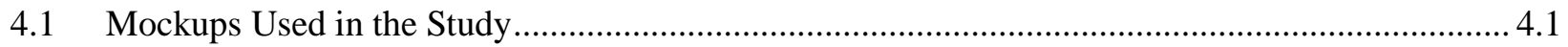

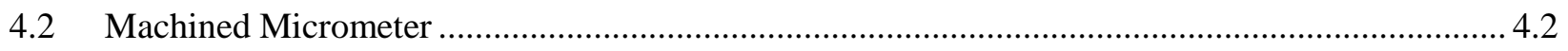

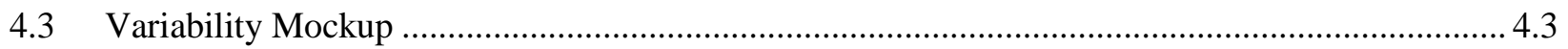

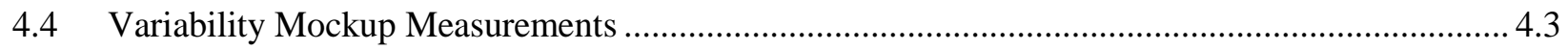

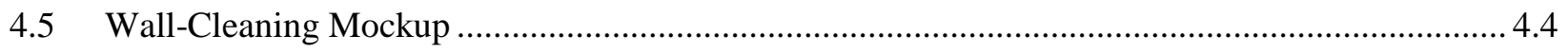

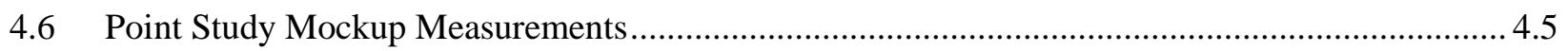

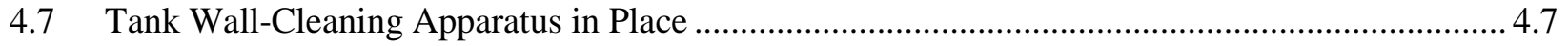

4.8 Wall-Cleaning Apparatus Using Flapper Wheel ......................................................................... 4.8

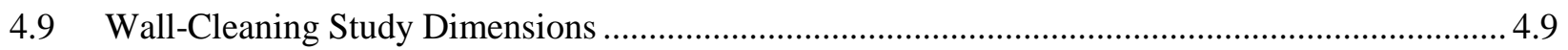

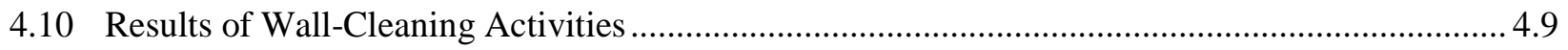

4.11 Wall-Cleaning Mockup Measurements ..................................................................................... 4.11

4.12 First Mockup Heater Configuration Using Four Heaters ........................................................ 4.12

4.13 Four-Heater Distribution After 18 Minutes................................................................................13

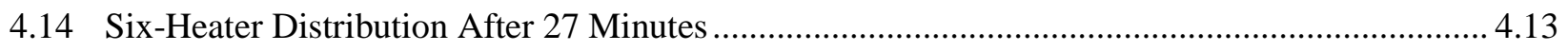

4.15 The Test Block in Heated Water Bath...................................................................................... 4.14

4.16 Heated Calibration Standard Being Monitored by Thermocouple .............................................. 4.14

4.17 Response Average - with Interaction...................................................................................... 4.16

4.18 Response Maximum - with Interaction............................................................................. 4.16

4.19 Response Average - No Interaction ........................................................................................ 4.17

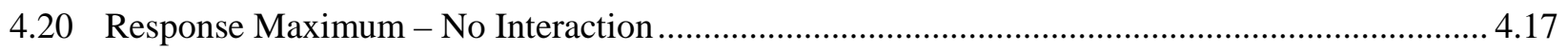

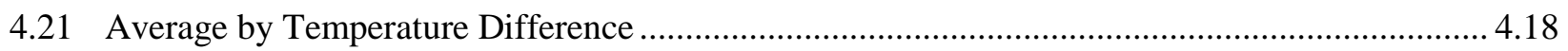

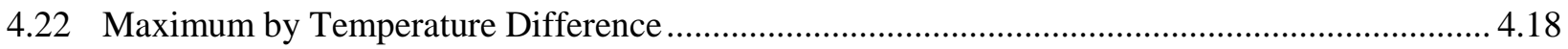

4.23 Reservoir Used to Control Couplant Temperature ................................................................... 4.20

4.24 Response Average - with Interaction ....................................................................................22 


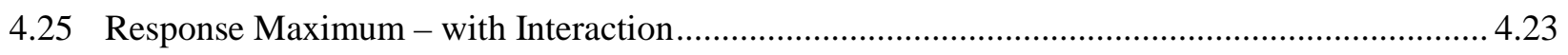

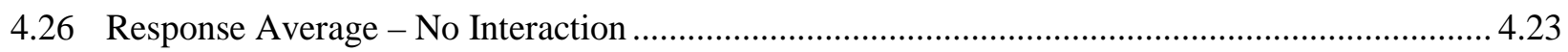

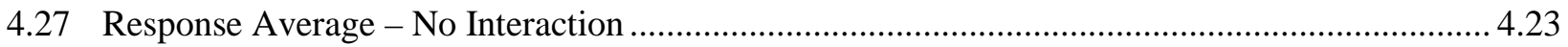

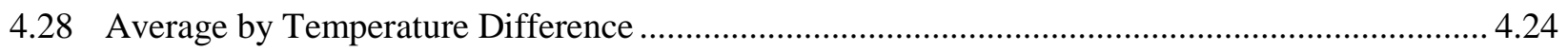

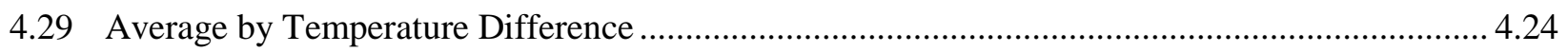

4.30 Transducer Holder Scissor Assembly ..................................................................................... 4.26

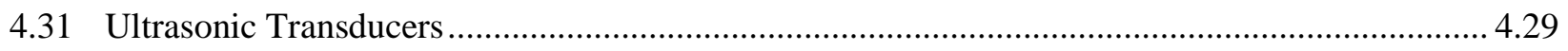

5.1 Inspection Path and Location of Point Measurements .............................................................. 5.1

5.2 AW-105 Average Column Wall Thicknesses............................................................................ 5.3

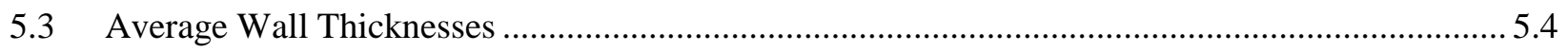

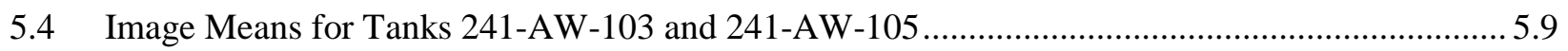

5.5 Original Transducer and Holder Assembly ................................................................................ 5.9

5.6 Graphic Representation of the Original Transducer and Holder ................................................. 5.10

5.7 Single-Ring Design - Easy to Assemble and Deploy ............................................................ 5.11

5.8 Double-Ring Apparatus - Suited to Laboratory Applications .................................................... 5.11

5.9 Components of the Fixed Position Apparatus and Associated Spanner Wrench ......................... 5.12

5.10 Components of the Adjustable Position Apparatus and Associated Spanner Wrench .................. 5.12

5.11 Mockup Variability Study Results ......................................................................................... 5.14

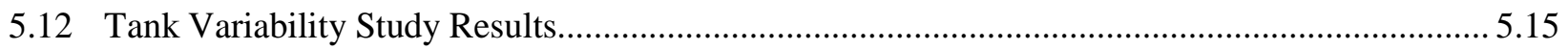




\section{Tables}

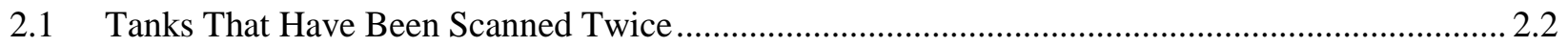

3.1 Analysts Who Performed the Wall-Thickness Measurements ...................................................... 3.4

3.2 Response Average Wall over Nominal ................................................................................... 3.11

3.3 Comparison of Old and New Inspection Thickness over Nominal ............................................ 3.12

4.1 Variability Mockup Baseline Measurements............................................................................. 4.2

4.2 Wall-Cleaning Mockup Baseline Measurements ........................................................................ 4.4

4.3 Summary Information for Response Thickness .......................................................................... 4.6

4.4 Wall-Cleaning Mockup Pre/Post Cleaning Measurements ........................................................ 4.10

4.5 Wall-Cleaning Mockup Scanning versus Point Measurements..................................................... 4.10

4.6 Impact of Varying Calibration Block and Test Block/Couplant Temperature ............................. 4.15

4.7 Impact of Varying Calibration Block and Test Block/Couplant Temperatures on Multiple-

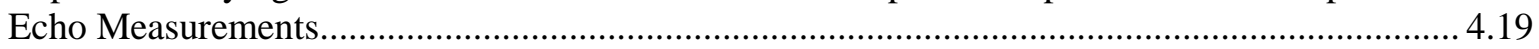

4.8 Impact of Varying Couplant and Calibration Block/Test Block Temperatures .......................... 4.21

4.9 Impact of Varying Couplant and Calibration Block/Test Block Temperatures on Multiple-

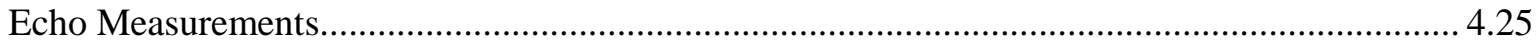

4.10 Thickness Measurements at Different Cable Lengths ............................................................. 4.28

4.11 Laboratory Thickness Measurements on a Flat Plate .............................................................. 4.30

4.12 Laboratory and P-scan Thickness Measurements on a Step Wedge .......................................... 4.31

4.13 Error in Laboratory and P-scan Thickness Measurements ....................................................... 4.32

5.1 A Top Corner of Tank 241-AW-105 Image Pixels ................................................................... 5.5

5.2 Comparison Between Mockup Scan and Stationary UT Measurements ....................................... 5.6

5.3 Scan and Point Averages for Tanks 241-AW-103 and 241-AW-105 .......................................... 5.8

5.4 Study Instrument/Transducer/Operator Combinations............................................................ 5.13

5.5 Mockup Variability Study Means.............................................................................................. 5.14

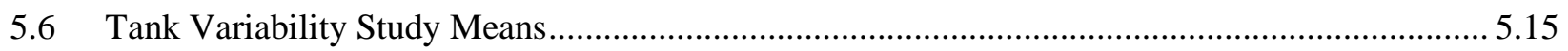

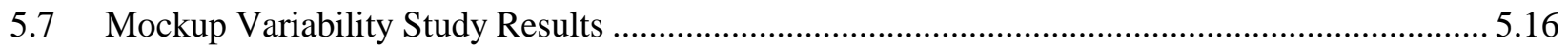

5.8 Tank AW-103 Variance Components ........................................................................................ 5.16 


\subsection{Introduction}

Washington River Protection Solutions (WRPS) under contract from the U.S. Department of Energy (DOE) is responsible for assessing the condition of the double-shell tanks (DST) on the Hanford nuclear site. WRPS has contracted with AREVA Federal Services LLC (AFS) to perform ultrasonic testing (UT) inspections of the 28 DSTs to assess the condition of the tanks, judge the effects of past corrosion control practices, and satisfy a regulatory requirement to periodically assess the integrity of the tanks. The primary requirements for the UT of each tank is to detect, characterize (identify, size, and locate), and record measurements made of any wall thinning, pitting, or cracks that might be present in the wall of the primary tank. Any measurements that exceed a specified requirement set forth by WRPS are to be reported. Specific measurements that are reported include the following:

- Wall thinning that exceeds 10 percent of the nominal thickness of the plate.

- Pits with depths that exceed 25 percent of the nominal plate thickness.

- Stress-corrosion cracks that exceed 0.10 inch (through-wall).

These indications are detected in the inner wall of the tank, heat-affected zone (HAZ) of welds, or in the tank knuckle.

The accuracy requirements for ultrasonic measurements for the different types of defects are as follows:

- Wall thinning - measure thickness within \pm 0.020 inch

- Pits - size depths within \pm 0.050 inch

- Cracks - size the depth of cracks on the inner-wall surfaces within \pm 0.1 inch

- Location - locate all reportable indications within \pm 1.0 inch.

Since measurement inception in 1997, nine waste tanks have been examined twice through Fiscal Year (FY) 2009 providing UT data that can now be compared over specific areas. During initial reviews of these two comparable data sets, a UT measurement variation was noted in some of the data. It is unknown whether such differences could be a result of actual wall thinning occurring on the waste-tanks walls or rather due to some unexplained measurement anomaly. WRPS contracted with the Pacific Northwest National Laboratory (PNNL) to assist in understanding why this variation exists and where it stems from. 


\subsection{Background}

The requirements for the UT inspections are defined in RPP-7574, The Double-Shell Tank Integrity Program Plan (Boomer, 2007). The primary tank wall examination consists of two vertical 15-inch-wide wall scans down the height of the tank along with vertical and horizontal welds areas. Additional scans of the tank knuckle are sometimes performed. The vertical wall scans are performed in both of the 24-inch risers for a total of four 15-inch strips and would provide the data necessary for corrosion comparisons. Figure 2.1 provides a graphic of a typical tank examination.

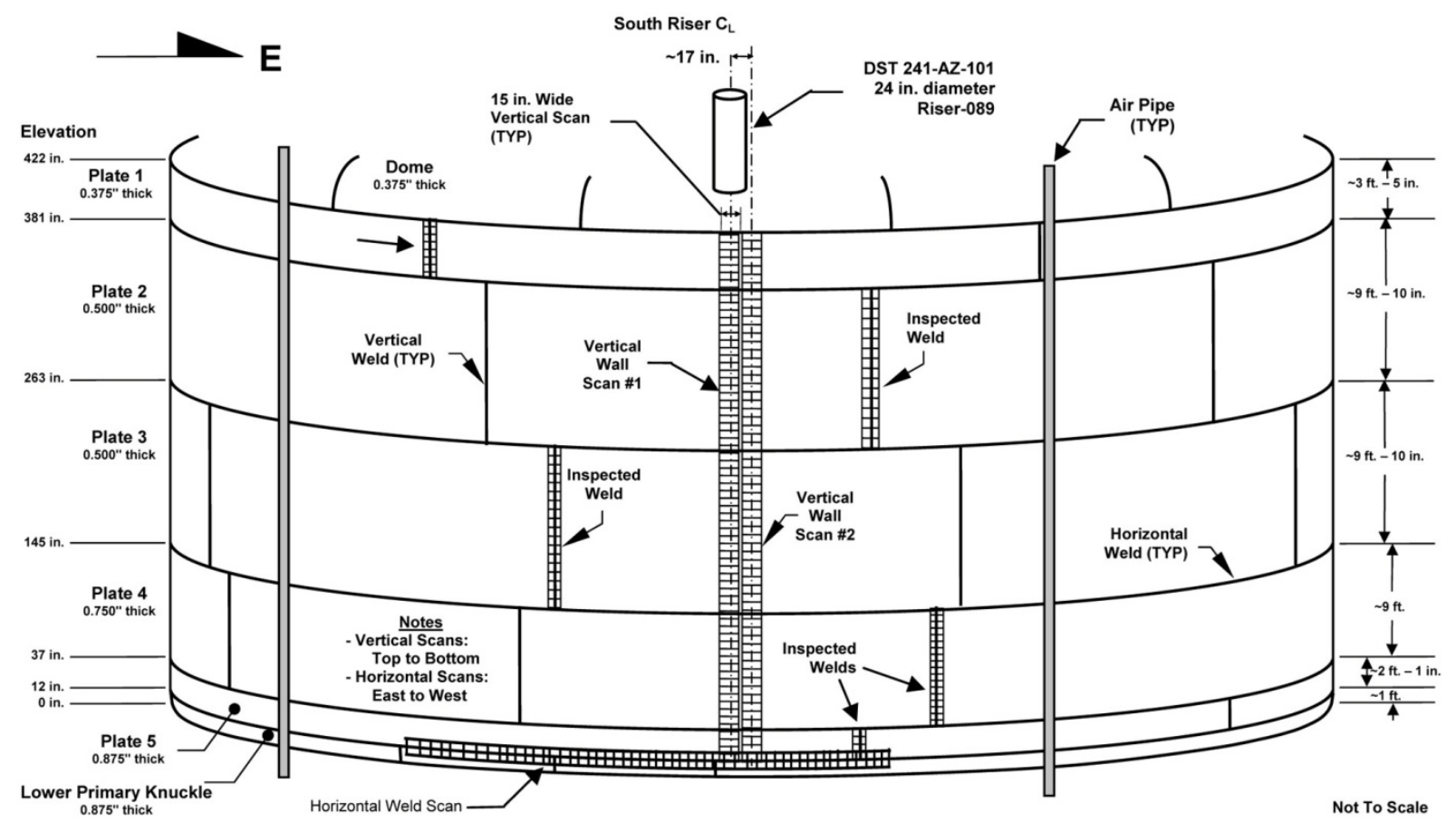

Figure 2.1. Typical Tank Examination Areas

Typically, only one of the risers includes the weld scans and any knuckle scans. From Figure 2.1, it can be visualized that an additional two vertical wall scans would be completed in a riser that is diametrically opposite from the shown riser. The DSTs that have been UT scanned twice in approximately the same locations (as close as possible) to provide comparison wall thickness measurements are shown in Table 2.1. 
Table 2.1. Tanks That Have Been Scanned Twice

\begin{tabular}{ccc}
\hline Tank & Initial Scan Year & Second Scan Year \\
\hline 241-AW-103 & 1997 & 2006 \\
241-AN-107 & 1998 & 2006 \\
241-AN-106 & 1999 & 2007 \\
241-AY-102 & 1999 & 2007 \\
241-AZ-101 & 1999 & 2007 \\
241-AP-107 & 2000 & 2008 \\
241-AP-108 & 2000 & 2008 \\
241-AN-102 & 2001 & 2008 \\
241-AY-101 & 2001 & 2008 \\
\hline
\end{tabular}

In the initial scan years, it was made evident by discussions with the UT contractor personnel that different types of evaluation were used in the analysis portion of the tank examinations. This report evaluated these analysis differences in Section 3.0, "Historical Data Review and Analysis.” Additionally, laboratory studies were performed to determine the effects of surface conditions, temperature variations, and mechanical variations on UT accuracy, which is covered in Section 4.0 of this report, "Laboratory Studies on Mockups.” Finally, a combined mockup and tank study was performed and discussed in Section 5.0, "Mockup/Tank Studies," using multiple UT operators and equipment in a field application to provide an explanation of differences seen between data acquired and evaluated in the initial scan years of the program as compared to those in the second scan year. 


\subsection{Historical Data Review and Analysis}

\subsection{Background on UT Data Acquisition and Analysis}

The contractor AFS uses UT equipment designed and fabricated by Force Technology ${ }^{(a)}$ for the examination of the DSTs at Hanford. The ultrasonic pulser and receiver used in the initial scanning of the first four tanks shown in Table 2.1 is the PSP-3. The PSP-3 is the third-generation P-scan ultrasonic system developed and delivered by Force Technology. The rest of the remaining five tanks shown in Table 2.1 were scanned with the newer model PSP-4. The scanning system is comprised of the P-scan ultrasonic system and a Force AWS-5D magnetic wheel crawler and scanning arm. This crawler and scanning arm were used for all of the nine tanks shown in Table 2.1. Figure 3.1 shows a picture of the PSP-4 ultrasonic scanning system.

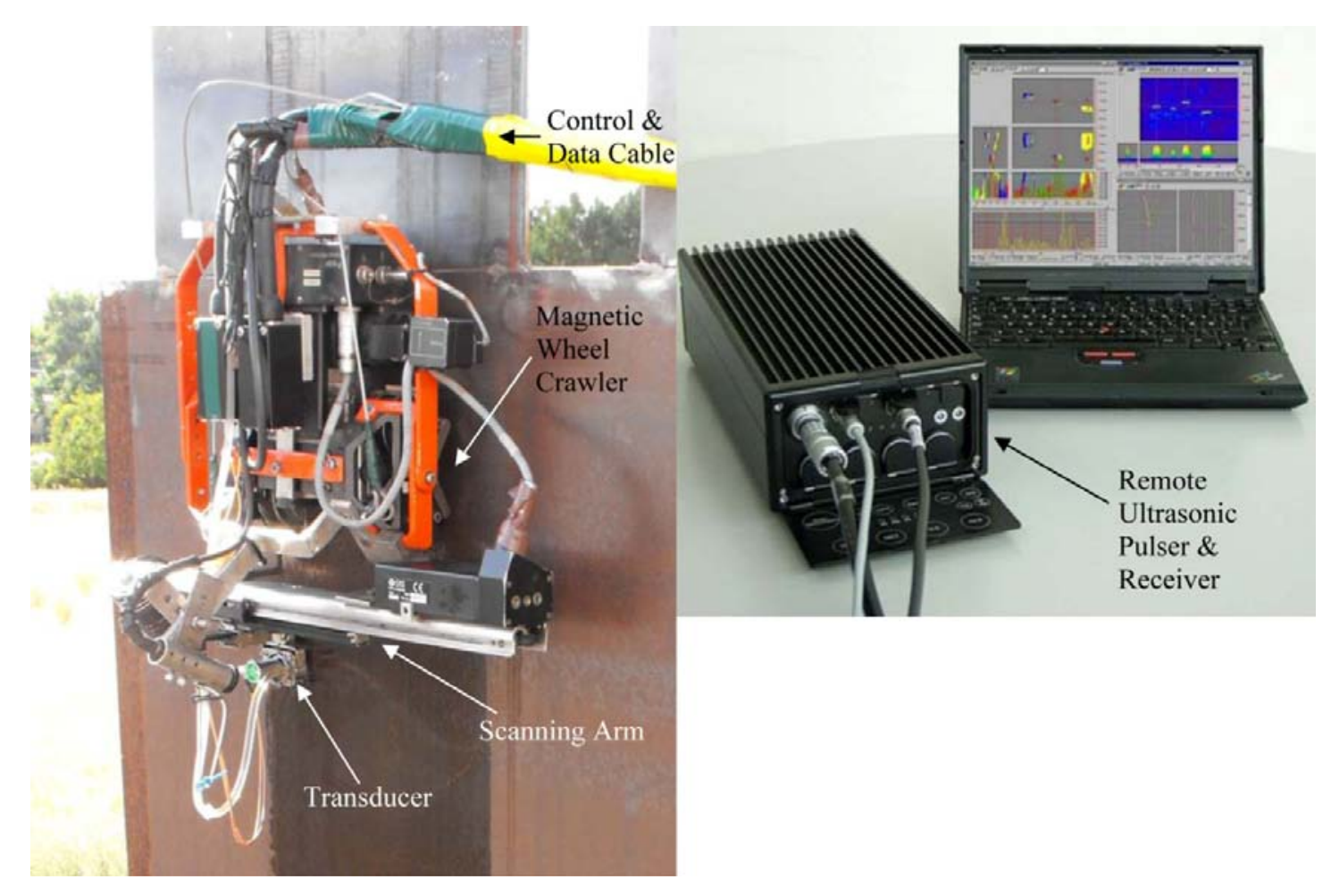

Figure 3.1. Ultrasonic Scanning System Used on Hanford Waste Tanks

\subsubsection{Ultrasonic Modes of Operation}

The data from the initial and second scans of the nine tanks were presented to PNNL in hardcopy report format. AFS performs both a thickness evaluation of the tank wall using normal-beam ultrasonic transducers as well as flaw detection and sizing using angle-beam transducers. In this study, we are interested in the wall-thickness measurements and how the Force ultrasonic pulser, receiver, and analysis

(a) Force Technology is a Danish company with headquarters located in Brøndby near Copenhagen. 
software evaluate and provide a measurement. A fundamental question was posed concerning the methodology behind the Force analysis of the return ultrasonic waveform.

The Force analysis software allows for measurement of the returned waveform using three discreet modes, which are "Edge," "Peak/Edge," and "Peak." These are the points on the return waveform that a thickness measurement is calculated from. The question posed was: during the initial first set of scans, was there a consistent evaluation performed (i.e., did you analyze all data to one specific mode)? Historical evidence indicates that the desire in the early stages of the program was to provide the best ultrasonic signal that could be analyzed (work around the noise spikes caused by surface roughness) and not much attention was paid to which of the three methods was used. In an effort to discern whether this could affect measurement variability, a study was proposed to evaluate the original data in these three methods and compare them to recent data on the same tanks to estimate effects. All of the second scans shown in Table 2.1 were analyzed using the peak/edge mode.

\subsubsection{Ultrasonic Waveform}

The return signal used in ultrasonic examinations is typically displayed in an A-scan format, which is simply an oscilloscope display of voltage versus time. By knowing the speed of sound in specific materials and adjusting your screen display using a calibration standard, material thickness can be accurately measured. Figure 3.2 provides an example of an A-scan display. The display represents the time taken for a sound wave to travel through a material, reflect off of the back wall, and return to the transducer.

The point on the A-scan display that is used to make the measurement can be varied in the Force analysis software. Choosing the leading edge (normally a point chosen that breaks some predetermined amplitude threshold) of the signal provides a time value that is less than the peak of the signal and would indicate less time for the sound wave to traverse through the material indicating a shorter path and thus a thinner measurement. Though AFS collects this data for all UT inspections, the UT operators currently report the thickness that corresponds to the peak/edge signal.

The peak/edge signal is a calculated value choosing a point that is $-12 \mathrm{~dB}$ down from the peak signal. This calculation is performed within the Force analysis software.

\subsubsection{Calibration}

It is important to understand that calibration of the system is the method used to verify that the system is measuring correctly. The portion of the signal that a UT operator is using whether it is the edge, peak/edge, or peak is calibrated using a known material of a specific thickness. This calibration procedure is done using the measurement mode of operation. The back-wall signal from the calibration standard is peaked and the index delay is set to provide the correct thickness. The setting of the index delay is based on whether you are calibrating using the edge portion of the signal, peak/edge portion of the signal, or the peak portion of the signal. Thus, it is important to know which portion of the signal is calibrated when analysis of the data takes place. If, for example, only the peak signal was calibrated prior to acquiring data and then the edge signal was used to analyze the data, a measurement error would occur as the edge signal is sooner in time and would provide a thinner measurement than what is the real thickness. 


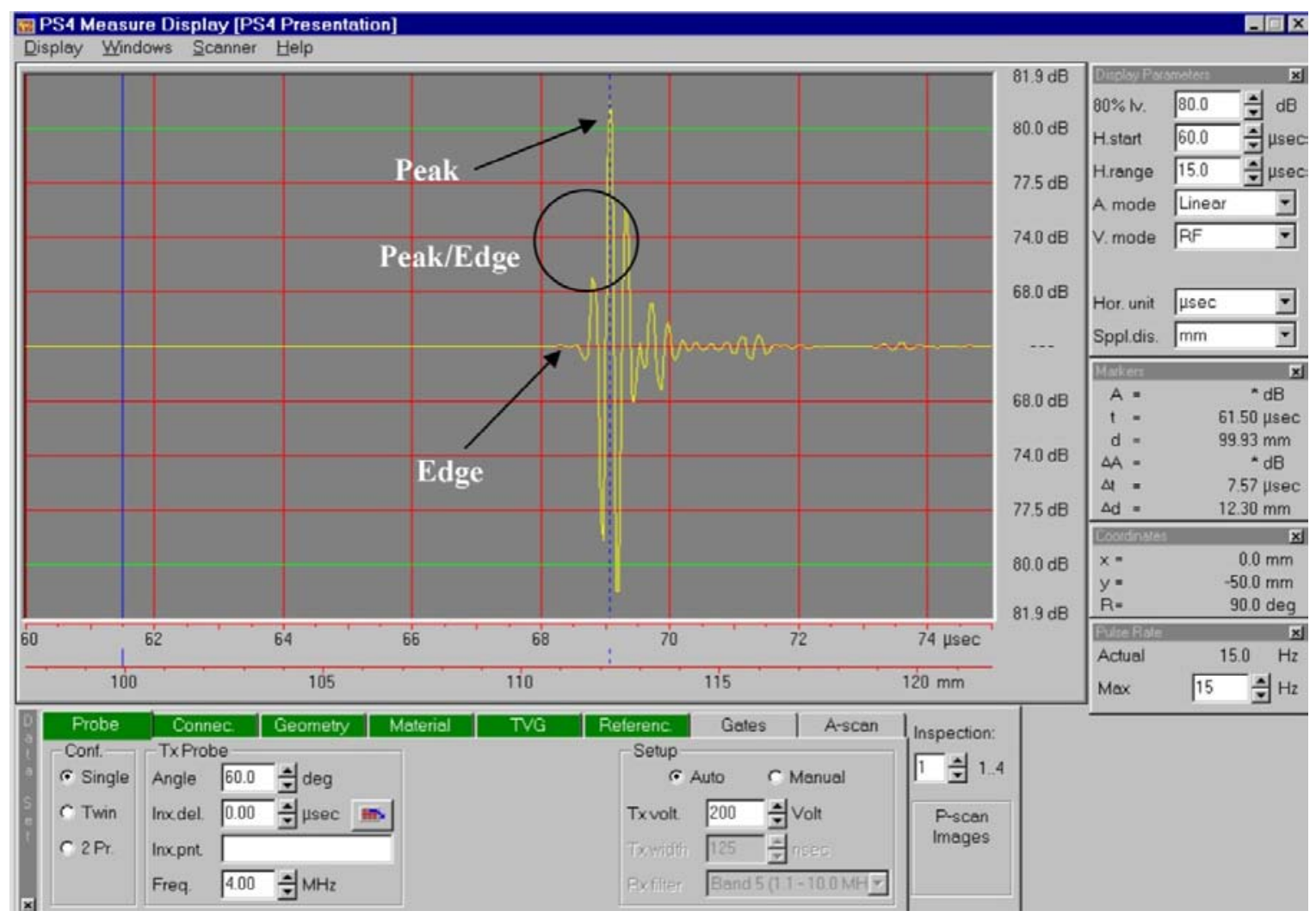

Figure 3.2. UT Signal Analysis on Back Wall Echo

\subsection{Tanks Evaluated}

PNNL obtained all of the available UT data from the three UT analysis techniques used during the initial scan years for six of the tanks in Table 2.1. Considerations were given to the necessary sample set needed to provide a rigorous statistical analysis. It was decided after some initial calculations that six tank data sets would be adequate. The data sets included the original data provided in the released reports and new data where the original analyst re-analyzed the data set again and included all available methods (edge, peak/edge, and peak). The six tanks that went through this process through the end of FY 2008 were AN-102, AN-107, AP-108, AZ-101, AN-106, and AY-102.

\subsection{Data Evaluation and Impact on Wall-Thickness Measurements}

Wall thickness UT image results were re-analyzed to determine new estimates of average thickness for each of three methods (peak, edge, and peak/edge) for the old and new inspections of four tanks (AN-102, AN-107, AP-108, and AZ-101). In most cases, the analyst who interpreted the data for the original tank UT images also performed the re-analysis. Two additional tanks (AN-106 and AY-102) were re-analyzed at a later date and added to the study. Table 3.1 shows the list of tanks and the associated analysts. The original analysis was peak/edge for new inspections (years 2007 and 2008), but not generally known for the old inspections (years 1998 to 2001). 
Table 3.1. Analysts Who Performed the Wall-Thickness Measurements

\begin{tabular}{ccll}
\hline Tank & $\begin{array}{c}\text { Year } \\
\text { Examined }\end{array}$ & $\begin{array}{c}\text { Analyst for } \\
\text { Original Data }\end{array}$ & $\begin{array}{c}\text { Analyst who } \\
\text { Performed } \\
\text { Re-Analysis }\end{array}$ \\
\hline 241-AN-107 & 1998 & Ron Swain & Jim Elder \\
& 2007 & Wes Nelson & Wes Nelson \\
241-AN-106 & 1999 & Jim Elder & Jim Elder \\
& 2007 & Wes Nelson & Wes Nelson \\
241-AY-102 & 2000 & Jim Elder & Jim Elder \\
& 2007 & Wes Nelson & No Re-Analysis \\
241-AZ-101 & 2000 & Jim Elder & Jim Elder \\
& 2007 & Wes Nelson & Wes Nelson \\
241-AP-108 & 2000 & Wes Nelson & Wes Nelson \\
& 2008 & Jim Elder & Wes Nelson \\
241-AN-102 & 2001 & Wes Nelson & Wes Nelson \\
& 2008 & Wes Nelson & Wes Nelson \\
\hline
\end{tabular}

Objectives were to identify the method likely used for the older inspections and to characterize the potential differences between peak, edge, and peak/edge analysis methods. If different methods were used between the old and new inspections for a tank, then interest was in whether the method difference could have contributed to any differences in wall thickness between the old and new tank inspections. To investigate these differences, figures of the old new and new tank inspections were prepared that showed the different signal measurements. Figure 3.3 shows the UT image averages for tank AN-102 and AN-107. Figure 3.4 shows the UT image averages for tanks AP-108 and AZ-101.

For each tank, the top two plots are the old inspections and the bottom two plots are the new inspections with the first scan path on the left plot and the second scan path on the right. The same risers and scan path locations were used in the old and new inspections. The vertical dashed lines indicate plate course boundaries. The higher tank elevations, and thus plate course 1, is on the right of each plot. Thus plates 1 through 5 go from right to left on the plots with decreasing elevations in the tank indicated in inches on the ordinate axis.

The thickness of the tank walls varies from the top to the bottom. In the figures, the nominal wall thicknesses are subtracted from the measured thickness so results can be plotted against the same vertical scale regardless of the original plate thickness. The dashed line at zero on the vertical axis is therefore nominal thickness with measurements above this line indicating that average wall thickness is still greater than drawing nominal.

The four curves on each plot represent average UT image thicknesses obtained using the four methods peak, edge, peak/edge, and original as shown on the legend at the bottom of each page. The first three of these methods are the results from the recent re-analyses, while original represents the results obtained in the actual inspections. One could try to compare the original curve to the others on a figure to see which it might be closest too, in particular for the old inspections to determine which method was used then, but a better approach for this determination is given later. If a curve is missing from a figure, it is because the needed calibration was not performed that would support that particular re-analysis method. 
Tank AN-102

Year $=2001$
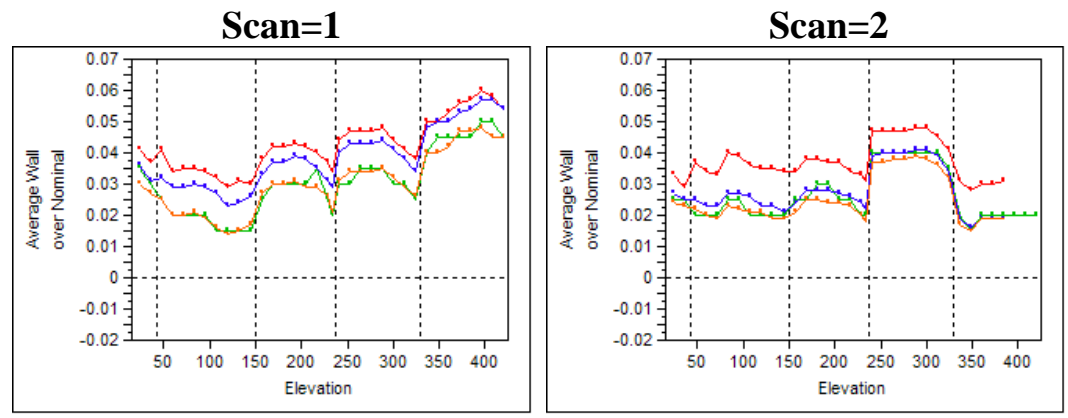

Year $=2008$

$\underset{i r}{\omega}$
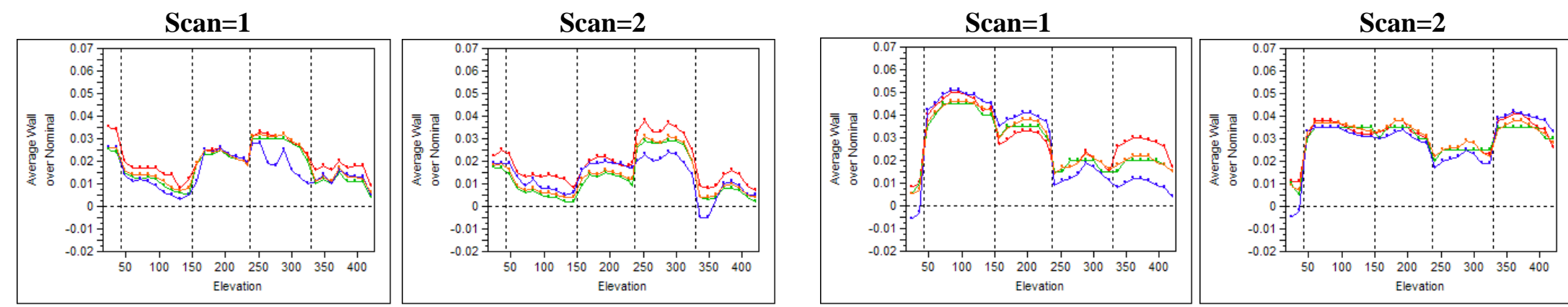

Year $=1998$

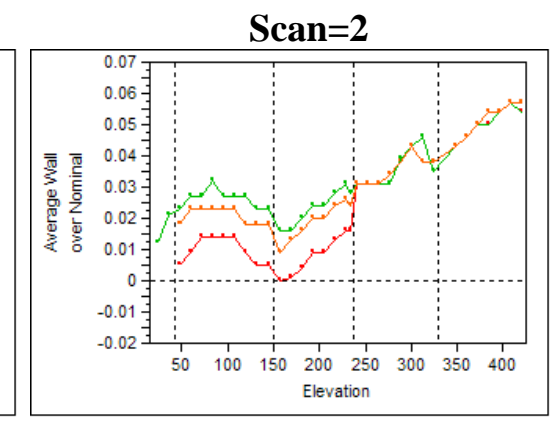

Year $=2007$

-Fit Each Value Method="Edge"
Fit Each Value Method="="Original"
Fit Each Value Method=="Peak"
Fit Each Value Method=" $=$ "Peak/Edge"

Figure 3.3. Tanks AN-102 and AN-107 Average Wall over Nominal by Elevation in Inches 
Tank AP-108

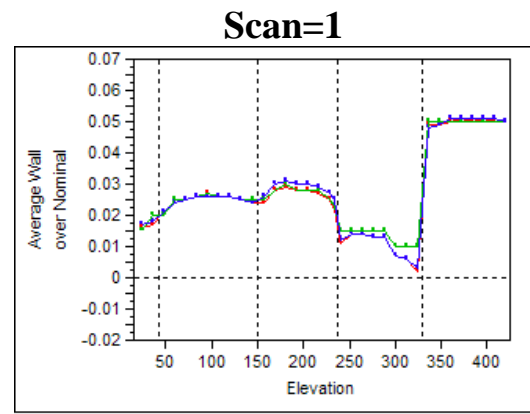

$\omega$

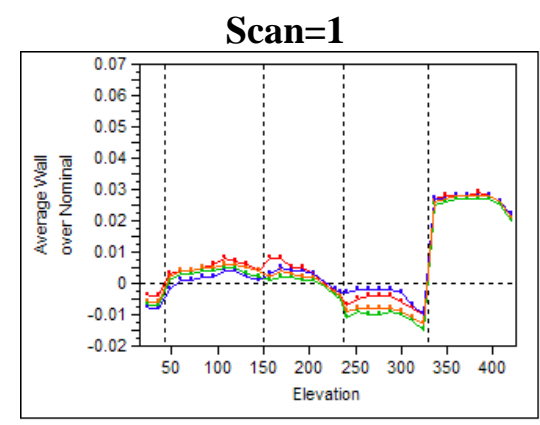

Year $=2000$

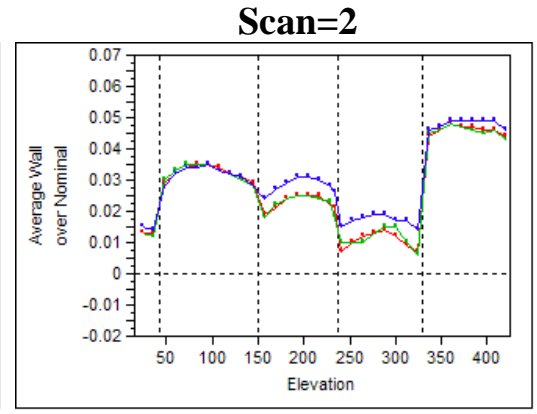

Year $=2008$
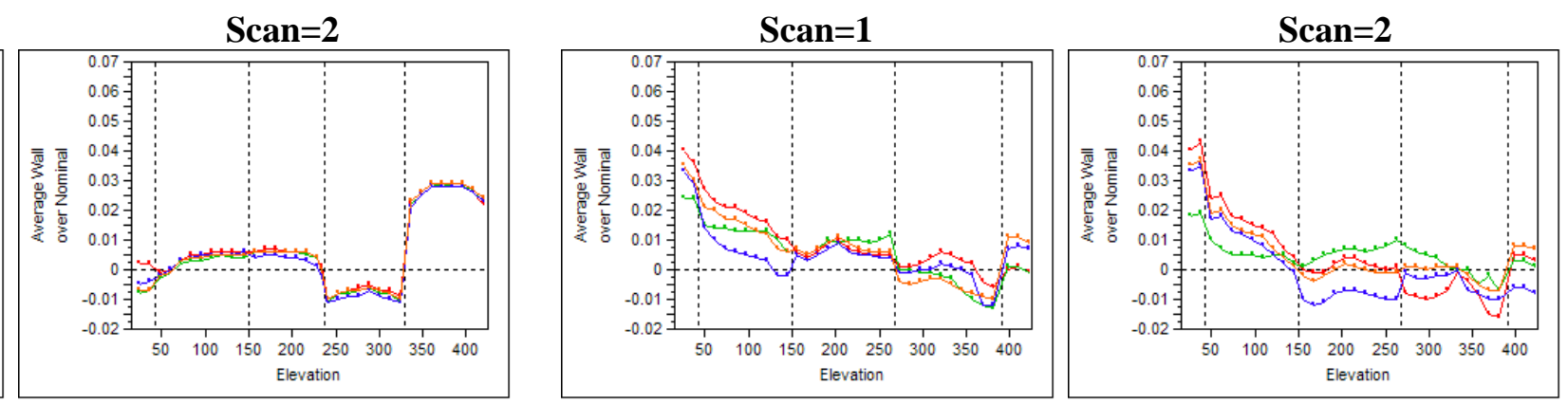

Year $=2000$

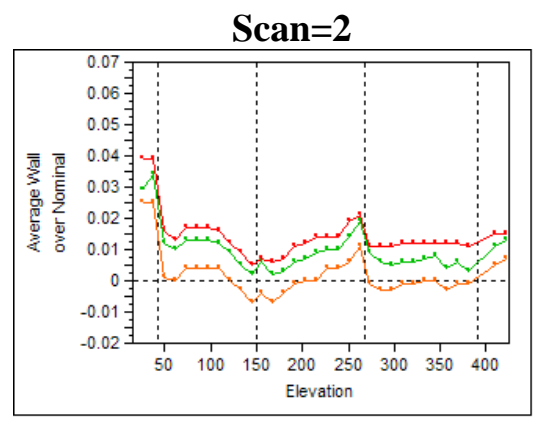

Year $=2007$

Fit Each Value Method="Edge"

Fit Each Value Method=="Original"

Fit Each Value Method $=="$ "Peak"

Fit Each Value Method=="Peak/Edge"

Figure 3.4. Tanks AP-108 and AZ-101 Average Wall over Nominal by Elevation in Inches 


\subsubsection{Inspection Method Evaluation}

As stated earlier, the "original” analysis method for all the new inspections was peak/edge. Rather than trying to match up curves in the previous figures to possibly determine which analysis method was used in the old inspections, the values from the "original" results are instead plotted against each of peak, edge, and peak/edge. These plots are then regressed to show the variability between the "original” results and each technique.

See, for example, the second row of plots in Figure 3.5. These plots are for the new inspection of Tank AN-102. From left to right, the original analysis results, which we know to be obtained from peak/edge, are plotted against the re-analysis results respectively for peak/edge, peak, and edge. The nearly perfect diagonal fit of a regression line, and the very little variability away from the line (indicated by the pink-shaded area), show how indeed the original analysis results are most like the new peak/edge re-analysis results.

Going back to the first row, for the old inspection, the analogous conclusion would be that the old inspection original analysis was based on peak/edge. The fit is not nearly as good as it is for the new inspection, but it is better than those for peak or edge. Note that for the old inspection, results were only reported to the nearest 0.005 -inch; this probably generates some of the variability spread indicated by the pink area. The conclusion for AN-102 would be that the original results for the old inspection were also based on peak/edge analysis.

The bottom half of Figure 3.5 shows the AN-107 results. Again for the new inspection in the final row, the best fit of peak/edge is indicated. The peak re-analysis cannot be done for the old inspection because the appropriate calibration was not done at that time. The best fit for achieving the diagonal line suggests that peak/edge was also used for the old inspection.

In Figure 3.6, the old inspection analysis methods would instead appear to be edge because the best diagonal fits are obtained for those values in the old inspections. For AP-108, the good peak/edge fit for the new inspections is again shown, but for the AZ-101 new inspection, the results are puzzling. There seem to be some data issues here.

But the primary results from Figure 3.5 and Figure 3.6 are that for Tanks AN-102 and AN-107, the original old inspection results appear to have used the peak/edge method while for Tanks AP-108 and AZ-101, the original old inspection results appear to have used the edge method.

Figure 3.7 was generated later for Tanks AN-106 and AY-102, for which re-analysis was done only for the old inspections. For AN-106, edge appears to only slightly have a better diagonal fit to the original analysis than does peak/edge; again edge is not available. For AY-102, three outlying values, indicated by the bold points, make it difficult to complete the comparison, so the three outliers are omitted in the final row of plots. Then again edge gives the better fit. These results are used to identify potential biases between old and new inspections and are given in a subsequent table. 
Tank=AN-102, Inspection=Old
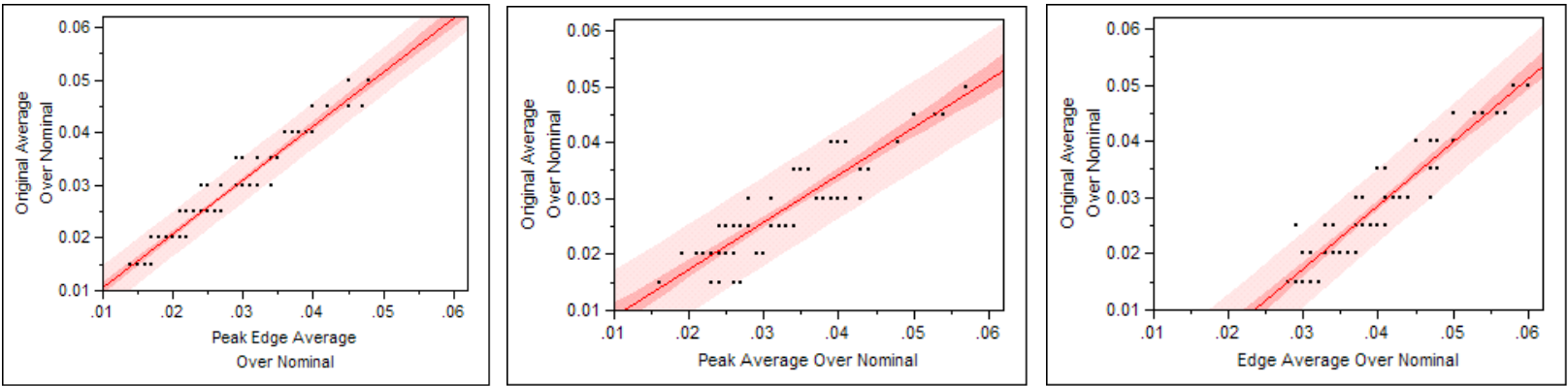

Tank=AN-102, Inspection=New
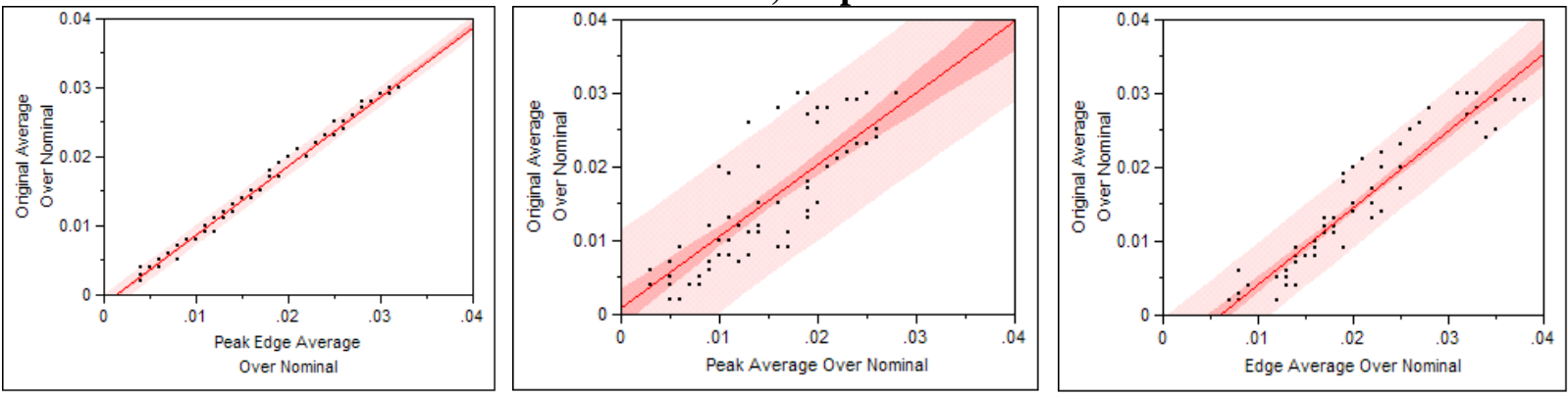

Tank=AN-107, Inspection= $=$ Old
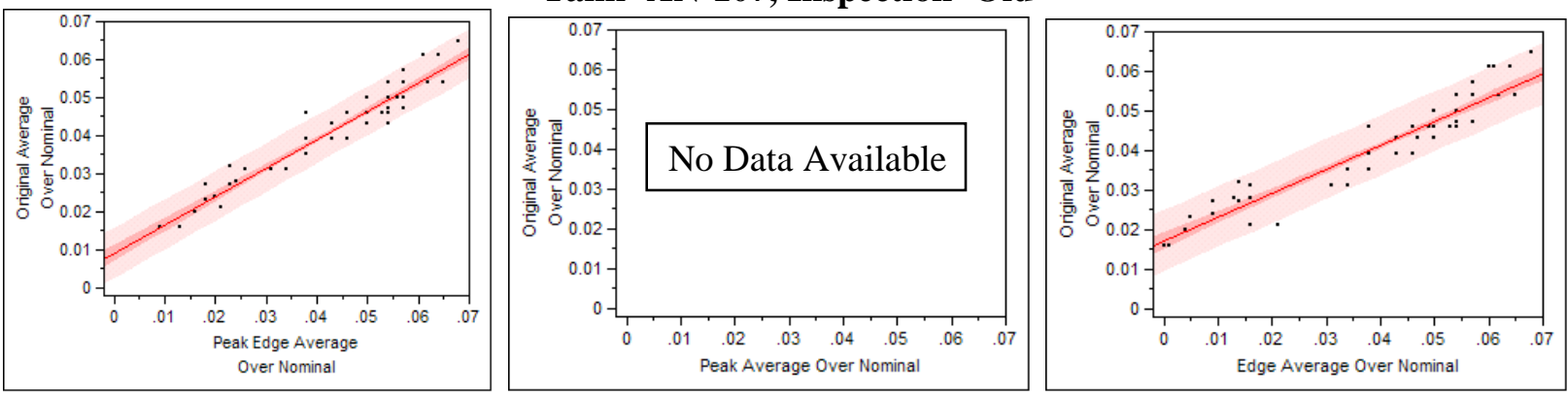

Tank=AN-107, Inspection=New
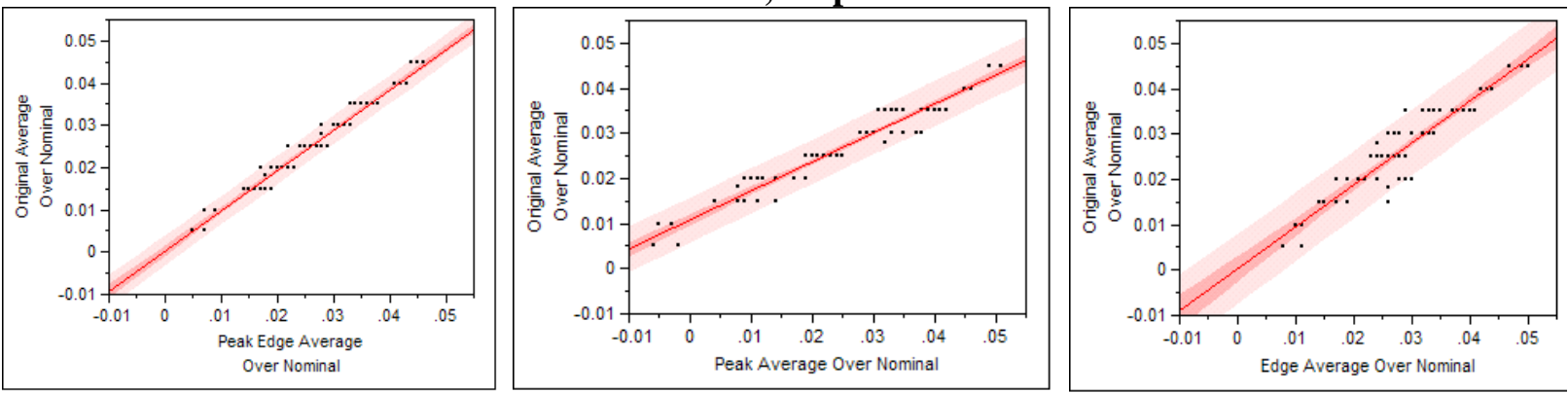

Figure 3.5. Tanks AN-102 and AN-107 Thickness over Nominal Original Method versus Peak/Edge/ Peak/Edge 
Tank=AP-108, Inspection=Old
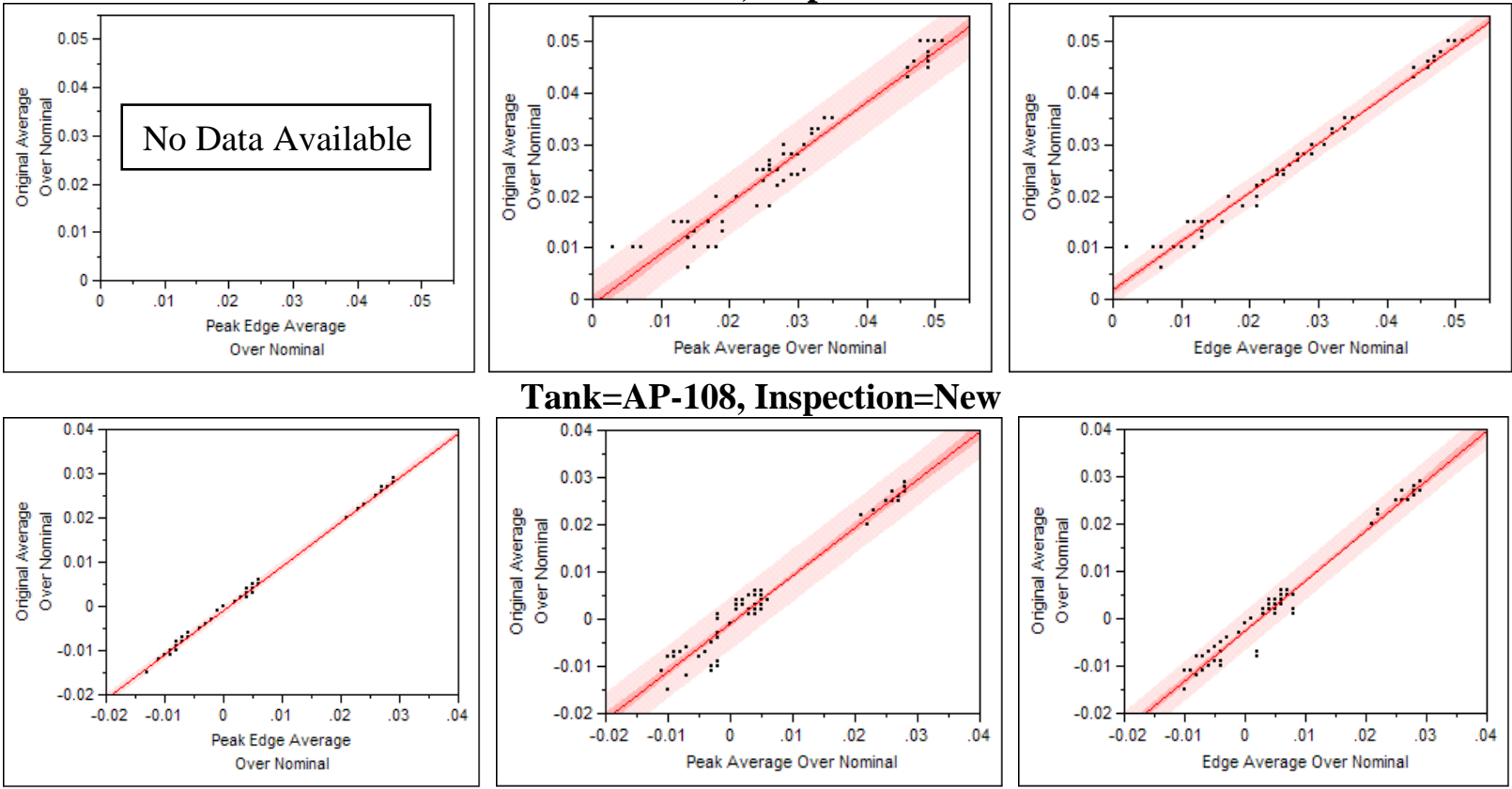

Tank=AP-108, Inspection=New
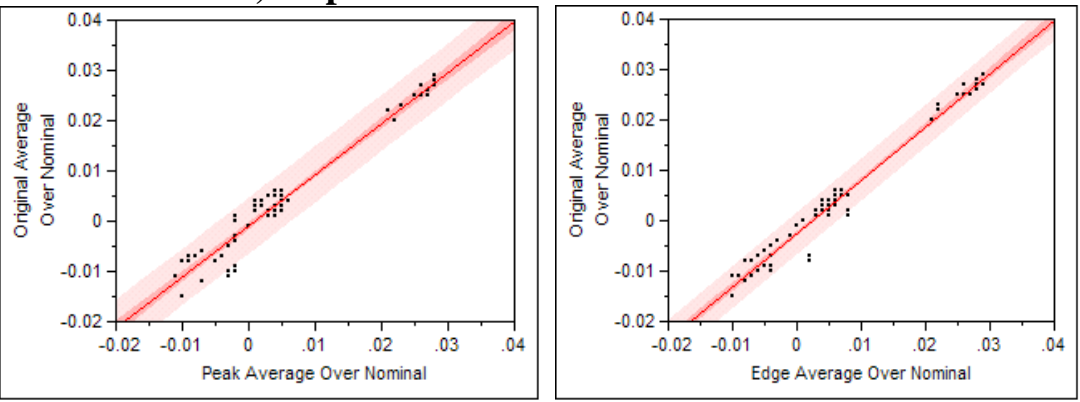

Tank=AZ-101, Inspection=Old
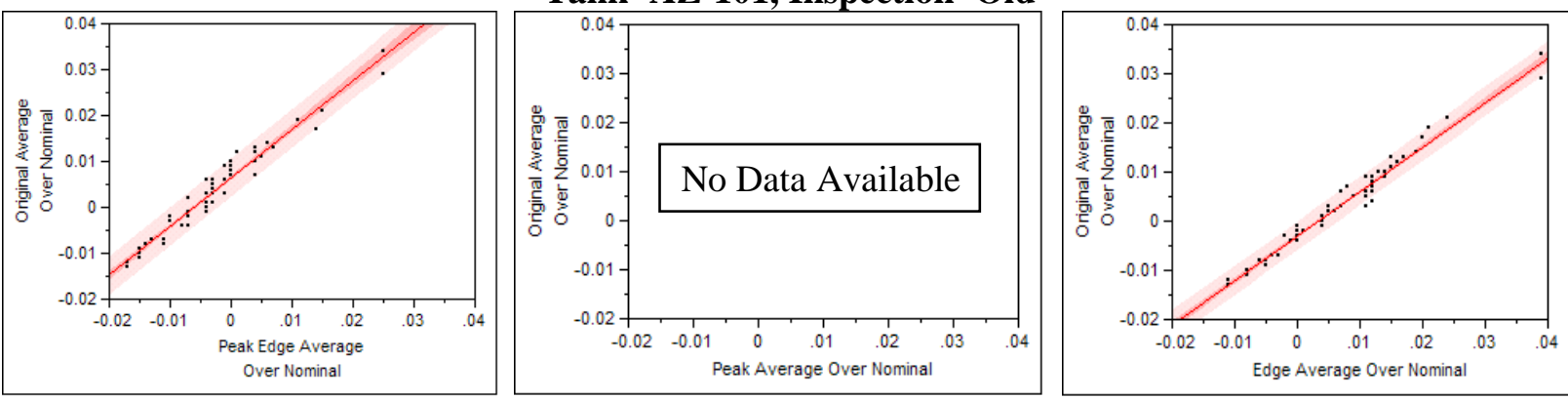

Tank=AZ-101, Inspection=New
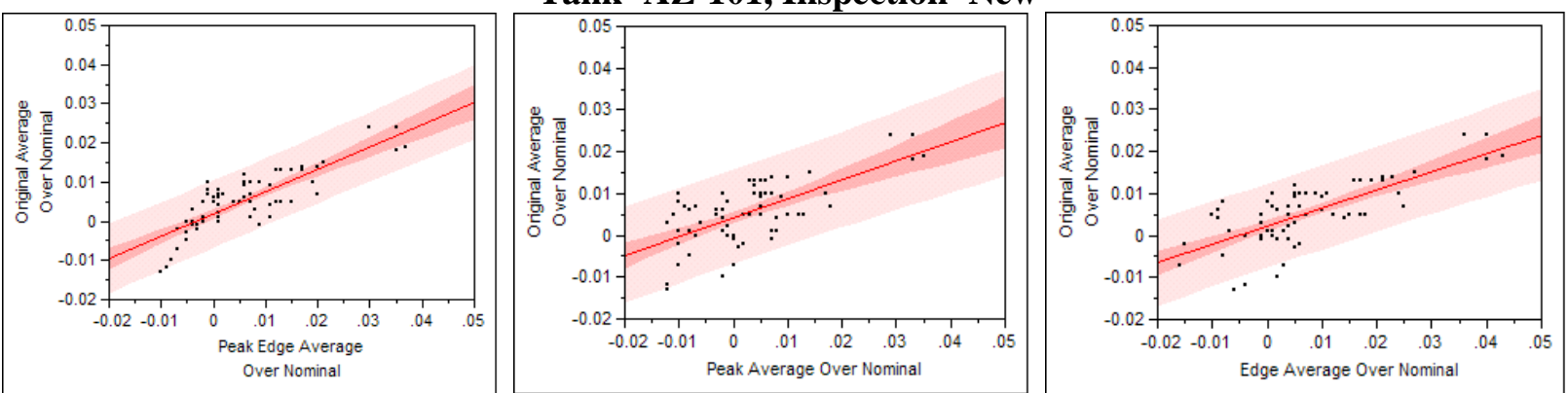

Figure 3.6. Tanks AP-108 and AZ-101 Thickness over Nominal Original Method versus Peak/Edge/ Peak/Edge 
Tank=AN-106, Inspection $=$ Old
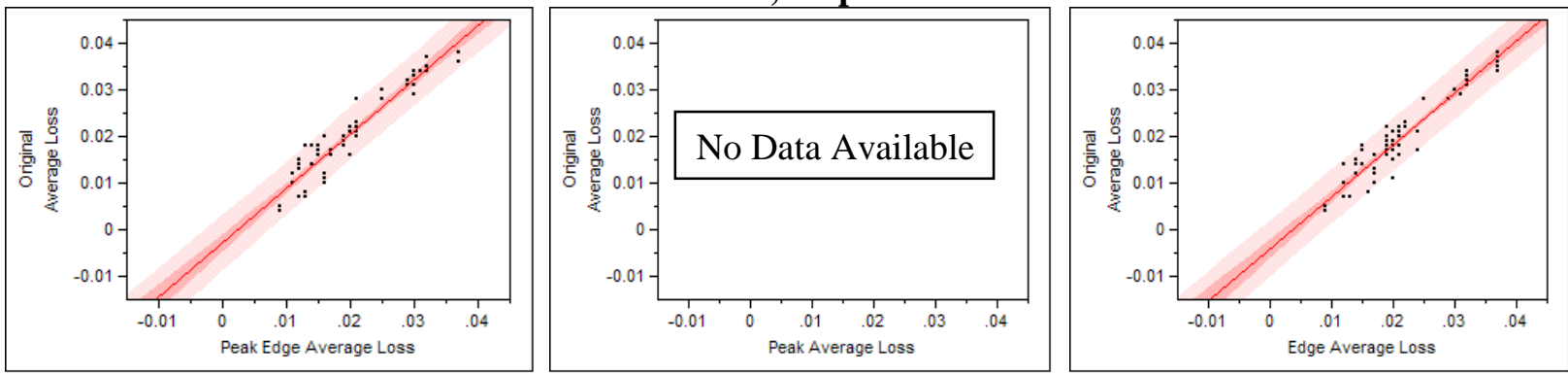

Tank=AY-102, Inspection=Old
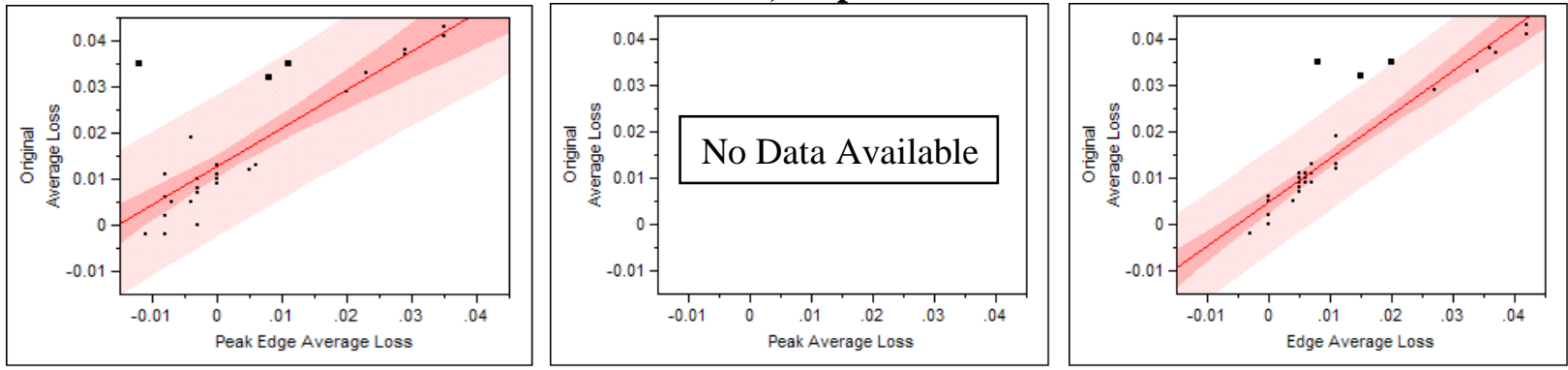

Tank=AY-102, Inspection=Old (outliers omitted)
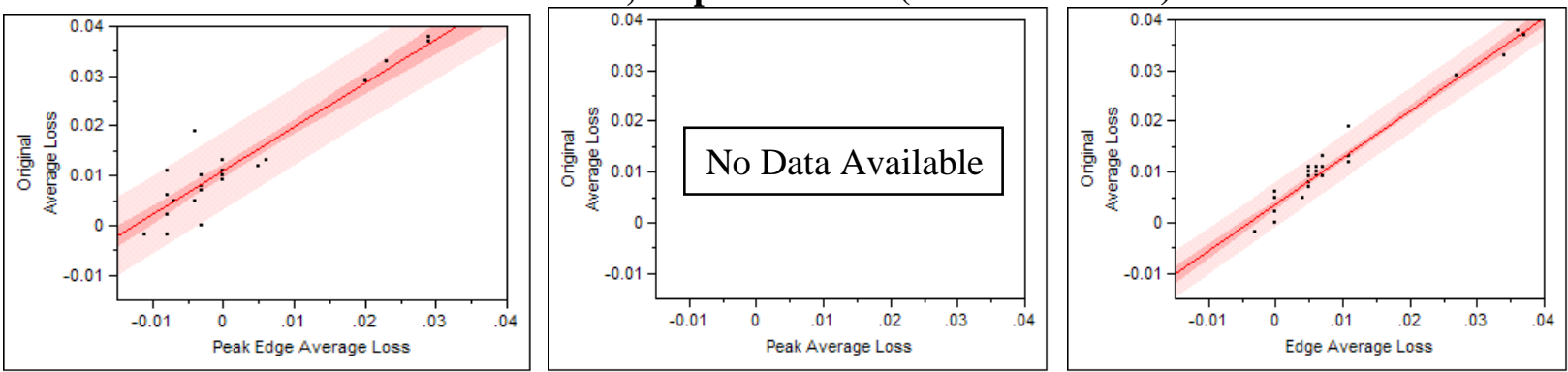

Figure 3.7. Tanks AN-106 and AY-102 Thickness over Nominal Original Method versus Peak/Edge/ Peak/Edge

\subsubsection{Wall Thickness Comparison}

Data was combined over all the cases when all three re-analysis methods were applied; this gave comparisons over 1468 UT images. A statistical model was then fit that included the factors (1) tank, (2) old vs. new inspection, (3) scan 1 or 2, (4) plate-ft (elevation), and (5) method, where method was again peak/edge, peak, or edge. Fitting the model gave the summary results in Table 3.2. The means for each level of the several factors are given under the so-labeled headings. Each of the factors did indicate statistically significant differences between the level means.

For example, under "Tank Means," the four values in the final column for the four tanks after round off are $0.025,0.033,0.015$, and 0.004 . These values are the average amount that wall thickness for the tanks still exceeds nominal. 
Table 3.2. Response Average Wall over Nominal

$\begin{array}{lr}\text { Response Average Wall over Nominal } & \\ \text { Summary of Fit } & 0.550862 \\ \text { RSquare } & 0.536322 \\ \text { RSquare Adj } & 0.012076 \\ \text { Root Mean Square Error } & 0.019549 \\ \text { Mean of Response } & 1436 \\ \text { Observations (or Sum Wgts) } & \end{array}$

$\begin{array}{lrrrr}\text { Analysis of Variance } & & & \\ \text { Source } & \text { DF } & \text { Sum of Squares } & \text { Mean Square } & \text { F Ratio } \\ \text { Model } & 45 & 0.24862918 & 0.005525 & 37.8849 \\ \text { Error } & 1390 & 0.20271631 & 0.000146 & \text { Prob > F } \\ \text { C. Total } & 1435 & 0.45134549 & & <.0001\end{array}$

$\begin{array}{lrrrrr}\text { Effect Tests } & & & & & \\ \text { Source } & \text { Nparm } & \text { DF } & \text { Sum of Squares } & \text { F Ratio } & \text { Prob }>\text { F } \\ \text { Tank } & 3 & 3 & 0.13482410 & 308.1572 & <.0001 \\ \text { Inspection } & 1 & 1 & 0.04730174 & 324.3420 & <.0001 \\ \text { Scan } & 1 & 1 & 0.00193925 & 13.2972 & 0.0003 \\ \text { Plate_Ft } & 38 & 38 & 0.02664489 & 4.8079 & <.0001 \\ \text { Method } & 2 & 2 & 0.00449324 & 15.4048 & <.0001\end{array}$

\section{Tank Means}

$\begin{array}{lr}\text { Level } & \text { Mean } \\ \text { AN-102 } & 0.025200 \\ \text { AN-107 } & 0.033026 \\ \text { AP-108 } & 0.014824 \\ \text { AZ-101 } & 0.003801\end{array}$

$\begin{array}{lr}\text { Inspection Means } \\ \text { Level } & \text { Mean } \\ \text { New } & 0.014374 \\ \text { Old } & 0.026658\end{array}$

\section{Scan Path Means \\ $\begin{array}{lr}\text { Level Mean } \\ 1 & 0.020910\end{array}$ \\ 20.018170}

$\begin{array}{lr}\text { Method Means } & \\ \text { Level } & \text { Mean } \\ \text { Edge } & 0.021978 \\ \text { Peak } & 0.018635 \\ \text { Peak/Edge } & 0.017559\end{array}$

The next factor means shown are for "new vs. old" with 0.027 for the old inspections and 0.014 for the new inspections. Then are scans 1 and 2, respectively, at 0.021 and 0.018 as shown in Table 3.3.

But of most importance in what we are investigating is the final means heading "Method Means" that suggests 0.0220 for edge, 0.0186 for peak, and 0.0176 for peak/edge. And because we have several tanks that appear to have had old inspection done using edge analysis, but new inspection done with peak/edge, this could introduce a 0.0220 minus 0.0176 bias, or 4.4 mils. Following the analysis results is a table of old versus new comparisons where this potential bias is addressed.

Old versus new inspection wall thickness averages are compared in Table 3.3. The third column from the right gives the average wall-thickness measurement difference (old minus new) over both scans 
combined. Positive values in this column indicate decreasing wall-thickness measurements from the old to new inspection. Only Tank AZ-101 shows modestly increased thickness measurements.

Table 3.3. Comparison of Old and New Inspection Thickness over Nominal

\begin{tabular}{|c|c|c|c|c|c|c|c|c|}
\hline Tank & Scan & Inspection & $\begin{array}{l}\text { Original } \\
\text { Method }\end{array}$ & $\begin{array}{l}\text { Average } \\
\text { Thickness } \\
\text { over } \\
\text { Nominal }\end{array}$ & $\begin{array}{c}\text { Old } \\
\text { Minus } \\
\text { New by } \\
\text { Scan }\end{array}$ & $\begin{array}{c}\text { Old } \\
\text { Minus } \\
\text { New } \\
\text { Overall }\end{array}$ & $\begin{array}{l}\text { Expected } \\
\text { Method } \\
\text { Difference }\end{array}$ & $\begin{array}{l}\text { Adjusted Wall } \\
\text { Thickness } \\
\text { Decrease from } \\
\text { Old to New }\end{array}$ \\
\hline \multirow[t]{4}{*}{ AN-102 } & \multirow[t]{2}{*}{1} & New & Peak Edge & 0.0177 & 0.0129 & \multirow[t]{4}{*}{0.0131} & \multirow[t]{4}{*}{0.0000} & \multirow[t]{4}{*}{0.0131} \\
\hline & & Old & Peak Edge & 0.0306 & & & & \\
\hline & \multirow[t]{2}{*}{2} & New & Peak Edge & 0.0126 & 0.0134 & & & \\
\hline & & Old & Peak Edge & 0.0260 & & & & \\
\hline \multirow[t]{4}{*}{ AN-107 } & \multirow[t]{2}{*}{1} & New & Peak Edge & 0.0270 & 0.0193 & \multirow[t]{4}{*}{0.0109} & \multirow[t]{4}{*}{0.0000} & \multirow[t]{4}{*}{0.0109} \\
\hline & & Old & Peak Edge & 0.0463 & & & & \\
\hline & \multirow[t]{2}{*}{2} & New & Peak Edge & 0.0299 & 0.0024 & & & \\
\hline & & Old & Peak Edge & 0.0323 & & & & \\
\hline \multirow[t]{4}{*}{ AP-108 } & \multirow[t]{2}{*}{1} & New & Peak Edge & 0.0037 & 0.0243 & \multirow[t]{4}{*}{0.0230} & \multirow[t]{4}{*}{0.0044} & \multirow[t]{4}{*}{0.0186} \\
\hline & & Old & Edge & 0.0280 & & & & \\
\hline & \multirow[t]{2}{*}{2} & New & Peak Edge & 0.0054 & 0.0218 & & & \\
\hline & & Old & Edge & 0.0271 & & & & \\
\hline \multirow[t]{4}{*}{ AZ-101 } & \multirow[t]{2}{*}{1} & New & Peak Edge & 0.0059 & -0.0090 & \multirow[t]{4}{*}{-0.0020} & \multirow[t]{4}{*}{0.0044} & \multirow[t]{4}{*}{-0.0064} \\
\hline & & Old & Edge & -0.0031 & & & & \\
\hline & \multirow[t]{2}{*}{2} & New & Peak Edge & 0.0048 & 0.0050 & & & \\
\hline & & Old & Edge & 0.0098 & & & & \\
\hline \multirow[t]{4}{*}{ AN-106 } & \multirow[t]{2}{*}{1} & New & Peak Edge & 0.0067 & 0.0120 & \multirow[t]{4}{*}{0.0131} & \multirow[t]{4}{*}{0.0044} & \multirow[t]{4}{*}{0.0087} \\
\hline & & Old & Edge & 0.0187 & & & & \\
\hline & \multirow[t]{2}{*}{2} & New & Peak Edge & 0.0067 & 0.0141 & & & \\
\hline & & Old & Edge & 0.0208 & & & & \\
\hline \multirow{4}{*}{$\begin{array}{l}\text { AY-102 } \\
\text { outliers } \\
\text { omitted }\end{array}$} & \multirow[t]{2}{*}{1} & New & Peak Edge & -0.0047 & 0.0378 & 0.0255 & 0.0044 & 0.0211 \\
\hline & & Old & Edge & 0.0331 & & & & \\
\hline & 2 & New & Peak Edge & -0.0028 & 0.0131 & & & \\
\hline & & Old & Edge & 0.0103 & & & & \\
\hline
\end{tabular}

For the first two tanks in the table, the "Original Method" column indicates that the peak/edge method was used in both the old and new inspections. Thus, in the final two columns, no corrections are made for a potential systematic error due to changing the analysis methods. For the other tanks, the probable methods used were edge for the old inspections and peak/edge for the new inspection. This potentially introduces a 4.4-mil bias between the old and new inspections because edge tends to generate larger values than does peak/edge.

The second to last column shows this bias for those tanks, and the last column reduces the measured decreases between old and new by that amount. The modest wall thickness gain in Tank AZ-101 is instead increased to an even larger gain amount. 
Figure 3.8 shows the old (blue) versus new (red) inspection results. The vertical axes are again the thickness above nominal. The first four tanks have the points plotted for all the original and re-analysis methods used while the last two tanks have only the original analysis results because re-analysis has not been performed on the new inspections.

The remaining three tanks are not currently scheduled for re-analysis using the peak, edge, and peak/edge methods. 

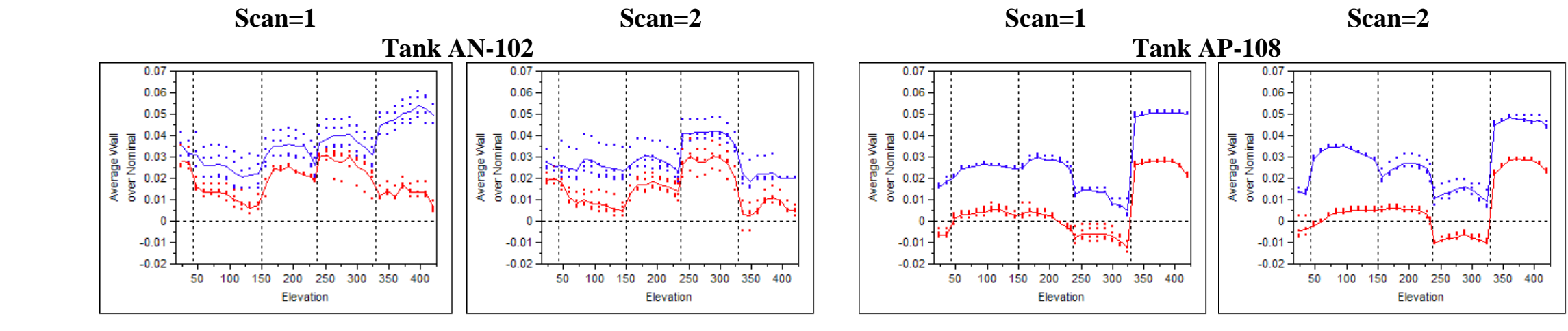

Tank AN-107
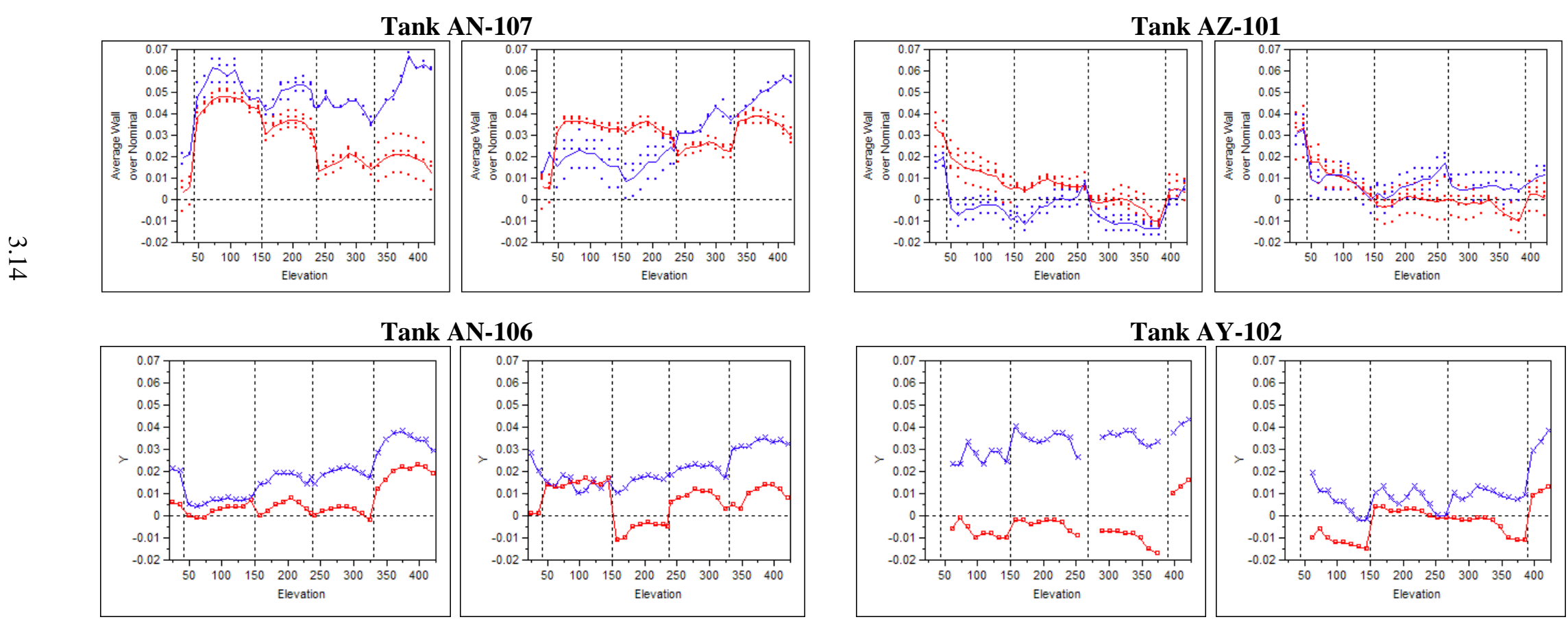

Tank AN-106
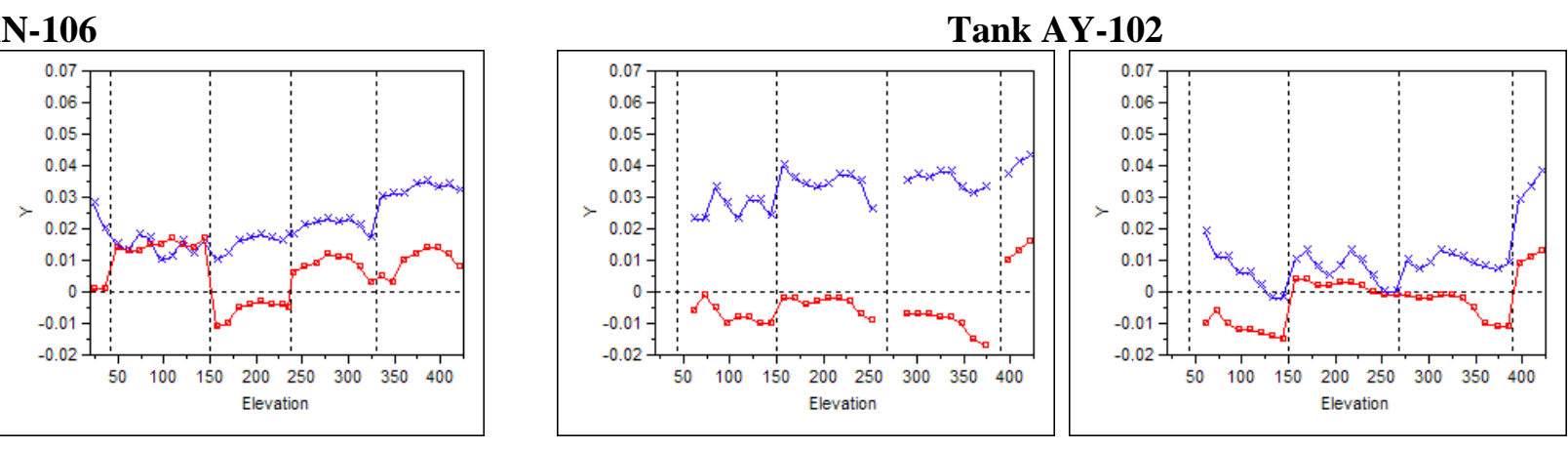

Fit Each Value Inspection=="New"
Fit Each Value Inspection=" $=$ "Old"

Figure 3.8. Tanks AN-102, AP-108, AN-107, AZ-101, AN-106, and AY-102 Average Wall over Nominal by Elevation 


\subsection{Laboratory Studies on Mockups}

In an effort to understand discrepancies between the ongoing coupon corrosion study and the UT program, WRPS has contracted with PNNL to perform a rigorous statistically based study to identify measurement differences from using different UT operators and different UT equipment. Additionally, the walls of the tank are cleaned prior to examination, and this laboratory study evaluated those potential causes of measurement variation as well. Other variables that were also studied included temperature variations between a calibration standard and mockup wall, spring tension of the transducer holders, couplant temperature variations, equipment modifications, and an evaluation of dual-element and singleelement transducers.

These studies were performed on knuckle mockups that were fabricated for prior DST work, but are of the same material and thicknesses as the actual tanks. AFS performed UT scanning on a laboratory mockup(s) in August and September 2009 according to plans developed by PNNL. The plan was developed to understand the relative amounts of variability in measurement results that could be caused by all of the variables discussed in the first paragraph.

\subsection{Baseline Measurements}

Baseline measurements were made of both mockups used in this study. Figure 4.1 shows the two mockups that were used. The mockup shown on the left has been designated the Variability Study Mockup and the one on the right is the Wall-Cleaning Mockup. These measurements were made using a digital deep-throat micrometer and a digital ultrasonic instrument calibrated using an existing PNNL step wedge at room temperature.
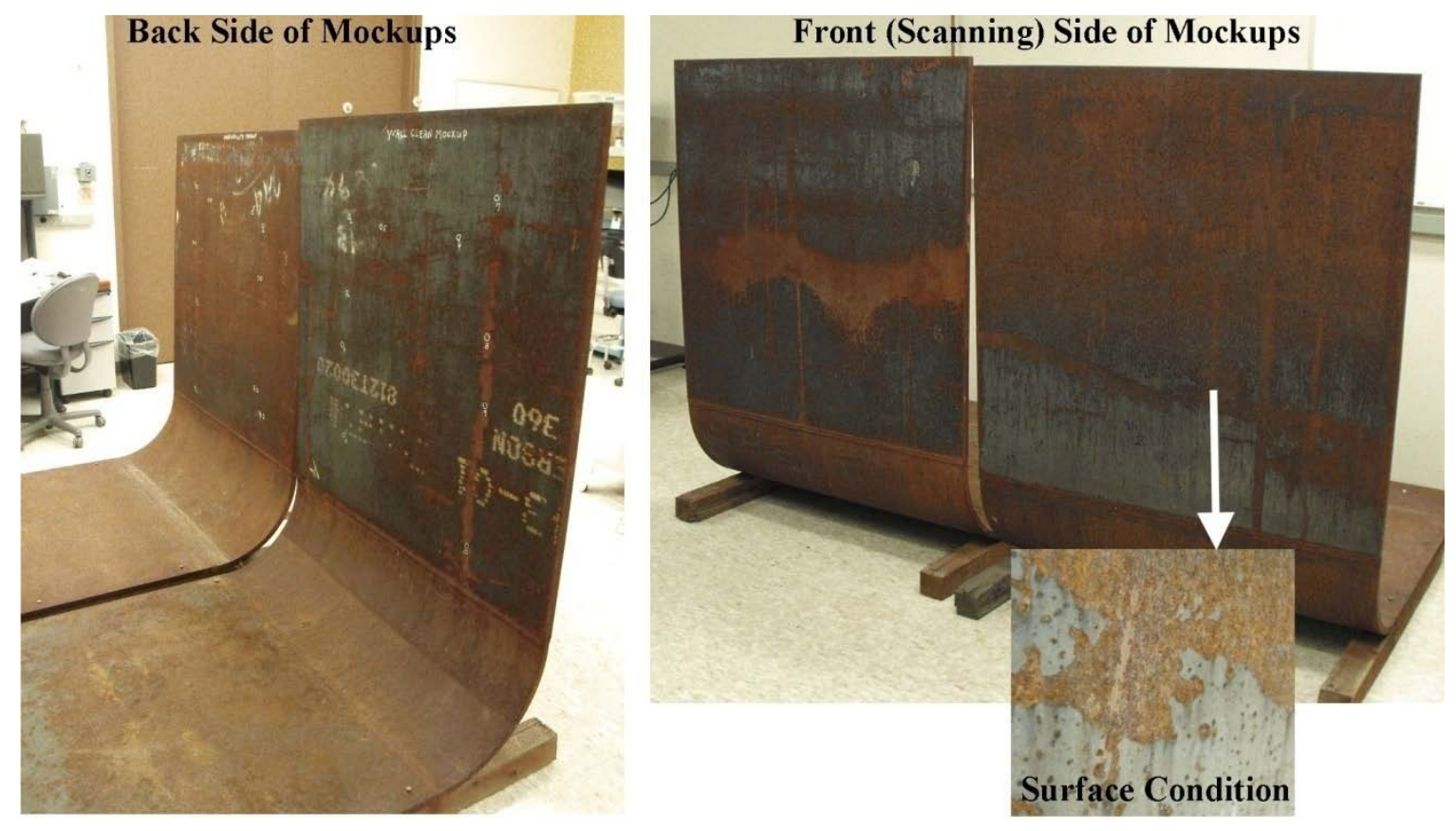

Figure 4.1. Mockups Used in the Study 
The only available (within reason) digital deep-throat micrometer (12-inch throat) came with a rounded barrel on one side and a flat barrel on the other side and had an opening of 1.0 inch. Initial measurements were made using this approach. A second set of measurements were made after machining the flat-barrel side to a point. There was no room to add a precision machined bead, which is normally done. This addition would have provided a better point measurement on the corroded surface of the mockups. Figure 4.2 shows the micrometer prior to and after machining. The manual ultrasonic measurements were made using a small diameter (0.25-inch), $10-\mathrm{MHz}$ transducer with a Krautkramer handheld UT instrument.
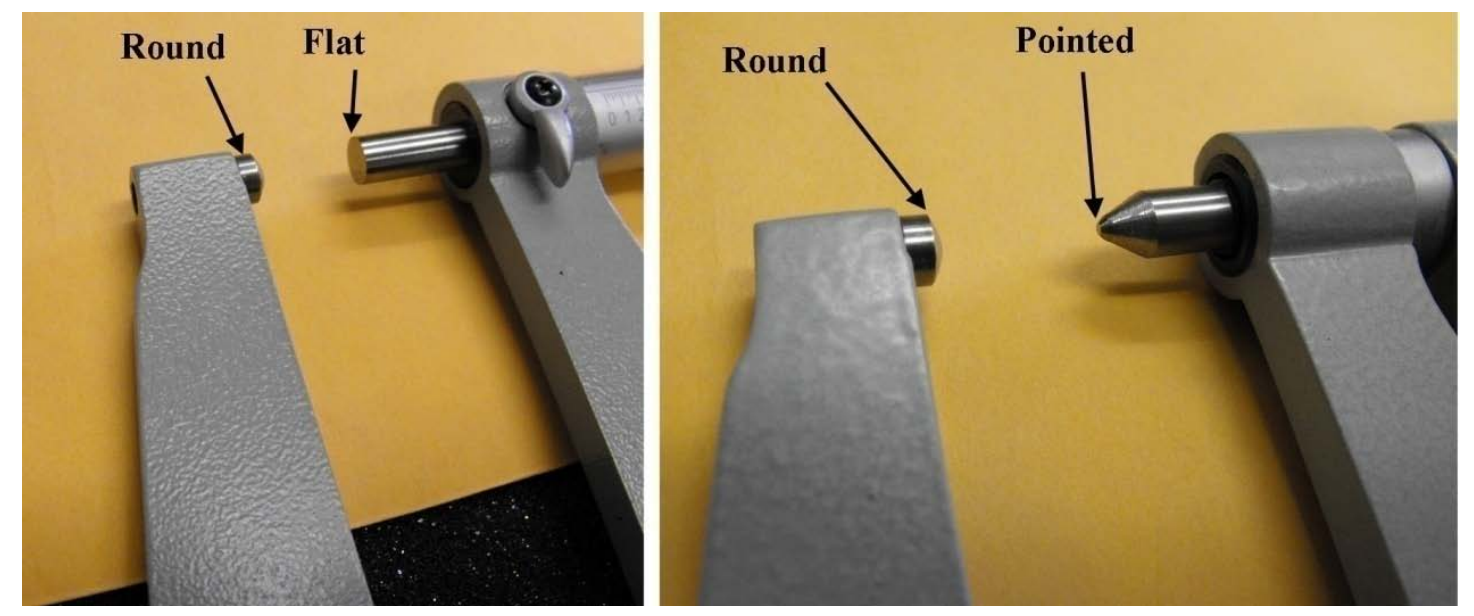

Figure 4.2. Machined Micrometer

\subsubsection{Variability Mockup}

Figure 4.3 is a photograph of the Variability Mockup used in this study. Staff from PNNL and AFS used the deep-throat micrometer in areas that could be reached using the micrometer. These areas are highlighted with white circles in the photograph. Each is numbered for reference. Table 4.1 provides the measurement values for each of the areas.

Table 4.1. Variability Mockup Baseline Measurements (inches)

\begin{tabular}{lcccc}
\hline Location & $\begin{array}{c}\text { Flat-Barrel } \\
\text { Micrometer }\end{array}$ & $\begin{array}{c}\text { Point-Barrel } \\
\text { Micrometer } \\
\text { (PNNL) }\end{array}$ & $\begin{array}{c}\text { Point-Barrel } \\
\text { Micrometer } \\
\text { (AFS) }\end{array}$ & $\begin{array}{c}\text { Manual UT } \\
\text { (PNNL) }\end{array}$ \\
\hline 1 & 0.890 & 0.888 & 0.888 & 0.888 \\
2 & 0.891 & 0.889 & 0.890 & 0.890 \\
3 & 0.896 & 0.894 & 0.892 & 0.893 \\
4 & 0.890 & 0.888 & 0.888 & 0.889 \\
5 & 0.890 & 0.888 & 0.889 & 0.889 \\
6 & 0.893 & 0.889 & 0.887 & 0.888 \\
7 & 0.892 & 0.888 & 0.888 & 0.892 \\
8 & 0.894 & 0.891 & 0.891 & 0.892 \\
9 & 0.893 & 0.892 & 0.892 & 0.894 \\
10 & 0.894 & 0.891 & 0.891 & 0.893 \\
\hline
\end{tabular}




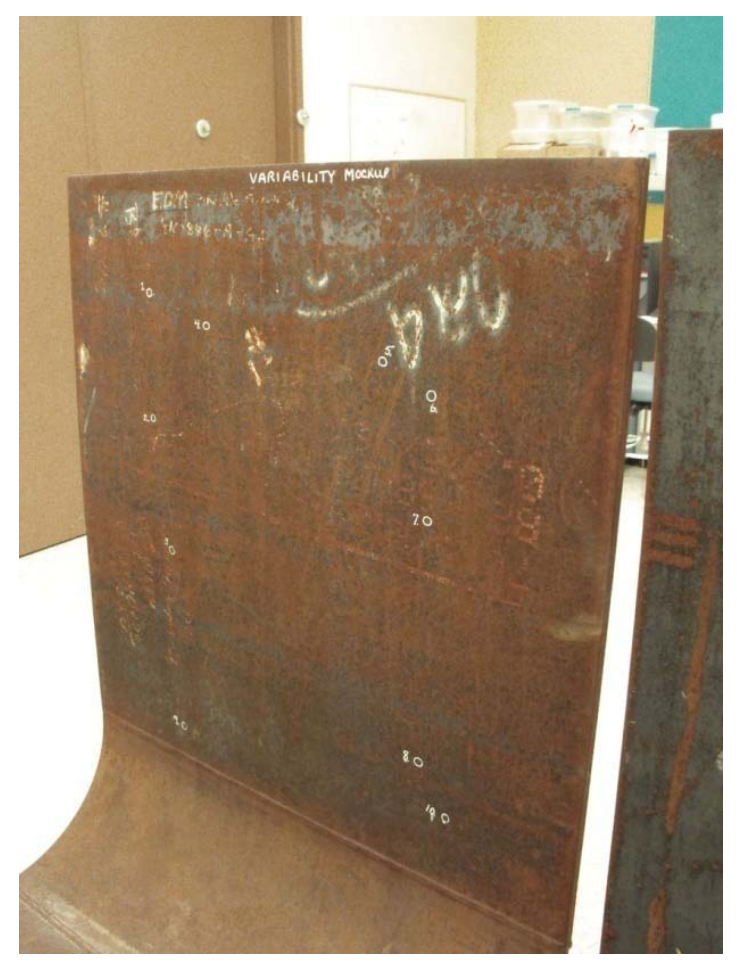

Figure 4.3. Variability Mockup

These measured thicknesses are displayed in Figure 4.4. The larger measurements due to using the flat-barrel micrometer (red line) rather the point-barrel (green lines) can generally be observed. As expected, very little difference is observed between the AFS and PNNL point-barrel measurements. Summary information is given in the next section following the similar plot for the cleaning study mockup.

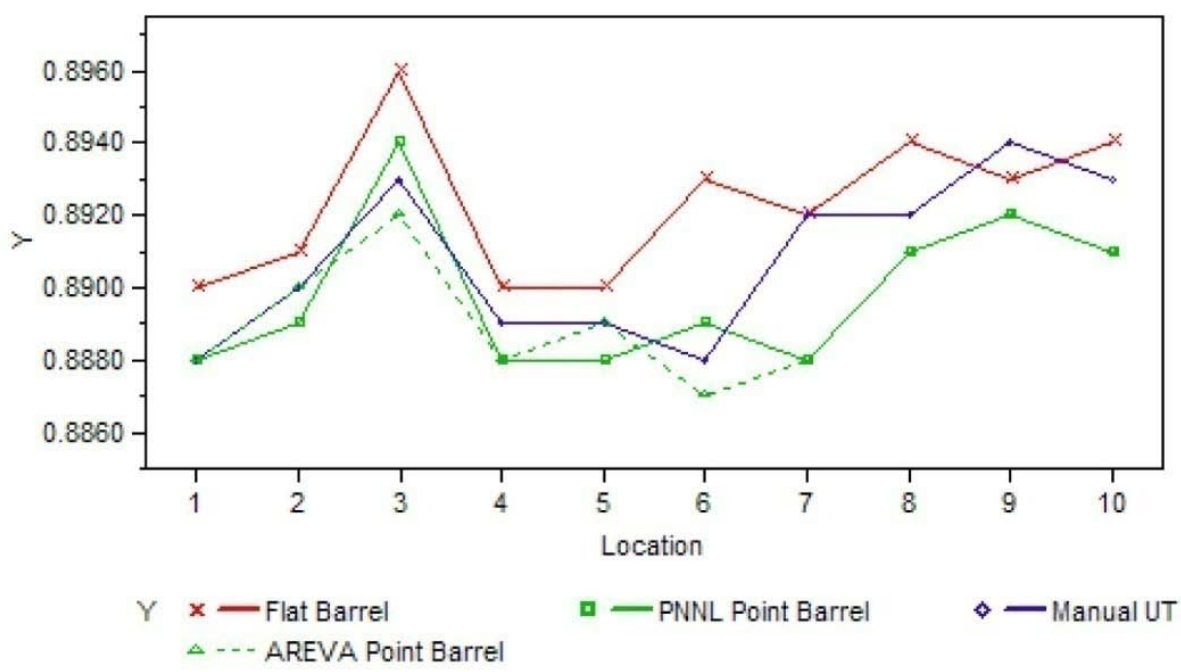

Figure 4.4. Variability Mockup Measurements 


\subsubsection{Wall-Cleaning Mockup}

Figure 4.5 is a photograph of the Wall-Cleaning Mockup used in this study. Using the deep-throat micrometer, measurements were taken in areas that could be reached using the micrometer. These areas are highlighted with white circles in the photograph. Each is numbered for reference. Table 4.2 provides the measurement values for each of the areas.

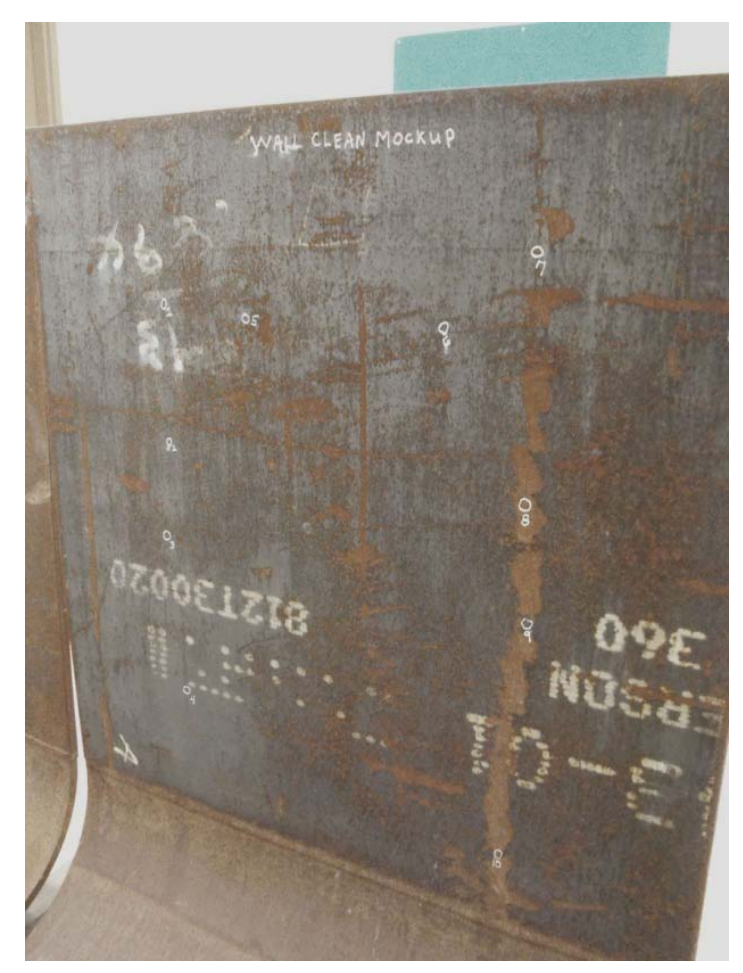

Figure 4.5. Wall-Cleaning Mockup

Table 4.2. Wall-Cleaning Mockup Baseline Measurements (inches)

\begin{tabular}{lcccc}
\hline Location & $\begin{array}{c}\text { Flat-Barrel } \\
\text { Micrometer }\end{array}$ & $\begin{array}{c}\text { Point-Barrel } \\
\text { Micrometer } \\
\text { (PNNL) }\end{array}$ & $\begin{array}{c}\text { Point-Barrel } \\
\text { Micrometer } \\
\text { (AFS) }\end{array}$ & $\begin{array}{c}\text { Manual UT } \\
\text { (PNNL) }\end{array}$ \\
\hline 1 & 0.893 & 0.892 & 0.891 & 0.892 \\
2 & 0.898 & 0.895 & 0.896 & 0.895 \\
3 & 0.898 & 0.895 & 0.896 & 0.897 \\
4 & 0.898 & 0.898 & 0.898 & 0.896 \\
5 & 0.894 & 0.891 & 0.893 & 0.892 \\
6 & 0.895 & 0.892 & 0.893 & 0.893 \\
7 & 0.894 & 0.891 & 0.891 & 0.893 \\
8 & 0.899 & 0.896 & 0.897 & 0.899 \\
9 & 0.899 & 0.897 & 0.897 & 0.901 \\
10 & 0.902 & 0.897 & 0.898 & 0.899 \\
\hline
\end{tabular}


These measured thicknesses are displayed in Figure 4.6. The larger measurements due to using the flat-barrel micrometer (red line) rather the point-barrel (green lines) can again be observed as was the case for the variability mockup in the previous section. And again, very little difference is observed between the AFS and PNNL point-barrel measurements.

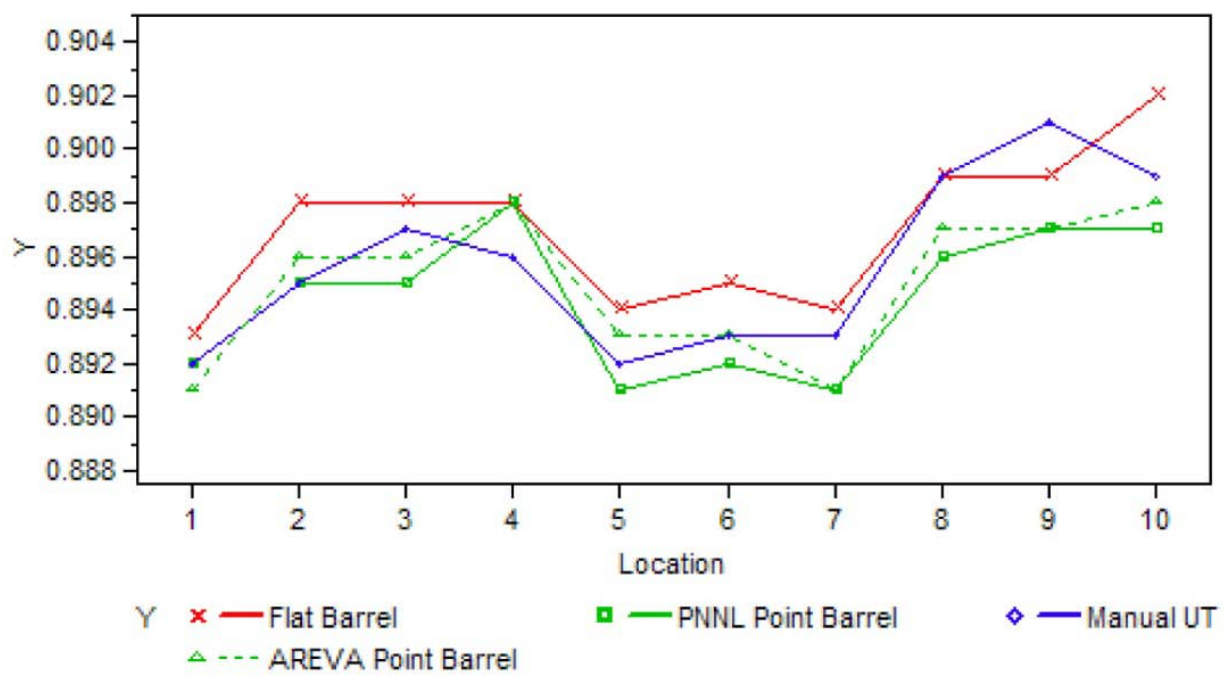

Figure 4.6. Point Study Mockup Measurements

\subsubsection{Summary of Wall Thickness}

Summary information from the thickness measurements for both the variability mockup and the wallcleaning mockup are given in the following. On the average, the flat-barrel measurements were 2.5 mils greater than those for the average of the PNNL and AFS point-barrel measurements. In turn, the manual UT values were in between the two micrometer measurements. The manual UT were 1.4 mils less than the flat-barrel micrometer and 1.1 mils greater than the point-barrel measurements.

\begin{tabular}{ccc}
\hline $\mathbf{N}$ & Flat-Barrel Minus Point Barrel & Manual UT Minus Point Barrel \\
\hline 20 & 0.0025 inch & 0.0011 inch \\
\hline
\end{tabular}

Table 4.3 shows that the difference between the two mockup plates was the greatest contributor to thickness variability (smallest p-value in the first set of red italic values for mockup means). This value is due to a 5-mil difference indicated in the "Mockup Means" section of the table. The next most significant source of variability was due to apparent thickness changes between locations within the plates. Finally, the measurement method was also statistically significant (all the p-values for these three factors were quite small, which indicates their statistical significance); the method means are given in the last set of means in Table 4.3. These means also generated the mean differences preceding this paragraph. Note practically no difference is indicated between the PNNL and AFS point-barrel micrometer means. 
Table 4.3. Summary Information for Response Thickness

\begin{tabular}{|c|c|c|c|c|c|}
\hline \multicolumn{6}{|c|}{ Analysis of Variance } \\
\hline Source & DF & & ff Squares & Mean Square & F Ratio \\
\hline Model & 6 & & 065207 & 0.000109 & 21.7071 \\
\hline Error & 73 & & 0036548 & 0.000005 & Prob $>$ F \\
\hline C. Total & 79 & & 0101755 & & $<0.0001$ \\
\hline \multicolumn{6}{|c|}{ Effect Tests } \\
\hline $\begin{array}{r}\text { Source } \\
\end{array}$ & Nparm & DF & Sum of Squares & F Ratio & Prob $>$ F \\
\hline Mockup & 1 & 1 & 0.00048020 & 95.9138 & $<0.0001$ \\
\hline Location[Mockup] & 2 & 2 & 0.00009062 & 9.0501 & 0.0003 \\
\hline Method & 3 & 3 & 0.00008125 & 5.4095 & 0.0020 \\
\hline \multicolumn{6}{|c|}{ Mockup Means } \\
\hline Level & \multicolumn{5}{|c|}{ Mean } \\
\hline Cleaning & \multicolumn{5}{|c|}{0.895525} \\
\hline Variability & \multicolumn{5}{|c|}{0.890625} \\
\hline \multicolumn{6}{|c|}{ Method Mean } \\
\hline Level & \multicolumn{5}{|c|}{ Mean } \\
\hline AREVA Point Barrel & \multicolumn{5}{|c|}{0.892300} \\
\hline Flat Barrel & \multicolumn{5}{|c|}{0.894650} \\
\hline Manual UT & \multicolumn{5}{|c|}{0.893250} \\
\hline PNNL Point Barrel & \multicolumn{5}{|c|}{0.892100} \\
\hline
\end{tabular}

The relative magnitudes of the method means are certainly reasonable. The flat-barrel measurements are greatest because the value reported would represent something of a maximum thickness in the relatively large region covered by the barrel. The point barrel would be an analogous maximum value, but now over a considerably smaller region contained within the flat-barrel area. The manual UT value is an average value (not a maximum value) over an area about the size of the area for the flat barrel. This average would certainly be expected to be less than the flat-barrel maximum, but it is not obvious how it would relate to the point-barrel maximum. Here it exceeds the point-barrel result on the average.

\subsection{Wall-Cleaning}

A wall-cleaning study was performed in September 2009 to help understand whether cleaning of the tank wall could affect the UT thickness measurements. A well-rusted mock-up plate was used for this study.

\subsubsection{Wall-Cleaning Study}

Figure 4.7 provides an example of how the wall-cleaning apparatus works. A pneumatic motor rotates the wire brush wheel or, in the case of Figure 4.7, the flapper wheel at high RPM and the scanning arm translates the wheel along the surface. The crawler steps the wheel down the wall for cleaning. A close-up of the flapper wheel apparatus is shown in Figure 4.8. Note that two steel plates approximately 1.5-ft square were welded to the top of the mock-up. This extension was done to allow mounting the scanner so it could begin cleaning/scanning very nearly at the top of the mockup section. 


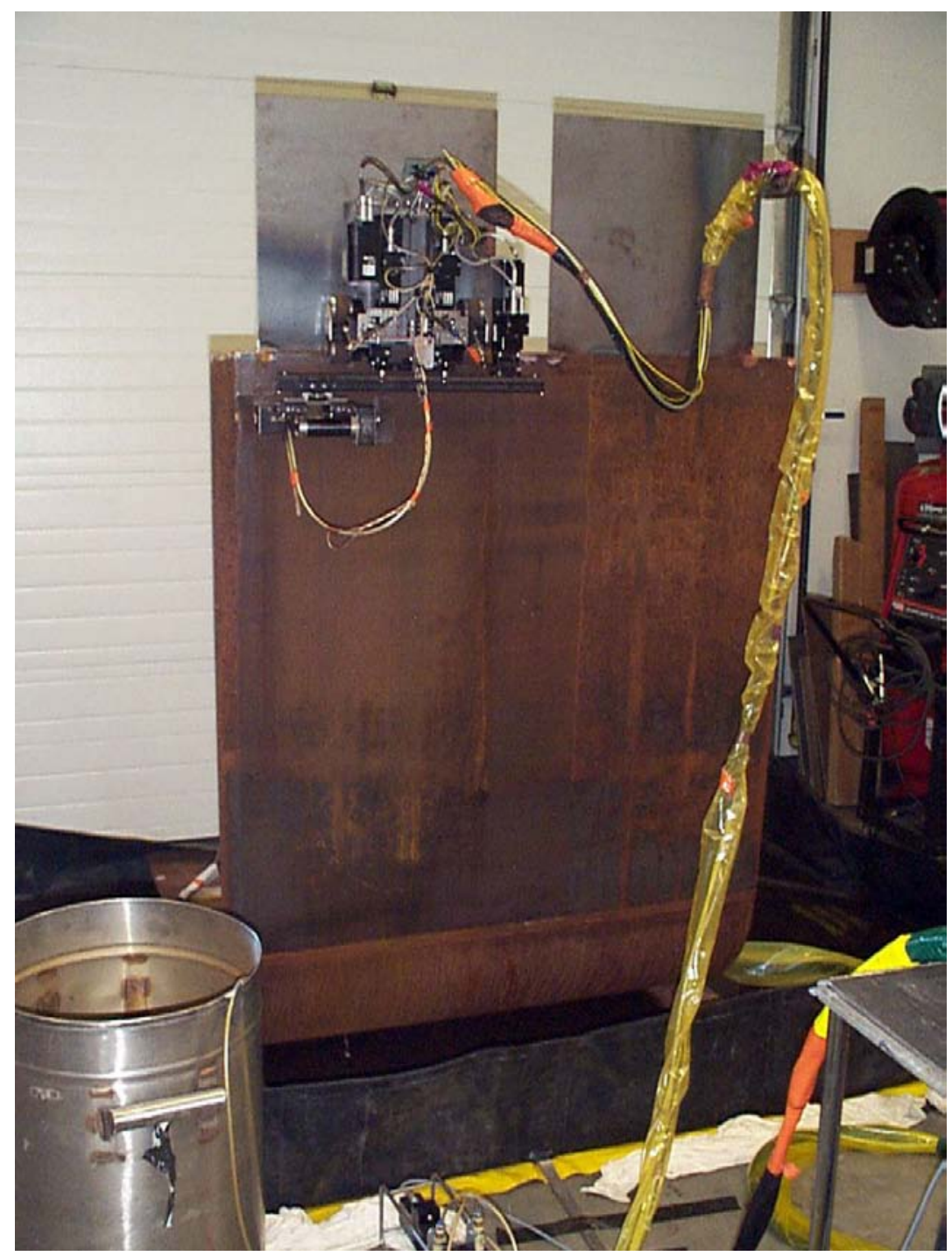

Figure 4.7. Tank Wall-Cleaning Apparatus in Place 


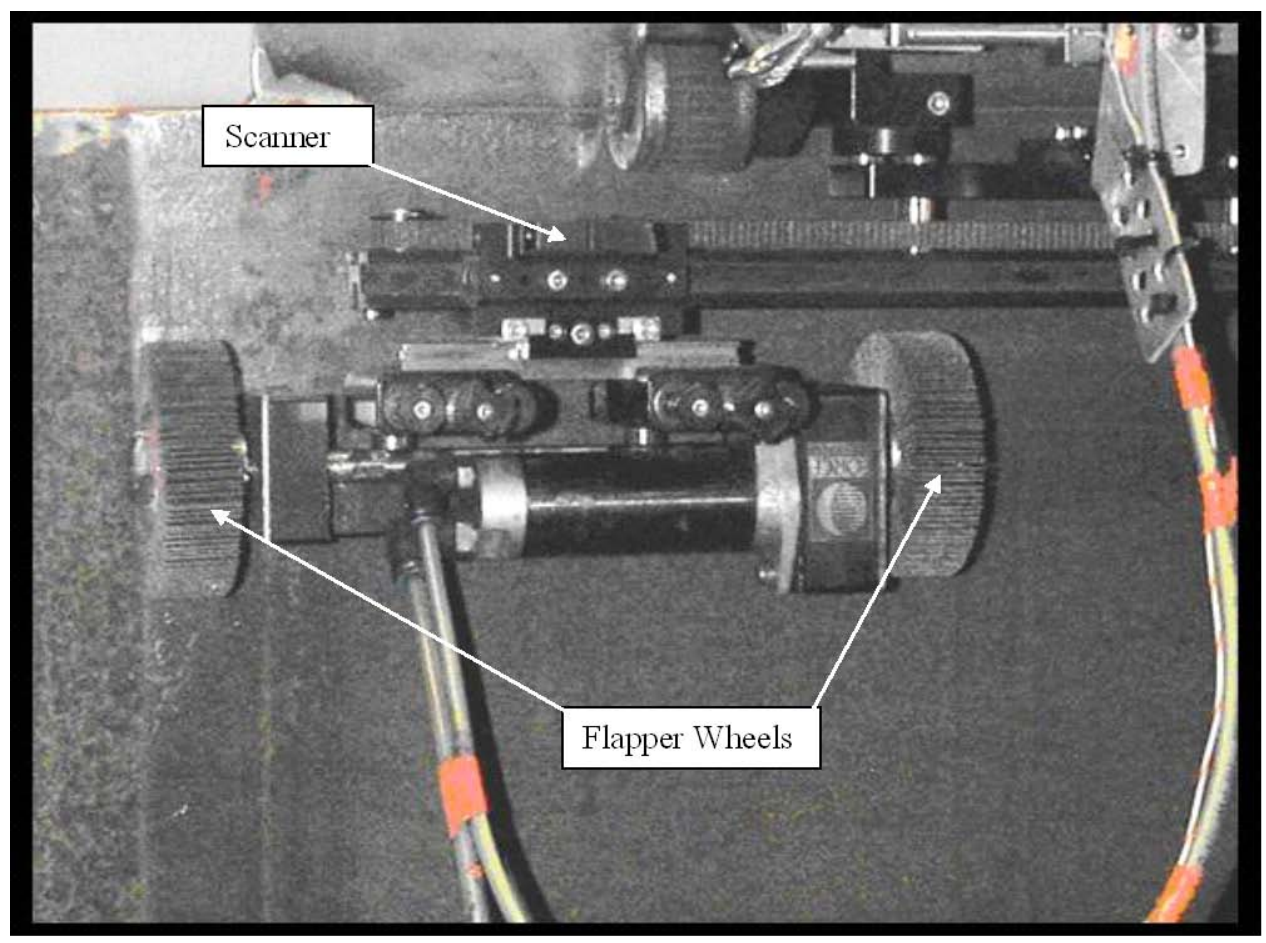

Figure 4.8. Wall-Cleaning Apparatus Using Flapper Wheel

\subsubsection{Data Acquisition Methods and Evaluation of Data}

Figure 4.9 shows dimensional information relating to the actual wall-cleaning test. The cleaning of this test plate resulted in four horizontal bands from the top of the plate and down 45 inches. Figure 4.10 shows the actual mockup and the results of the wall-cleaning activities. The upper cleaned area was done using the rotating wire brush. The lower cleaned area was done using the flapper wheel.

A single operator, instrument, and transducer was used to inspect a vertical path 15-inch wide, and crossing the two cleaning sections. In this manner, it was intended that 15 -inch $\times 12$-inch UT images would be generated within each area. However, when the analysis results were obtained, they were given in 12-inch vertical increments that did not perfectly match the intended areas. In Table 4.4, some small un-cleaned areas were in fact included in areas that were described as cleaned and vice versa. Pre- and post-cleaning averages for these somewhat mis-aligned UT images were generated and are shown. Initially, requests were going to be made for a new analysis that better fit the images to the cleaned/uncleaned areas, but when the minimal average thickness differences were observed, little need for doing so was indicated. The data below were, therefore, used in spite of the minor "shifts" that had occurred. 


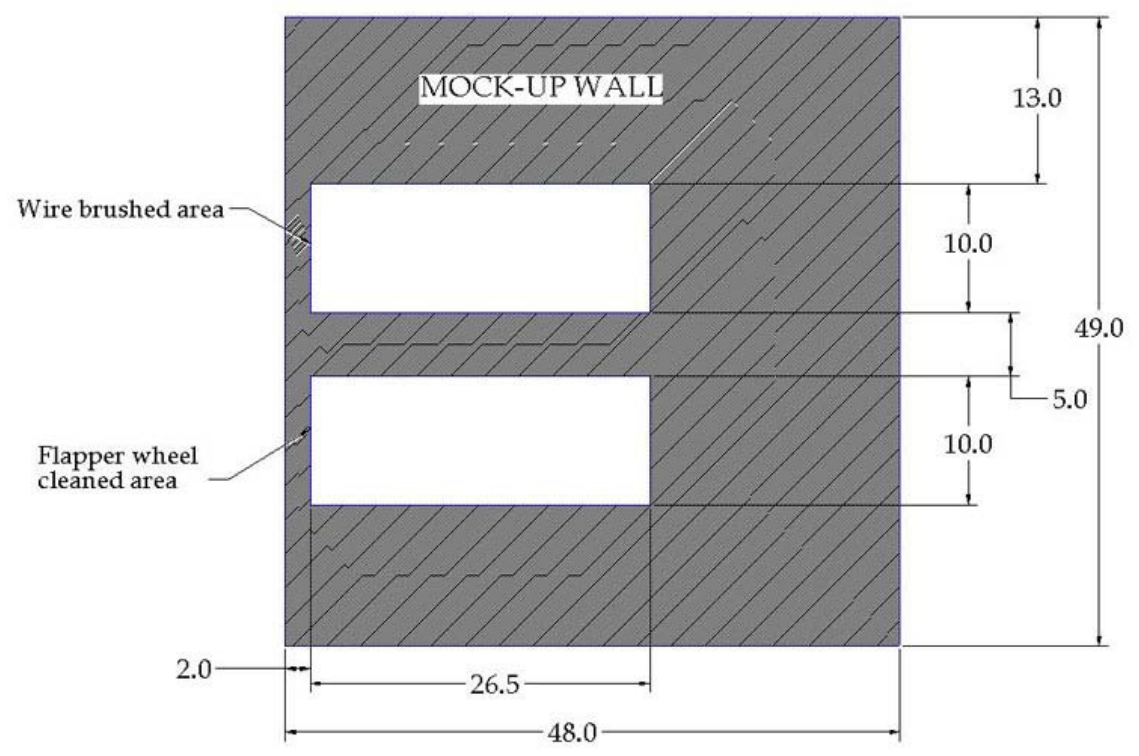

Figure 4.9. Wall-Cleaning Study Dimensions

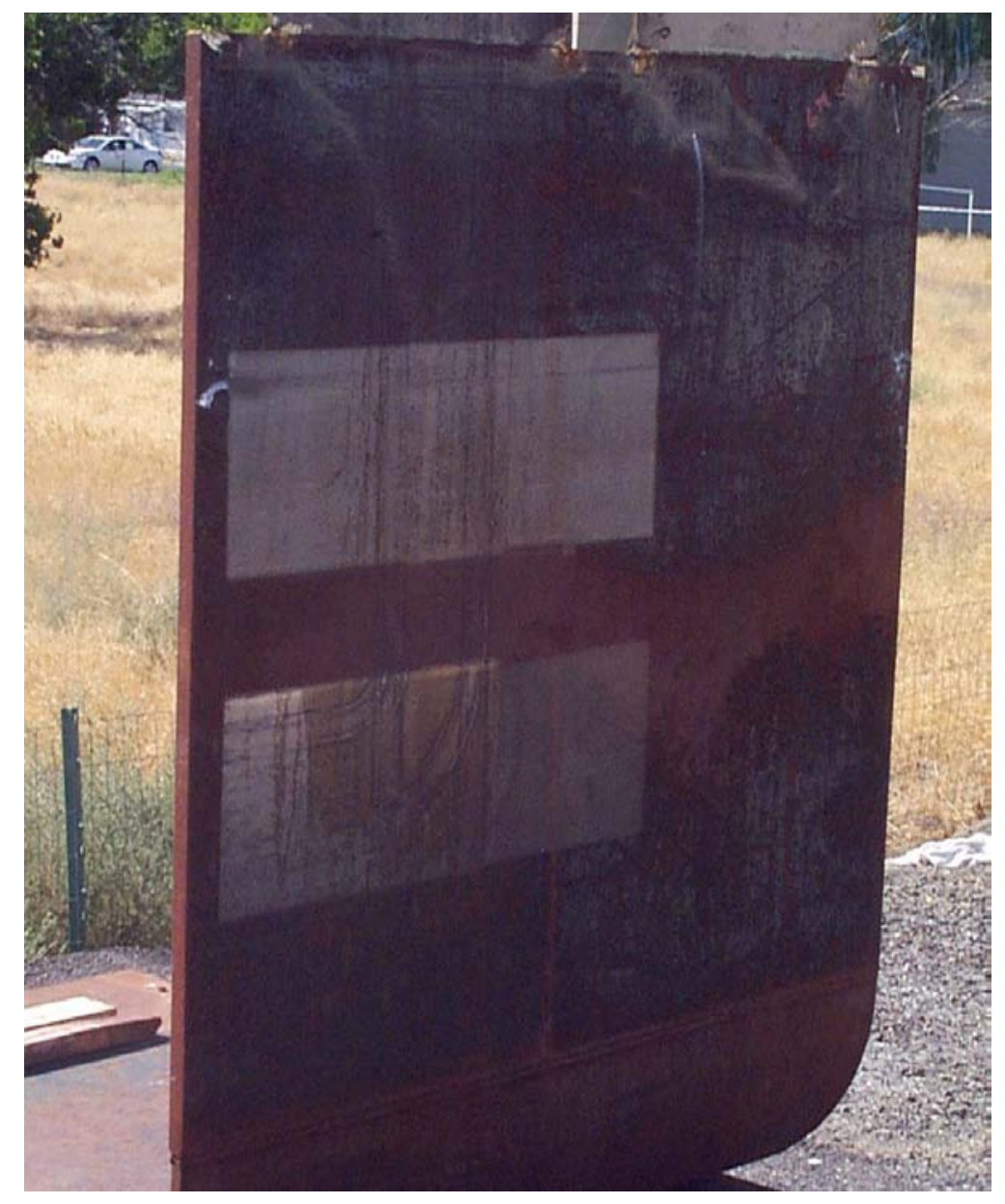

Figure 4.10. Results of Wall-Cleaning Activities 
Table 4.4. Wall-Cleaning Mockup Pre/Post Cleaning Measurements

\begin{tabular}{lccc}
\hline \multicolumn{1}{c}{ Location } & $\begin{array}{c}\text { Pre-Cleaning } \\
\text { Averages }\end{array}$ & $\begin{array}{c}\text { Post-Cleaning } \\
\text { Averages }\end{array}$ & $\begin{array}{c}\text { Pre-Post Average } \\
\text { Differences }\end{array}$ \\
\hline $0-12$ inch & 0.881 & 0.881 & 0.000 \\
$12-24$ inch & 0.883 & 0.884 & -0.001 \\
$24-36$ inch & 0.885 & 0.886 & -0.001 \\
36-45 inch & 0.886 & 0.887 & -0.001 \\
\hline
\end{tabular}

Statistical summary of these results is of little use because the thickness measurement results are so consistent from pre- to post-cleaning. This similarity is the case for both cleaning methods, as well as for the un-cleaned areas, so no attributing impact can be assigned to the cleaning methods. The only conclusion that can be drawn, then, is that the cleaning method has essentially no impact on the thickness measurement results.

Recall, however, the baseline measurements on the wall-cleaning mockup, from Section 4.1.2. Several of the micrometer measurements were located in these same cleaning areas. This data generates Table 4.5 where the point-barrel micrometer and manual UT measurements are listed along with the precleaning scan image averages.

Table 4.5. Wall-Cleaning Mockup Scanning versus Point Measurements

\begin{tabular}{lccc}
\hline $\begin{array}{c}\text { Average } \\
\text { Thickness }\end{array}$ & $\begin{array}{c}\text { Scan } \\
\text { Pre-Cleaning }\end{array}$ & $\begin{array}{c}\text { Point-Barrel } \\
\text { Micrometer }\end{array}$ & Manual UT \\
\hline Un-cleaned 1 & 0.881 & 0.892 & 0.893 \\
Wire brush & 0.883 & 0.896 & 0.899 \\
Flapper wheel & 0.885 & 0.897 & 0.901 \\
Un-cleaned 2 & 0.886 & 0.897 & 0.899 \\
\hline
\end{tabular}

The problematical issue is why the scan measurements are so much smaller than the point-barrel micrometer or manual UT measurements. The data plotted in Figure 4.11 require little statistical analysis because the results are obvious. When the average of the micrometer and manual UT measurements are compared to the scan average values, a mean 13-mil difference is obtained. A similar analysis for the variability mockup showed a corresponding difference with the scan measurements being about 12 mils less than the point-barrel micrometer and manual UT values.

A potential explanation is biases generated with couplant, calibration block, and mockup temperatures not sufficiently close together as is demonstrated later in this report. That could potentially have generated the apparent low bias of the scan pre-cleaning measurements in Table 4.5. 


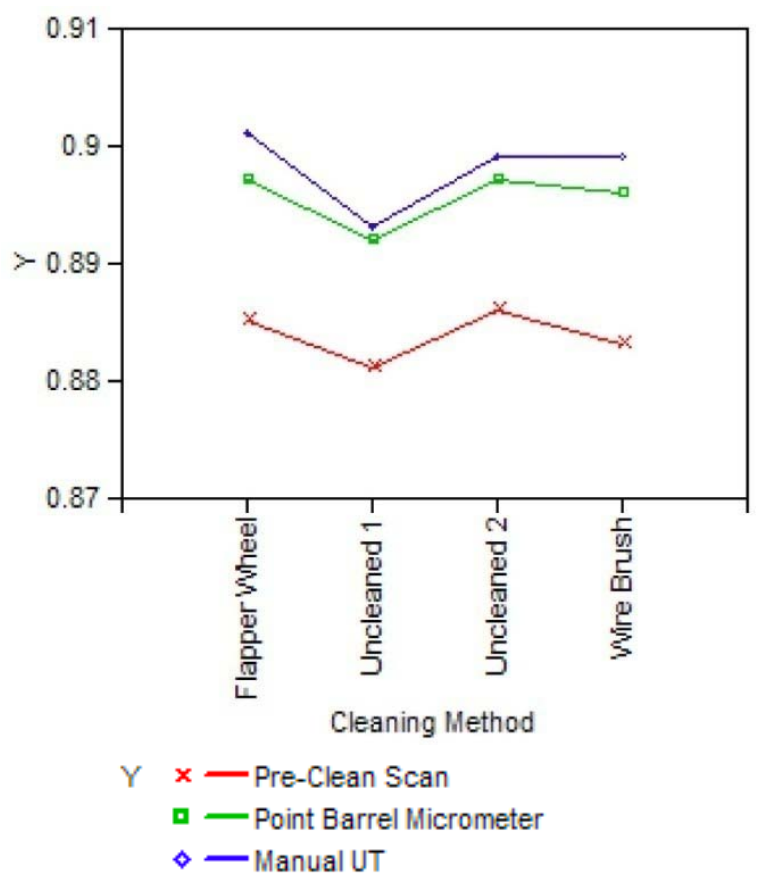

Figure 4.11. Wall-Cleaning Mockup Measurements (inches)

\subsection{Calibration Block and Test Block/Couplant Temperature Variations}

The temperatures of three features of UT inspection of tank wall thickness were varied in the studies discussed in this section and in Section 4.5. For this section, the temperatures of the calibration block and the test block (representative of the tank wall) were varied and thickness measured to help understand whether such temperature changes could affect the UT thickness measurements. This study attempts to reproduce the temperature characteristics that are relevant with regards to sound velocity in the tank wall steel. Note that the procedural requirement for the calibration standard is to be within $25^{\circ} \mathrm{F}$ of the actual tank steel temperature.

\subsubsection{Temperature Study}

The test block steel was maintained at several specific temperatures that are representative of the actual tank temperatures within reason. Heaters were used to control such temperatures during testing. The original intent in the study was for the couplant (water) to be maintained at an ambient temperature and not varied. However, miscommunication led to the couplant being adjusted to match the test block temperature. This "statistically confounds" the couplant and test block temperature changes, so their relative impact cannot be separated in the analyses. The similar miscommunication affected the Section 4.4 study as well, but there the unplanned temperature changes were actually an improvement to the intended study. 


\subsubsection{Data Acquisition Methods and Evaluation of Data}

To obtain the temperature for the test, high-wattage heaters were fastened by magnetic fixtures to the back of the mockup and used to heat the plate for this test. Initially four heaters were used (see Figure 4.12). Infrared images of the mockup showed that heat distribution with four heaters was localized and uneven after 18 minutes of operation. This configuration led to uneven heating, see Figure 4.13.

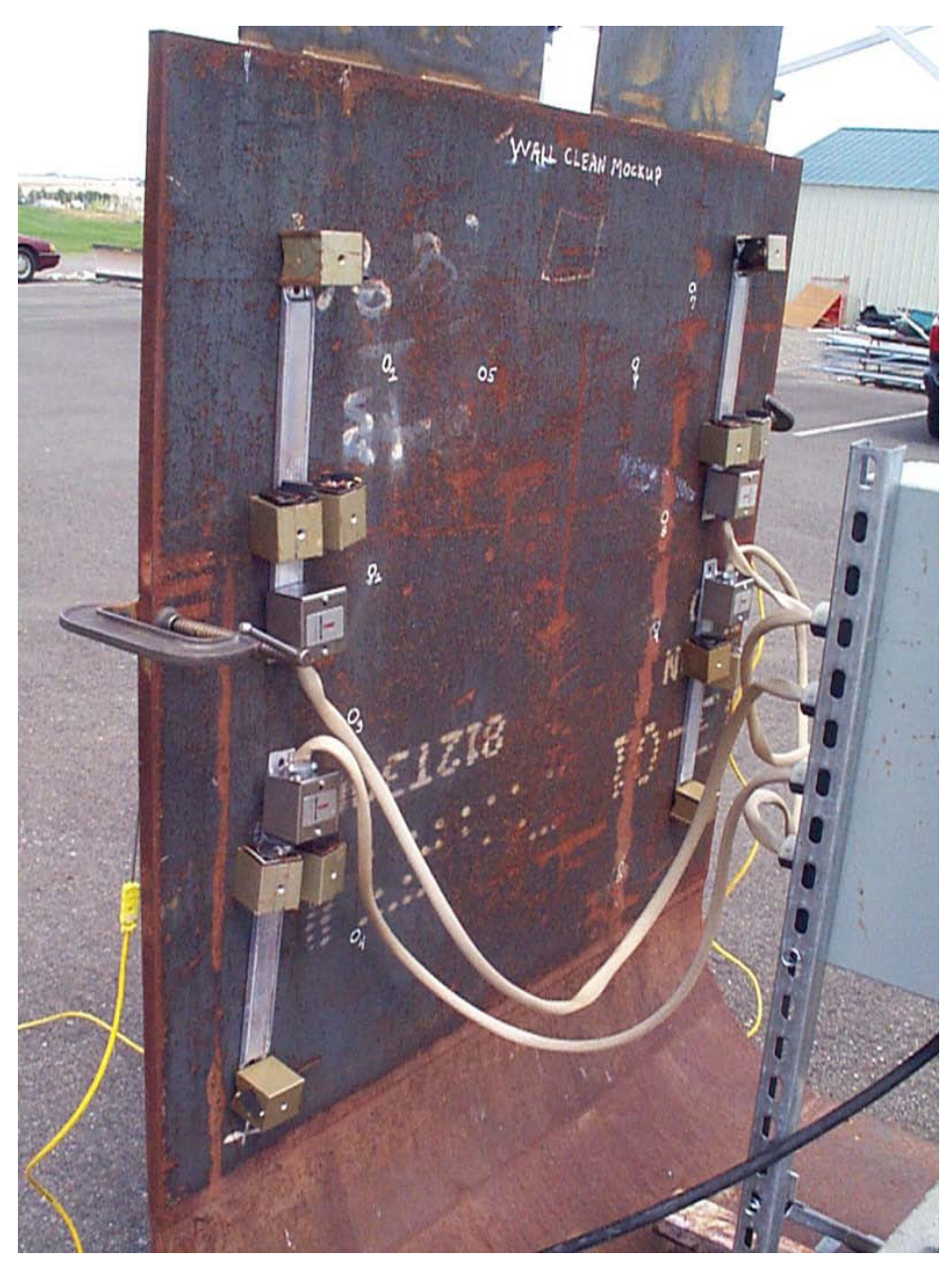

Figure 4.12. First Mockup Heater Configuration Using Four Heaters

In an effort to attain a more homogeneous heat distribution, two additional heaters were added to the center of the plate, the four outer heaters were moved closer to the center, and thermal insulating blankets were used to cover the plate back to limit heat losses. This configuration did improve the distribution of heat in the plate (Figure 4.14), but even with the six-heater configuration the distribution of heat was not satisfactory. 


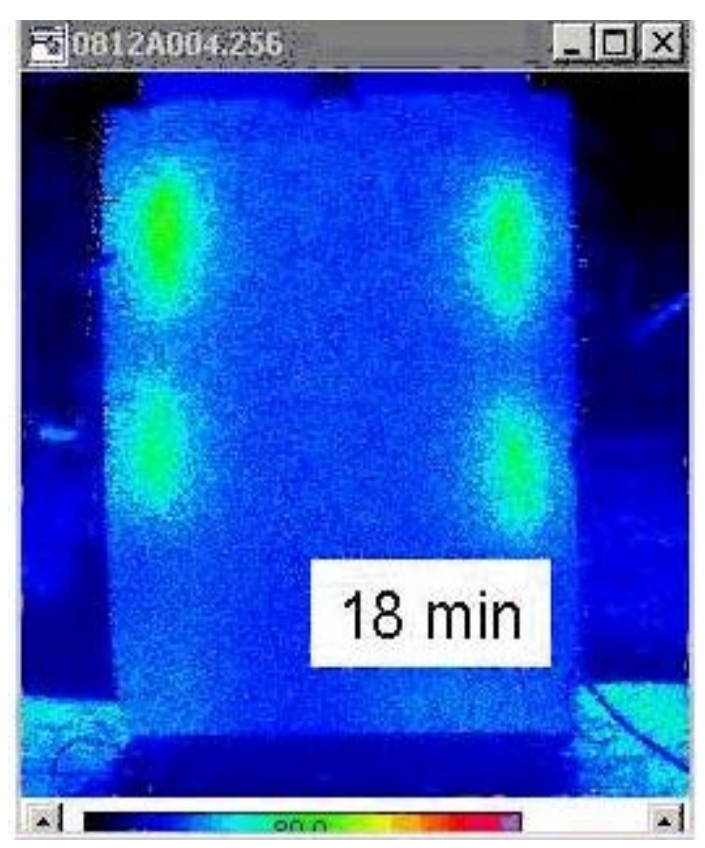

Figure 4.13. Four-Heater Distribution After 18 Minutes

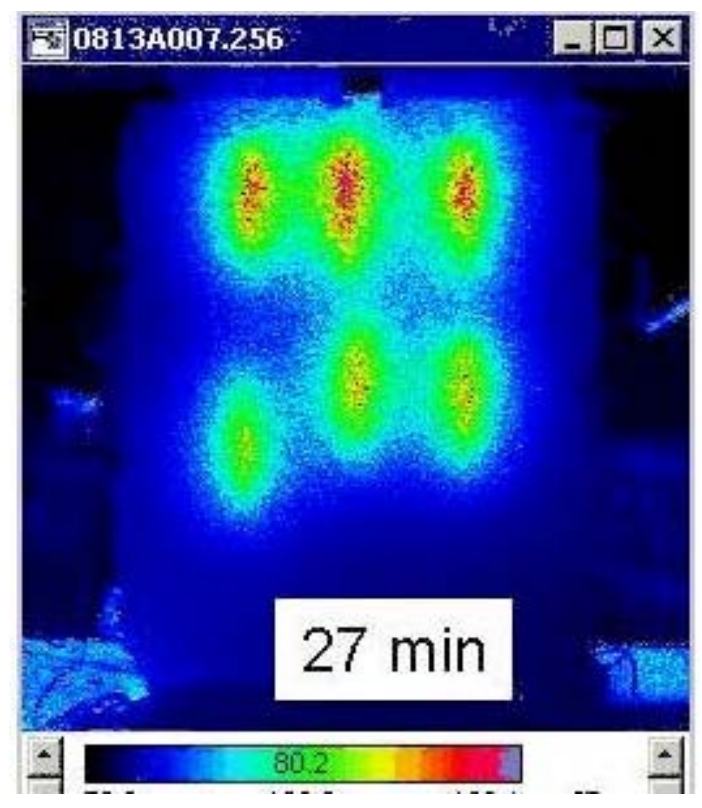

Figure 4.14. Six-Heater Distribution After 27 Minutes

So it was decided to reconfigure the experiment to utilize a single, much smaller plate (termed the test block in this section of the report) in a heated water bath (Figure 4.15). A laboratory hot plate was used to raise the test block/couplant bath temperature to the desired test points as reported by the thermocouple-type thermometer shown in the photo. 


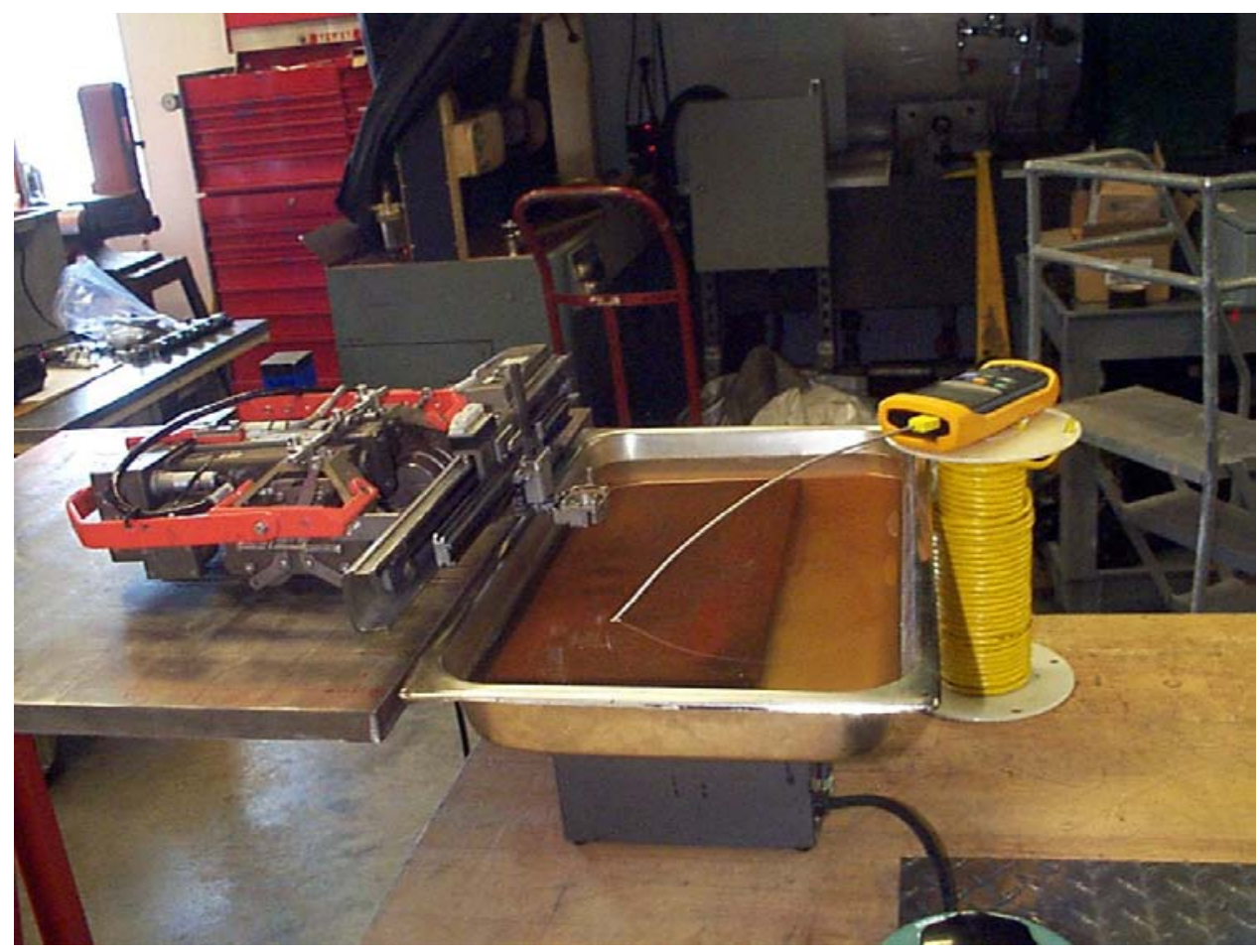

Figure 4.15. The Test Block in Heated Water Bath

At the same time, a calibrated standard was raised to predetermined temperatures using a hot plate as shown in Figure 4.16.

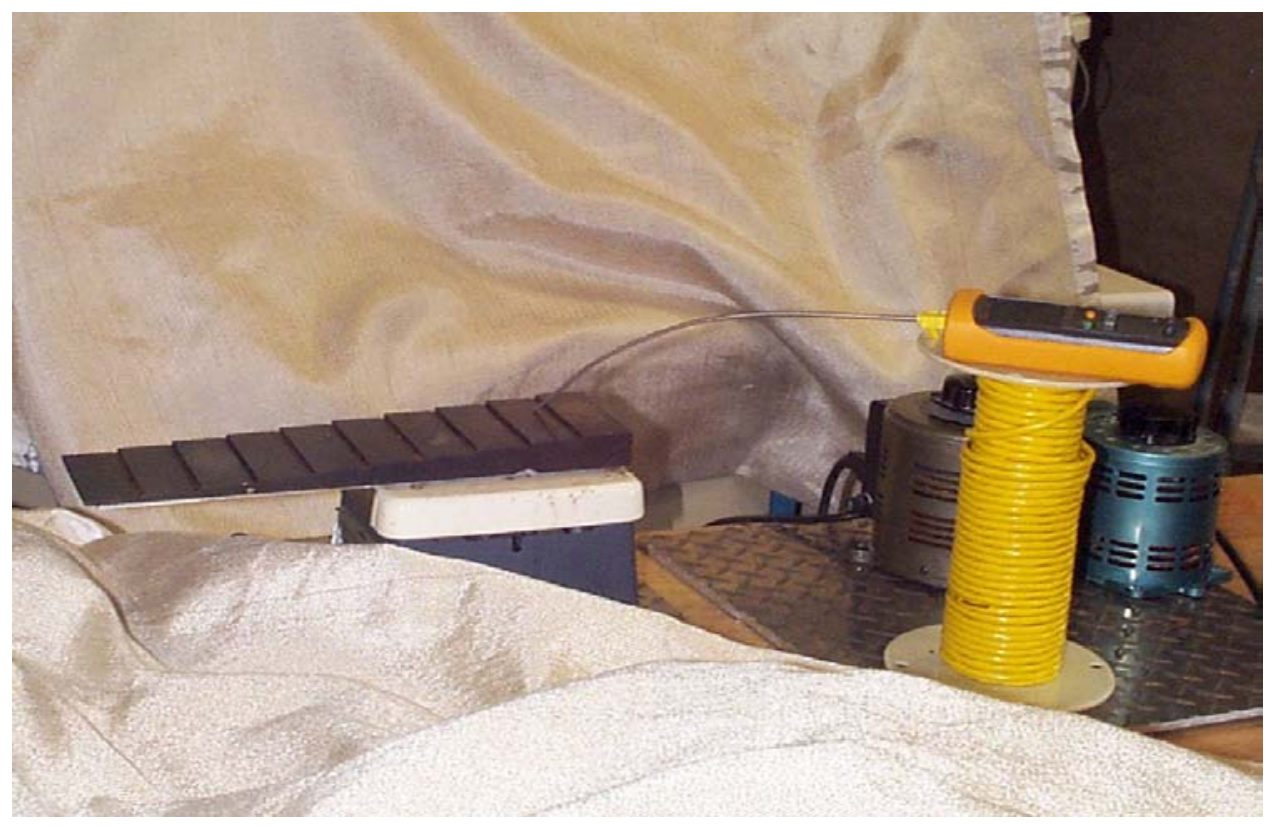

Figure 4.16. Heated Calibration Standard Being Monitored by Thermocouple 
A total of nine comparative tests were made with this apparatus; with the test block/couplant temperature held steady at $70^{\circ} \mathrm{F}$, the calibration block was examined at three different temperatures $\left(70^{\circ} \mathrm{F}\right.$, $90^{\circ} \mathrm{F}$, and $120^{\circ} \mathrm{F}$. This three-step evaluation was repeated with the test block/couplant temperature held at $90^{\circ} \mathrm{F}$ and again at $120^{\circ} \mathrm{F}$.

A single operator, instrument, and transducer were used to inspect a small area on the test block at specific test block/couplant temperature and calibration block temperature combinations. Average and maximum wall thicknesses over the small area were recorded. The temperature combinations shown in Table 4.6 were used and generated the thicknesses in the table; the top and bottom values of the pair within in each cell are respectively the average and maximum values.

Note that from the bottom left of the table to the top right, a dramatic measured thickness change of about 0.060 -inch occurred. Smallest values are at top right where the calibration block temperature difference was the highest compared to the test block/couplant temperature. Conversely, the largest values occurred when the test block/couplant temperature difference was the highest compared to the calibration block temperature. Note also that the top left to bottom right diagonal cases, where within each the temperatures were the same, give the values consistently closest to the nominal 1-inch thickness of the test block.

Table 4.6. Impact of Varying Calibration Block and Test Block/Couplant Temperature

\begin{tabular}{|c|c|c|c|c|}
\hline \multirow{2}{*}{\multicolumn{2}{|c|}{$\begin{array}{l}\text { Average and Maximum } \\
\text { Thicknesses (inch) }\end{array}$}} & \multicolumn{3}{|c|}{ Calibration Block Temperature $\left({ }^{\circ} \mathrm{F}\right)$} \\
\hline & & 70 & 90 & 120 \\
\hline \multirow{5}{*}{$\begin{array}{l}\text { Test Block/Couplant } \\
\text { Temperature }\end{array}$} & \multirow{2}{*}{70} & 1.001 & 0.989 & 0.965 \\
\hline & & 1.003 & 0.995 & 0.970 \\
\hline & \multirow{2}{*}{90} & 1.010 & 0.993 & 0.981 \\
\hline & & 1.013 & 0.998 & 0.990 \\
\hline & 120 & $\begin{array}{l}1.026 \\
1.029\end{array}$ & $\begin{array}{l}1.005 \\
1.009\end{array}$ & $\begin{array}{l}0.996 \\
1.000\end{array}$ \\
\hline
\end{tabular}

\subsubsection{Regression Analysis}

The data were evaluated with regression analysis to explain the average wall thickness variability in the tabled values as a function of the various temperatures and their statistical "interaction" (the crossproduct term). Under the "Parameter Estimates" section in Figure 4.17, the values in red font italics, along with the r-square value at the bottom of the plot, are the pertinent values to consider.

The r-square value is the proportion of the changing measured thickness variability that can be attributed to the temperature changes. Here it is 0.97 or $97 \%$, so indeed most of the measured thickness changes are related to temperature changes. The $3 \%$ of variability remaining unexplained is possibly due to actual wall thickness changes or other causes of measurement uncertainty/variability.

The values under the column heading "Prob $>|t|$ " are $p$-values that indicate the statistical significance of the amount of measured thickness variability explained by the associated terms listed under the "Term" column. P-values can range from 0.0 to 1.0 with small values indicating large contributions to explaining thickness variability. 
A regression analysis was also performed for the maximum thickness shown in Figure 4.18. Results are very similar for both thicknesses.

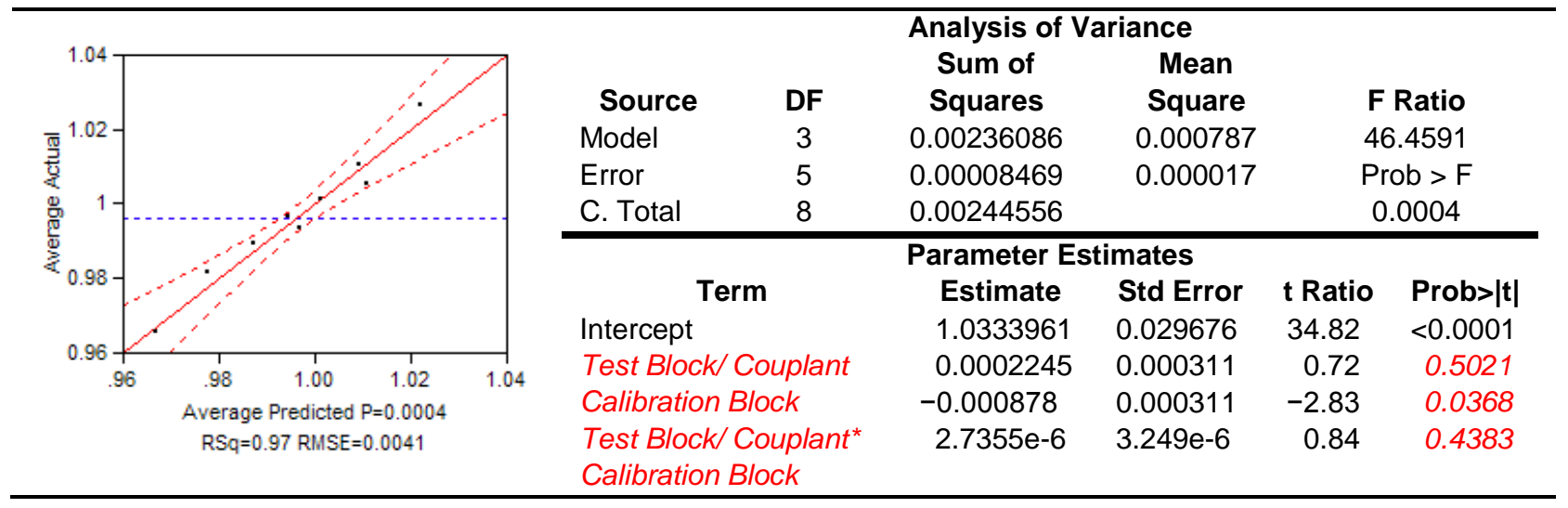

Figure 4.17. Response Average - with Interaction

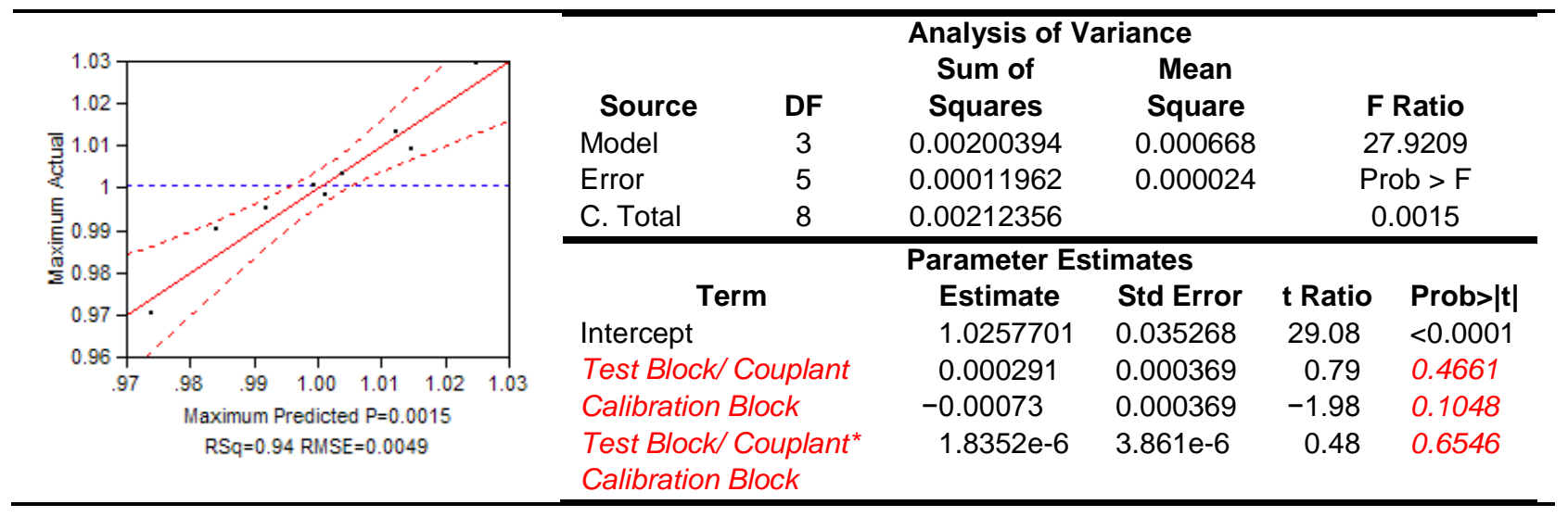

Figure 4.18. Response Maximum - with Interaction

In the previous regression models, the relatively large p-values for the interaction (cross-product) terms indicate they add little to the models and likely needlessly complicate them. Therefore, Figure 4.19 and Figure 4.20 show the no-interaction model results in a similar format. Note that the r-square value for the averages drops from $97 \%$ with the interaction term to $96 \%$ without it, so its non-utility is shown. The corresponding drop for the maxima is from 96\% to 94\%. In the "Parameter Estimates" sections, it can be seen by the only slightly smaller p-values for calibration block that its temperature changes have only slightly more impact than the similar temperature changes for test block/couplant. The signs of the terms under the "Estimate" columns show that measured thicknesses decrease with increasing calibration block temperatures and increase with increasing test block/couplant temperatures (i.e., respectively, the two terms have negative and positive slopes).

Given the measured thickness changes (60 mils) pointed out earlier from bottom left to top right in Table 4.6, one might conclude that the actual temperatures are not as important as are the temperature 
differences between the calibration block and the test block/couplant. That is probably the most important point of this whole topic. That analysis is presented following the no-interaction models in Figure 4.19 and Figure 4.20 .

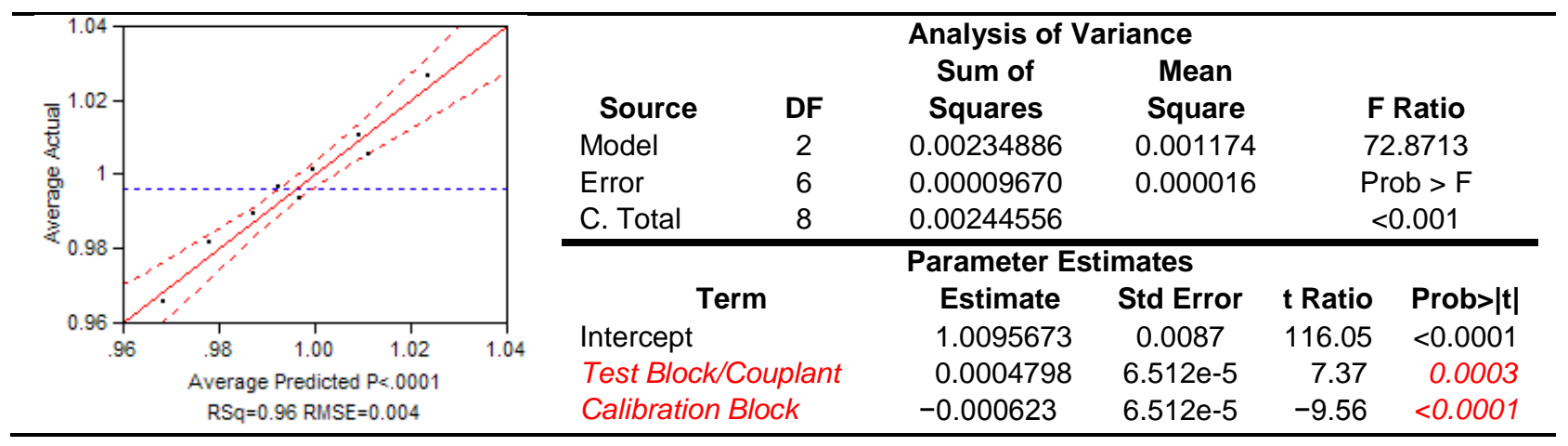

Figure 4.19. Response Average - No Interaction

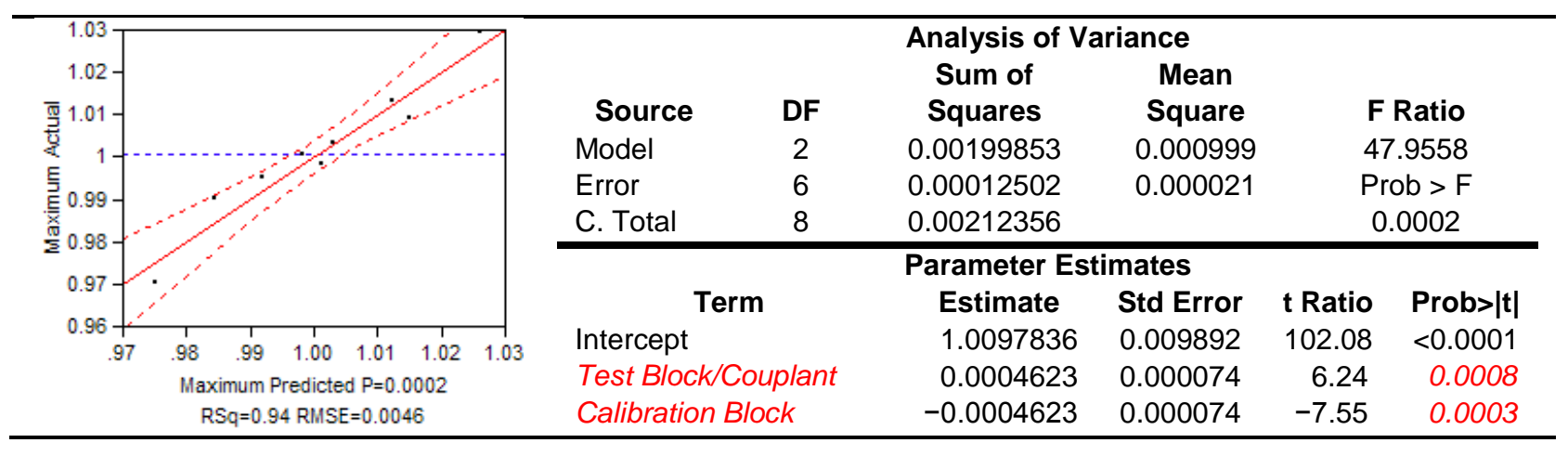

Figure 4.20. Response Maximum - No Interaction

The models that use only the difference "test block/couplant temperature minus calibration block temperature” are given in Figure 4.21 and Figure 4.22, respectively, for the thickness averages and maxima. For the thickness averages, the r-square value for the interaction model in Figure 4.17 was $97 \%$ and dropped to $96 \%$ when the interaction term was dropped in Figure 4.19. When the two temperatures are reduced to only their difference, the r-square value only decreases to $94.5 \%$ in Figure 4.21 . So, little information is lost by only considering the temperature differences. The corresponding r-square reduction for the maximum values in Figure 4.22 is even less. This reduction is probably the better modeling approach.

The two prediction equations are given by:

$$
\begin{gathered}
\text { Average }=0.9962222+0.0005513 \text { Temp Diff } \\
\text { Maximum }=1.0007778+0.0005105 \text { Temp Diff }
\end{gathered}
$$




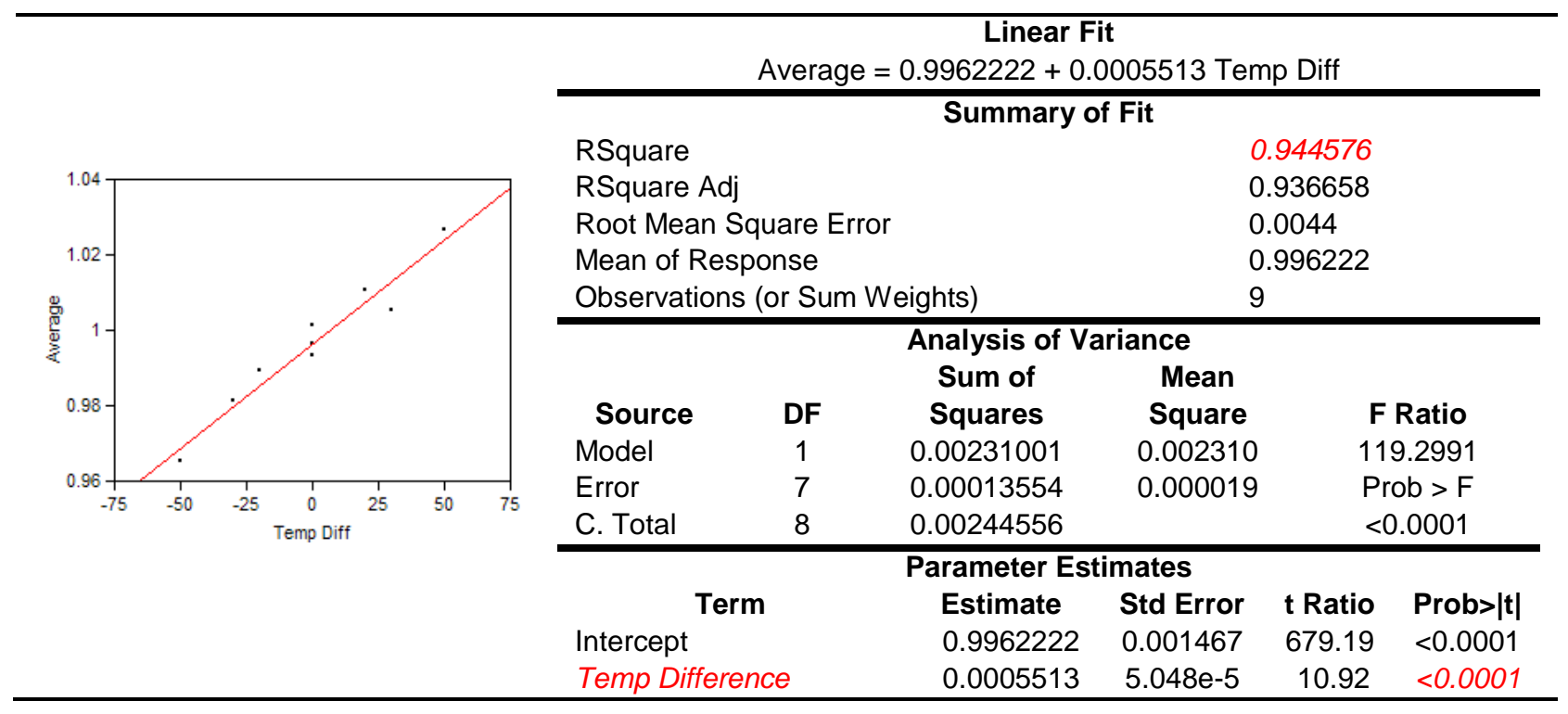

Figure 4.21. Average by Temperature Difference

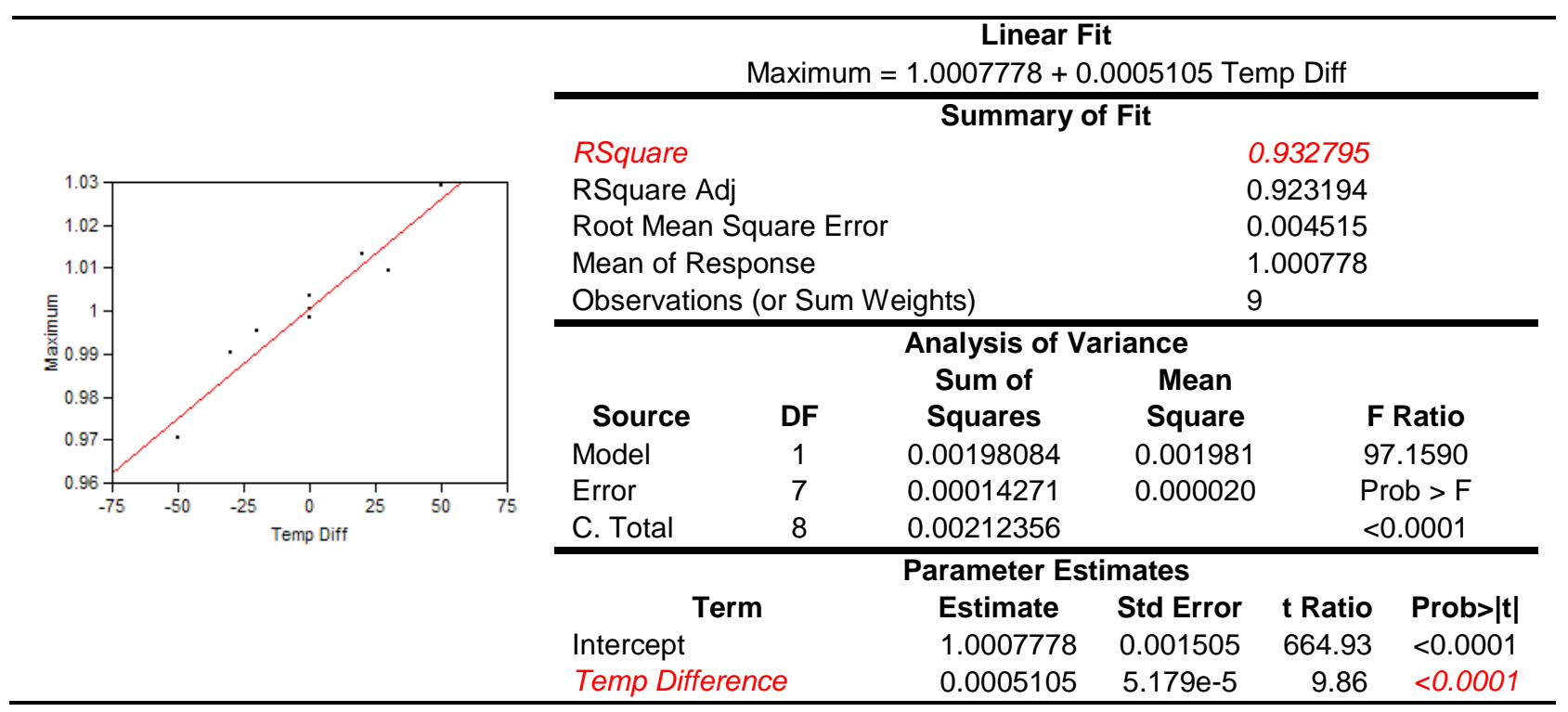

Figure 4.22. Maximum by Temperature Difference

Thus, when the test block/couplant and calibration block temperatures are the same, the average thickness is measured at 0.996 inch and the maximum thickness at 1.001 inch for the mockup plate at a nominal 1.000 inch. For every degree greater the test block/couplant temperature is than the calibration block temperature, the average increases 0.55 mils while the maximum increases 0.51 mils. With the current requirement that the two temperatures need to be within 25 degrees of each other, this requirement suggests the measured average tank wall/couplant thickness could in fact change by as much as \pm 0.0138 inch simply due to mismatched calibration block and tank wall temperatures. Such measured thickness variability will be further investigated for mismatched couplant and test block/calibration block temperatures in Section 4.5. 


\subsubsection{Multiple-Echo Improvement}

Note that while peak/edge analysis was used to generate the Table 4.6 measured values used in the previous discussion, a multiple-echo analysis approach (an ultrasonic analysis method being considered which utilizes the difference between return signals) was used as well to generate an alternative set of measurements, which are shown in Table 4.7. It is readily seen that much less measurement variability results with the multiple-echo approach. The 0.060-inch range from top right to lower left in Table 4.6 is only about 0.004 -inch in Table 4.7 .

Table 4.7. Impact of Varying Calibration Block and Test Block/Couplant Temperatures on MultipleEcho Measurements

\begin{tabular}{|c|c|c|c|c|}
\hline \multirow{2}{*}{\multicolumn{2}{|c|}{$\begin{array}{l}\text { Average and Maximum } \\
\text { Thicknesses (inch) }\end{array}$}} & \multicolumn{3}{|c|}{ Calibration Block Temperature $\left({ }^{\circ} \mathrm{F}\right)$} \\
\hline & & 70 & 90 & 120 \\
\hline \multirow{6}{*}{$\begin{array}{l}\text { Test Block/Couplant } \\
\text { Temperature }\end{array}$} & \multirow{2}{*}{70} & -- & 1.000 & 0.999 \\
\hline & & -- & 1.001 & 1.001 \\
\hline & \multirow{2}{*}{90} & 1.001 & 1.001 & 1.001 \\
\hline & & 1.003 & 1.002 & 1.003 \\
\hline & \multirow{2}{*}{120} & 1.003 & 1.003 & -- \\
\hline & & 1.005 & 1.005 & -- \\
\hline
\end{tabular}

The same regression analyses performed for the original measurements were also performed for the multiple-echo measurements. Only the final model for the average thickness discussed earlier is repeated here. It fit the measured values to the difference between the test block/couplant and calibration block temperatures. For the usual peak/edge analyses, the following prediction equation was given:

$$
\text { Average }=0.9962222+0.0005513 \text { Temp Diff }
$$

This suggests that even within the required 25 degrees of each other, the measured average tank wall/couplant thickness could in fact change by as much as \pm 0.0138 inch simply due to mismatched calibration block and tank-wall temperatures (this value comes from the Temp Diff slope 0.0005513 times \pm 25 ). The corresponding equation for the multiple-echo measurements is:

$$
\text { Multiple-Echo Average = } 1.0011429+0.00003684 \text { Temp Diff }
$$

Now the change within the 25 degree differentials is only as much as \pm 0.0009 inch due to mismatched calibration block and tank-wall temperatures (again from the reduced Temp Diff slope 0.00003684 times \pm 25$)$.

The similar comparison results from the maximum thicknesses as well. Note that with much reduced multiple-echo variability, the r-square values are smaller for the multiple-echo and thus the related relative uncertainty results around the predicted values are a little larger, but still the worst-case uncertainty results on these predicted values would be well over an order-of-magnitude reduced with multiple-echo. 


\subsection{Couplant and Test Block/Calibration Block Temperature Variations}

Similarly to the Section 4.3 temperature study, couplant temperature studies on a test block were performed to help understand whether couplant temperature variations could affect the UT thickness measurements. A similar experimental design was used as in the earlier study.

\subsubsection{Temperature Study}

The original intent was to vary the couplant and calibration block temperatures for the study while maintaining the test block (representative of the tank wall) at a specific temperature similar to actual tank wall temperatures. However, miscommunication resulted in the test block temperature being controlled at the same (though varying) temperatures as the calibration block. While not planned, this change is actually an improvement on the study because in the field the goal is for the calibration block and tank wall temperatures to be reasonably the same.

\subsubsection{Data Acquisition Methods and Evaluation of Data}

In the study, heaters were used to control the test block and calibration block temperatures during testing. The couplant (water) was also varied to represent possible water temperatures that could be used during an examination. Figure 4.23 shows the reservoir used to control couplant temperature during this test.

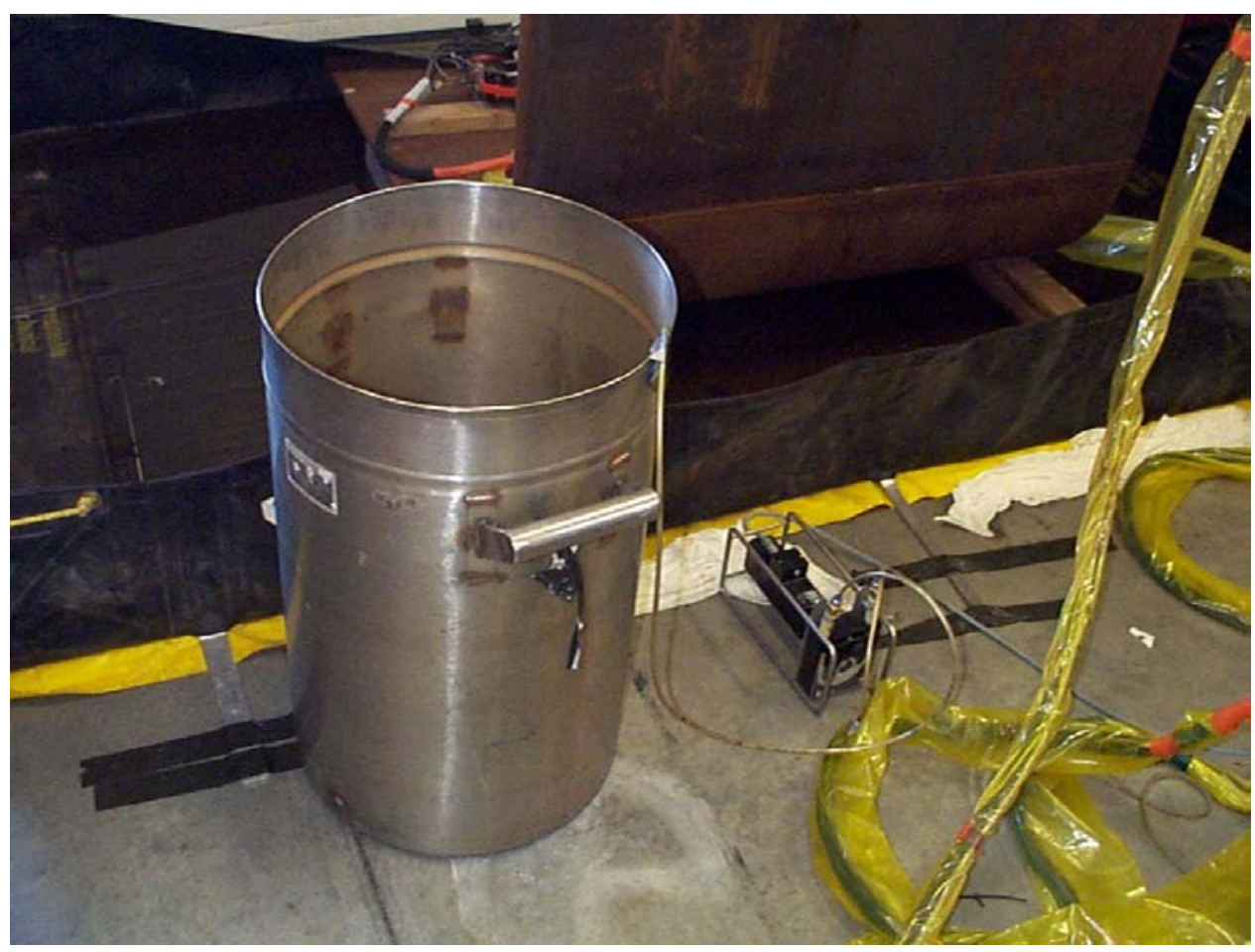

Figure 4.23. Reservoir Used to Control Couplant Temperature 
A single operator, instrument, and transducer were then used to inspect a small area on the test block at several specific test block and calibration temperatures (as close as reasonable). The couplant water temperature was then varied according to Table 4.8 and average and maximum thickness measurements were recorded. Top and bottom values in each cell of the table are, respectively, the average and maximum thicknesses recorded over the mockup area inspected.

In Table 4.8, the smallest thicknesses were generated at the bottom left where the calibration block/test block temperatures exceeded the couplant temperatures the most. Larger values then occur by moving horizontally, vertically, or diagonally in the table. This trend indicates that couplant temperature exceeding the metal temperatures does not have as big an impact on thickness measurement as does the converse.

Table 4.8. Impact of Varying Couplant and Calibration Block/Test Block Temperatures

\begin{tabular}{|c|c|c|c|c|}
\hline \multirow{2}{*}{\multicolumn{2}{|c|}{$\begin{array}{c}\text { Average and Maximum } \\
\text { Thicknesses (inch) }\end{array}$}} & \multicolumn{3}{|c|}{ Couplant Temperature $\left({ }^{\circ} \mathrm{F}\right)$} \\
\hline & & 70 & 90 & 120 \\
\hline \multirow{6}{*}{$\begin{array}{c}\text { Calibration Block/ } \\
\text { Test Block } \\
\text { Temperature }\end{array}$} & \multirow{2}{*}{70} & 1.001 & 0.989 & 0.965 \\
\hline & & 1.003 & 0.993 & 0.981 \\
\hline & \multirow{2}{*}{90} & 0.996 & 0.993 & 0.981 \\
\hline & & 1.002 & 0.998 & 0.986 \\
\hline & \multirow{2}{*}{120} & 0.999 & 1.006 & 0.996 \\
\hline & & 1.009 & 1.009 & 1.000 \\
\hline
\end{tabular}

\subsubsection{Regression Analysis}

The same modeling approach as was used in Section 4.3 follows. Regression analysis was used to explain the average wall-thickness variability in the tabled values as a function of the various temperatures and their statistical "interaction" (the cross-product term). Under the "Parameter Estimates" sections in Figure 4.24 to Figure 4.27, the values in red font italics, along with the r-square values at the bottom of the plots, are the pertinent values to consider. The r-square values are the proportions of the changing measured thickness variability that can be attributed to the temperature changes.

In Figure 4.24, for the thickness averages, the r-square value is 0.94 or $94 \%$, so indeed most of the thickness changes are again related to temperature changes. The $6 \%$ of variability remaining unexplained is possibly due to actual wall thickness changes or other causes of measurement uncertainty/variability. The values under the column heading "Prob $>|t|$ " are $p$-values that indicate the statistical significance of the amount of measured thickness variability explained by the associated terms listed under the "Term" column. P-values can range from 0.0 to 1.0 with small values indicating large contributions to explaining thickness variability. Figure 4.25 gives the same information for the maximum thickness where the r-square value is $97 \%$.

In the previous Section 4.3, the interaction (cross-product) term was not statistically significant with relatively "large" p-values, so it was left off the regression models with little impact, in particular with little reduction in r-square. Here that is not the case. For the "average" model in Figure 4.24, the interaction term has a relatively "small” p-value 0.0103 , so in the model it is also useful for explaining 
measured thickness variation. If the interaction term is left off, the r-square drops from $94 \%$ to only $73 \%$ (as shown in Figure 4.26). So it needs to be included here.

The interaction term not being useful in Section 4.3 meant it did not matter much at what temperature you are for one of the factors because the influence of the changing temperature for the other factor is then still about the same. That is, for example, in Section 4.3, regardless of whether the test block/couplant temperature is at 70,90 , or $120^{\circ} \mathrm{F}$, increasing the calibration block temperature has about the same decreasing impact on the measured thickness. The two factors can be reversed in an analogous manner in the previous sentence as well.

Here instead the temperature level of one term does affect the influence of the other term on the measured thickness. In particular, consider Table 4.8. For couplant temperature $70^{\circ} \mathrm{F}$, increasing the calibration block/test block temperature from $70^{\circ} \mathrm{F}$ to $120^{\circ} \mathrm{F}$ dramatically decreases the measured thickness. However, for couplant temperature $120^{\circ} \mathrm{F}$, increasing the calibration block/test block temperature from $70^{\circ} \mathrm{F}$ to $120^{\circ} \mathrm{F}$ has little impact. In the previous two sentences, the two terms could again be reversed as well to attain analogous statements. That is, the interaction term is significant, so the influence of one factor's temperature on the measured thickness depends on the temperature used for the other factor.

For the averages in Figure 4.24, the interaction term p-value under the "Probability $>|t|$ " column is 0.0103; its being so small indicates its statistical significance and value in explaining the measured thickness variability. For the maxima in Figure 4.25, the corresponding p-value is 0.0396, which indicates somewhat less statistical significance, but that the interaction term is still important.

Thus, we would not drop the interaction terms and move on to the simpler no-interaction models as we did in Section 4.3. Nonetheless, such simpler models' results are shown in Figure 4.26 and Figure 4.27. It was already stated that by dropping the interaction term, the r-square value for the thickness averages drops from $94 \%$ to $73 \%$. For the thickness maxima, the change in r-square is not as severe, going from $97 \%$ to $91 \%$. The interaction term is somewhat less statistically significant in that case, so less loss of variability explanation is realized by dropping the interaction term as compared to the case for the averages.

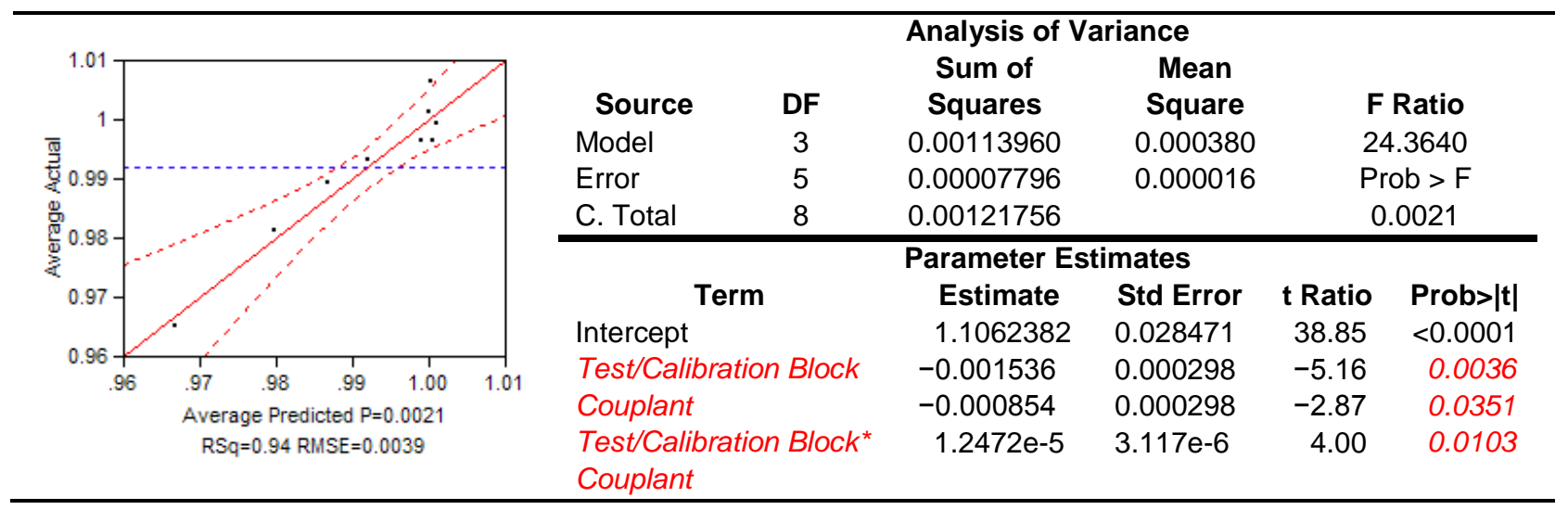

Figure 4.24. Response Average - with Interaction 


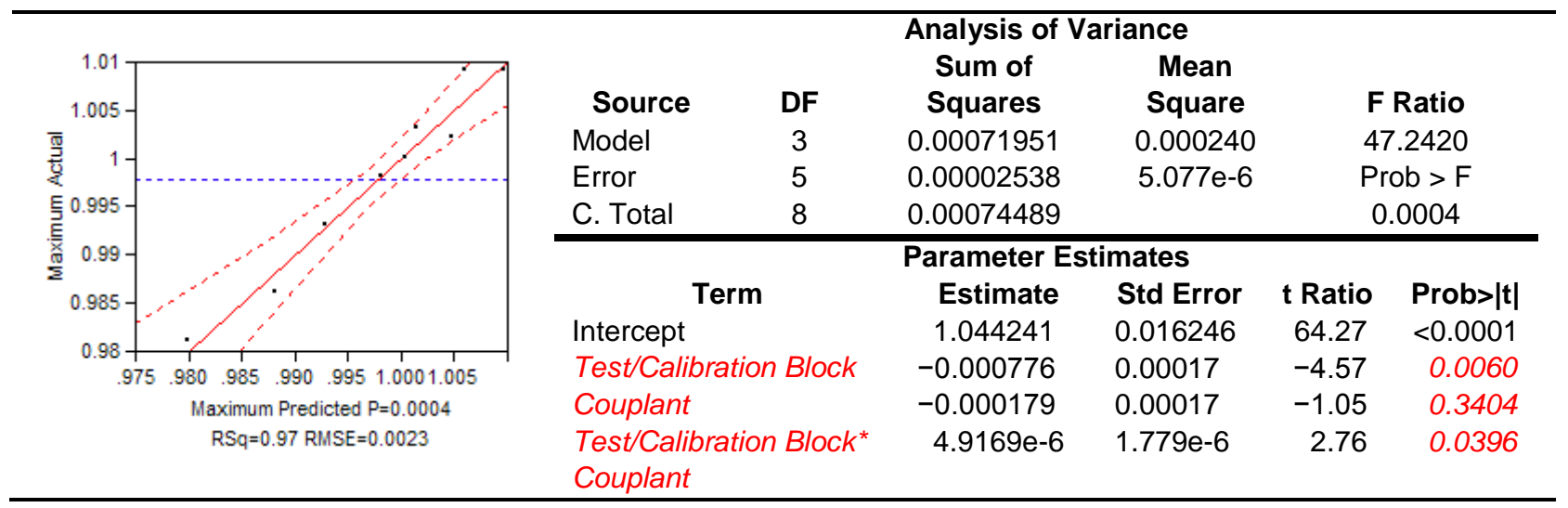

Figure 4.25. Response Maximum - with Interaction

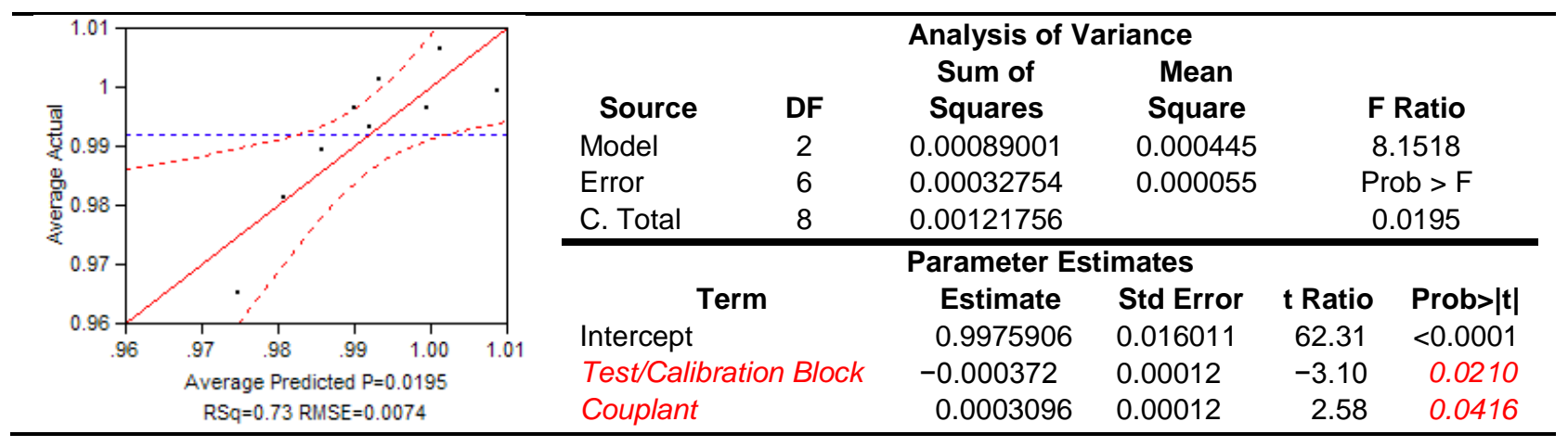

Figure 4.26. Response Average - No Interaction

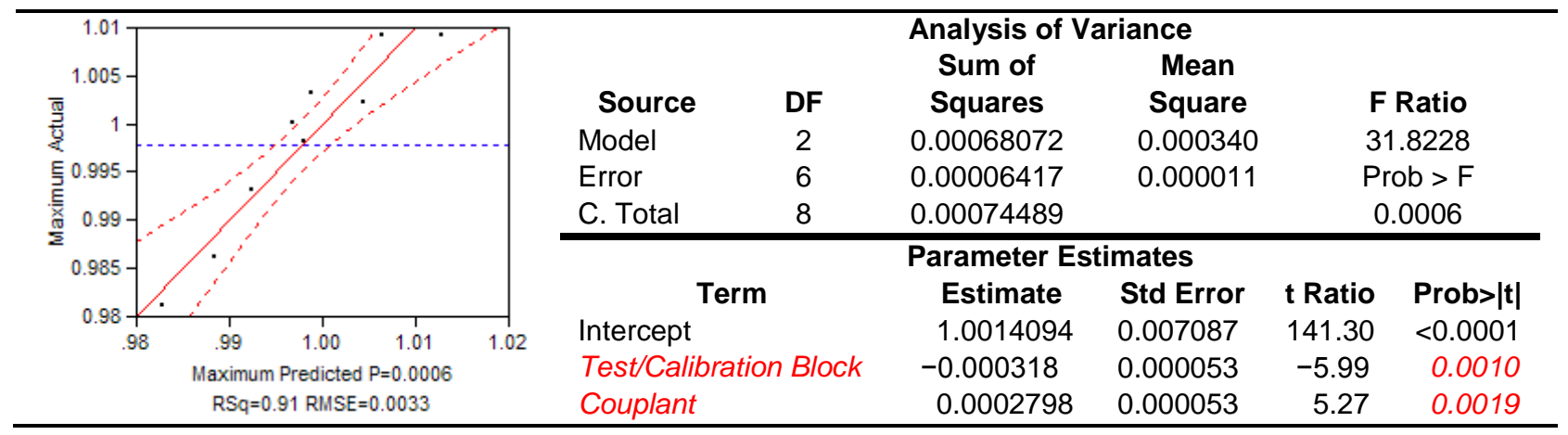

Figure 4.27. Response Average - No Interaction

Because the previous discussion showed the impact of the interaction term, considering only the temperature difference between the two factors cannot be as successful as it was in Section 4.3. The analysis of these even simpler models is given in Figure 4.28 and Figure 4.29; however, the differences are computed as "test block/calibration block temperature minus couplant temperature." For the average and maximum thicknesses, the r-square values are respectively about $72 \%$ and $91 \%$, which correspond to the no-interaction cases in Figure 4.24 and Figure 4.25. The variability in the thickness maxima are 
therefore considerably better explained by the temperature differences than is the variability in the thickness averages.

In either case, the thicknesses do decrease with larger test block/calibration block temperature minus couplant temperature differences. This is shown by the negative slopes in the regression equations:

$$
\begin{gathered}
\text { Average }=0.9917778-0.0003408 \text { Temp Diff } \\
\text { Maximum }=0.9978889-0.0002987 \text { Temp Diff }
\end{gathered}
$$

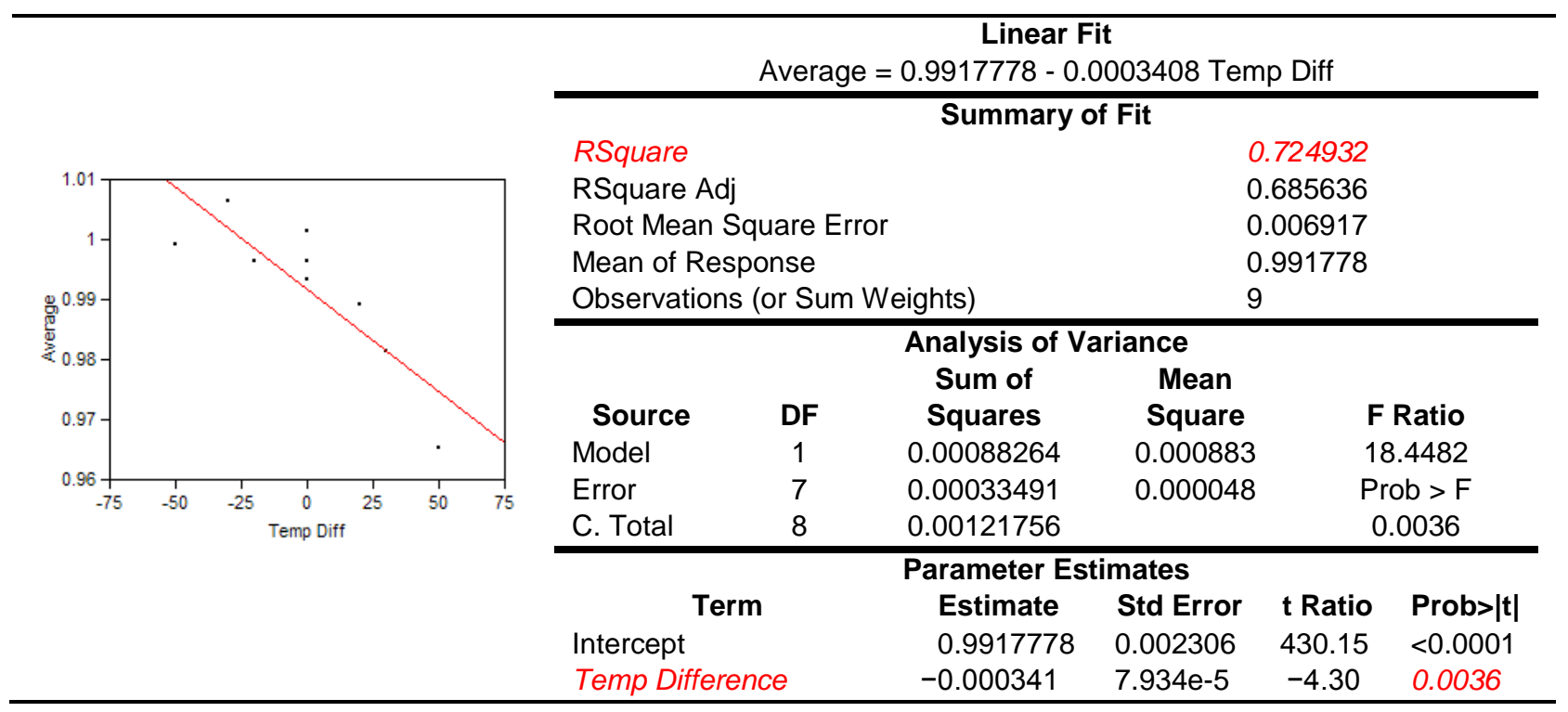

Figure 4.28. Average by Temperature Difference

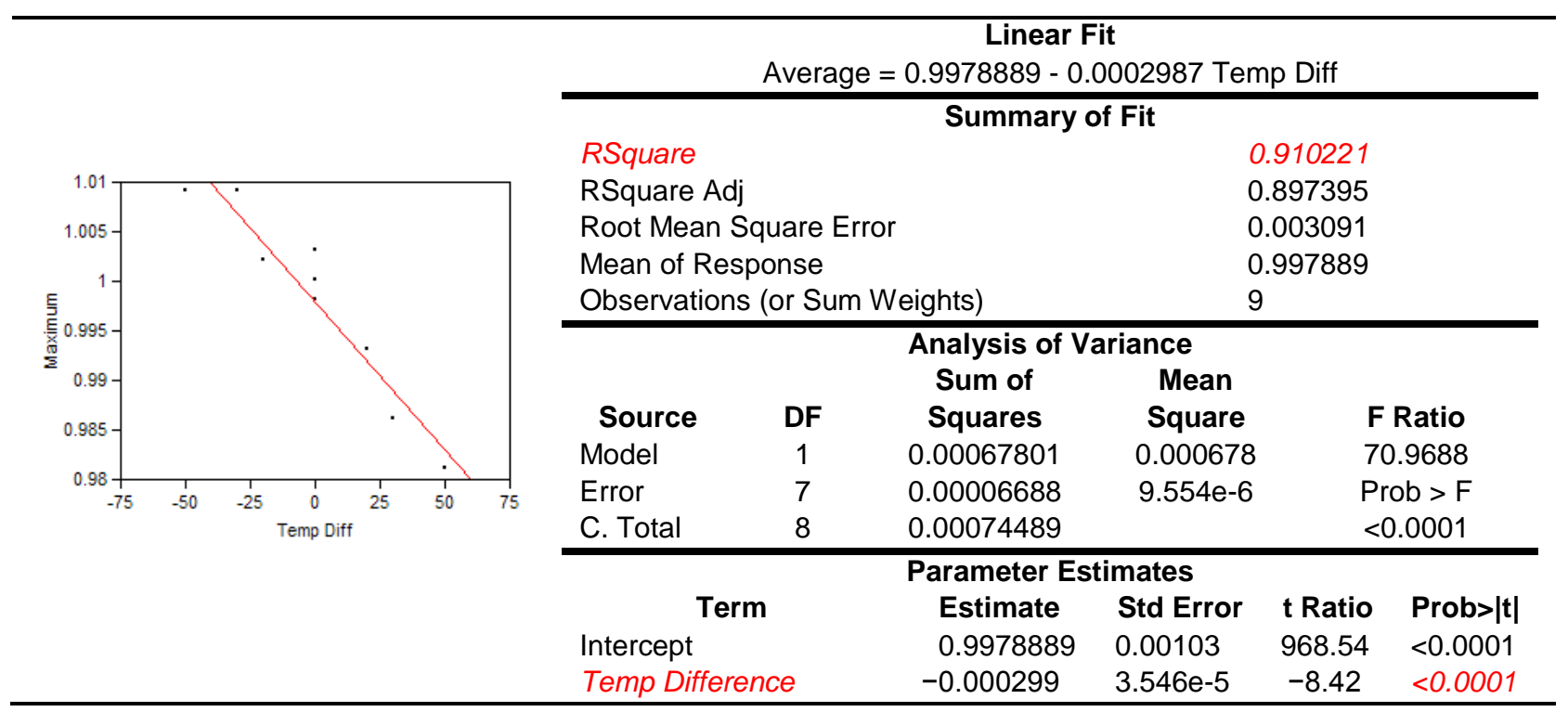

Figure 4.29. Average by Temperature Difference 
However, better predictions of measured thickness will be obtained from the interaction models first discussed. From Table 4.8, the operational situation to be avoided is relatively "warm" couplant in combination with fairly "cool” tank and calibration block temperatures. Such a combination results in considerably under-estimated thickness measurements; in Table 4.8 this was about 0.035 -inch.

\subsubsection{Multiple-Echo Improvement}

In Section 4.3, it was mentioned how the multiple-echo analysis approach is much less sensitive to the temperature changes than is the peak/edge-analysis approach used for the analysis of UT scans in these studies and in tank inspections. The same observation is made here. With the multiple-echo approach, the Table 4.9 average thickness range was only from 1.000 inch to 1.003 inch and the maximum thickness range was only from 1.001 inch to 1.006 inch. Therefore, again, the much reduced temperature sensitivity of the multiple-echo approach is demonstrated.

Table 4.9. Impact of Varying Couplant and Calibration Block/Test Block Temperatures on MultipleEcho Measurements

\begin{tabular}{|c|c|c|c|c|}
\hline \multirow{2}{*}{\multicolumn{2}{|c|}{$\begin{array}{l}\text { Average and Maximum } \\
\text { Thicknesses (inch) }\end{array}$}} & \multicolumn{3}{|c|}{ Couplant Temperature $\left({ }^{\circ} \mathrm{F}\right)$} \\
\hline & & 70 & 90 & 120 \\
\hline \multirow{6}{*}{$\begin{array}{c}\text { Calibration Block/ } \\
\text { Test Block } \\
\text { Temperature }\end{array}$} & \multirow{2}{*}{70} & -- & 1.000 & 1.000 \\
\hline & & -- & 1.001 & 1.001 \\
\hline & \multirow{2}{*}{90} & 1.001 & 1.001 & 1.001 \\
\hline & & 1.003 & 1.002 & 1.003 \\
\hline & \multirow{2}{*}{120} & 1.003 & 1.003 & -- \\
\hline & & 1.006 & 1.006 & -- \\
\hline
\end{tabular}

Again the same regression analyses performed for the original measurements were also performed for the multiple-echo measurements. Only the final model for the average thickness discussed earlier is repeated here. Although it does not give the best prediction equations due to the statistical significance of the interaction term in the earlier model, the comparison to multiple-echo results is still useful. For the usual peak/edge analyses, the following prediction equation was given:

$$
\text { Average }=0.9917778-0.0003408 \text { Temp Diff }
$$

This suggests that even within the required 25 degrees of each other, the measured average tank wall/couplant thickness could in fact change by as much as \pm 0.0085 inch simply due to mismatched calibration block and tank wall temperatures (this value comes from the Temp Diff slope 0.0003408 times \pm 25$)$.

The corresponding equation for the multiple-echo measurements is:

$$
\text { Multiple-Echo Average }=1.0012857+0.000030263 \text { Temp Diff }
$$

Now the change within the 25-degree differentials is only as much as \pm 0.0008 inch due to mismatched calibration block and tank wall temperatures (again from the reduced Temp Diff slope 0.000030263 times \pm 25$)$. 
Again the similar comparison results from the maximum thicknesses as well. For both of the temperature studies in this and the previous section, the multiple-echo approach appears to offer an orderof-magnitude reduction in sensitivity to mismatched coolant, calibration block, and tank wall temperatures.

\subsection{Spring Tension of the Transducer Holders}

Spring-tension studies on the wall mockup were performed in August 2009 to help understand whether spring-tension variations could affect the UT thickness measurements. The UT personnel adjust the number of springs to get good surface contact and to reduce lift-off from the surface. The amount of force on the transducer can have an influence on thickness measurements (Perdrix, et. al. 1980).

\subsubsection{Spring Tension Study}

The impact on wall-thickness measurements was evaluated against the amount of tension in the scissor springs (Figure 4.30), which support the transducers. The mockup was scanned in a specific location to ascertain the effect of changing the spring tension. The scanning followed normal procedural steps such as calibration and scanning speeds. An analysis was performed to identify if any variations in the thickness measurements occur in the acquired data.

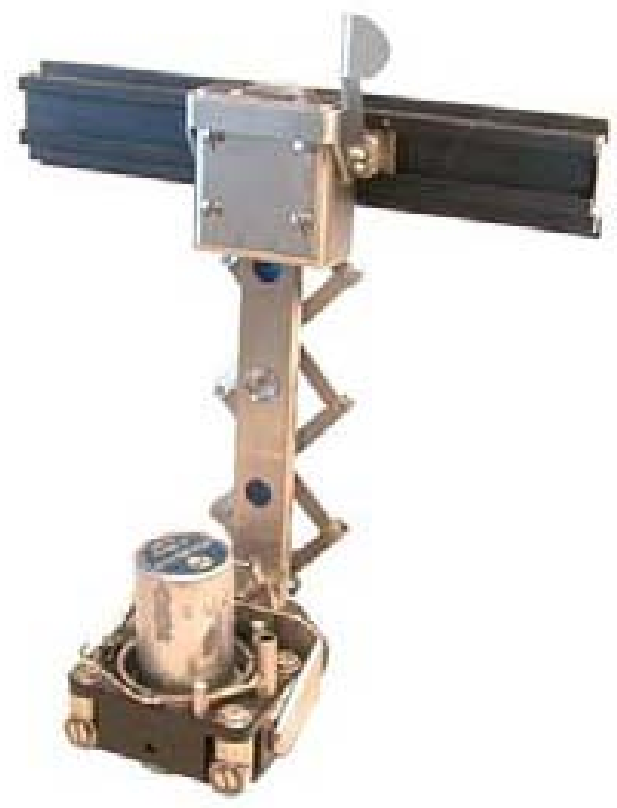

Figure 4.30. Transducer Holder Scissor Assembly

\subsubsection{Data Acquisition Methods and Evaluation of Data}

The transducer holder scissor assembly provides the needed pressure to couple the transducer to the inspection surface. Inadequate pressure could result in lift-off of the transducer and loss of data. 
Excessive pressure could cause erratic movement and noise spikes in the data. The current scissor assembly has small springs (wire- and coil-type) attached on the back side of the scissor, which can be removed or added depending on inspection surface conditions. The intent of this test was to test all of the conditions to see what the effect would be on the measurements.

There are three configurations that were tested, which bound all of the configurations that have ever been used in field applications. The three configurations are:

1) Two wire springs and one coil spring

2) Two wire springs and two coil springs

3) One wire spring and one coil spring

The same area on one of the mockups was scanned using all these different configurations. The area scanned was approximately 3 -inch $\times 6$-inch in extent. The following data was provided by the inspection team.

Two wire spring and one coil spring: $\quad$ Average: 0.882 -inch $\quad$ Maximum: 0.890 -inch

Two wire spring and two coil spring: Average: 0.881-inch Maximum: 0.890-inch

One wire spring and one coil spring: $\quad$ Average: 0.881-inch Maximum: 0.890-inch

It is evident when reviewing this data that the spring-tension range used during the testing (which bounds what is actually used in the field) has essentially no effect on the thickness measurements. No further analyses were performed on the scissor assemblies.

\subsection{Equipment Modifications}

Equipment modification studies on the UT equipment were performed in August 2009 to help understand whether any modifications could affect the UT thickness measurements. The modification that would most likely cause thickness measurement changes and the only one studied in this report was changing of the coaxial cable lengths. Only two lengths of coaxial cable have been used for tank inspections. These two lengths are 75 -feet and 100-feet.

\subsubsection{Equipment Modification Study}

The equipment modification study evaluated whether changing the coaxial cable lengths would affect the wall-thickness measurements. The normal procedural steps were performed and a step wedge of varying thicknesses was used. The intent was to isolate the UT system to only see changes in the cable lengths.

\subsubsection{Data Acquisition Methods and Evaluation of Data}

The P-scan ultrasonic system was configured as is typically used in field operations. The transducer was removed from the transducer holder and used in a manual mode of application. The transducer was coupled to a step wedge of varying thicknesses. The measurement mode of operation in the P-scan 
system software was used to record the wall thicknesses. The step wedge thicknesses have been verified. Table 4.10 provides the data acquired by the inspector at the two different cable lengths.

Table 4.10. Thickness Measurements at Different Cable Lengths

\begin{tabular}{ccc}
\hline $\begin{array}{c}\text { Step Wedge } \\
\text { Thickness (inch) }\end{array}$ & $\begin{array}{c}\text { 75-ft Cable } \\
\text { (inch) }\end{array}$ & $\begin{array}{c}\text { 100-ft Cable } \\
\text { (inch) }\end{array}$ \\
\hline 1.000 & 1.00 & 1.00 \\
0.800 & 0.800 & 0.798 \\
0.600 & 0.599 & 0.599 \\
0.400 & 0.401 & 0.399 \\
0.300 & 0.301 & 0.301 \\
\hline
\end{tabular}

The thickness measurements shown in Table 4.10 indicate very small differences using the two different cables during data acquisition. No further analyses were performed.

\subsection{Dual Element Transducers versus Single Element}

A study was performed on the use of dual-element transducers versus single-element transducers in July and August 2009 in order to understand and document any measurement differences between the two different types of probes.

\subsubsection{Dual Element Transducer versus Single Element Study}

A General Electric (GE) dual-element probe is currently being used to make wall-thickness measurements in the DSTs. With this style of probe, the sound is generated by one transducer element and received by the second transducer element as shown in Figure 4.31(a). In many dual probes, the transmit and receive crystals are angled to produce a cross-over zone at the probe exit point or at some distance in the material under test. This angle is called a roof angle. The GE dual-element probes used in the DST inspections have a roof angle that is typically approximately 8 degrees. The issue of probe accuracy due to this inherent "V" path in a dual-element probe is driving this study. For short distances, this "V" error may be considerable but for the wall thickness in the DST inspections, 0.5-0.875 inch, this is not expected to cause significant error. In this study, a GE single-element transducer was purchased and compared to the dual-element probe. In a single-element probe, the transducer element acts as both transmitter and receiver as shown in Figure 4.31(b). With a single-element probe, there is generally a near-surface dead zone or time when the probe cannot function as a receiver. This is due to the transmit ringing over some brief period. While the transmit element is sending, the receiver element cannot be actively receiving a return signal. Probe design and electronics can minimize this near-surface dead zone, but to eliminate it a dual-element design is used. Additional reasons for selecting a dual-element probe are that they can be better focused than a single-element probe, giving a smaller spot size, and they have an improved signal-to-noise ratio (Birks, et.al. 1991).

The dual-element to single-element comparison was performed on a step-wedge standard. Data were acquired using the specific dual-element probe that is currently used for the DST program thickness measurements and a single-element probe manufactured by the same company. Both probes were 
evaluated in a laboratory environment with a pulser, receiver, and oscilloscope setup. Then the probes were evaluated with the P-scan system on the step wedge for comparison.

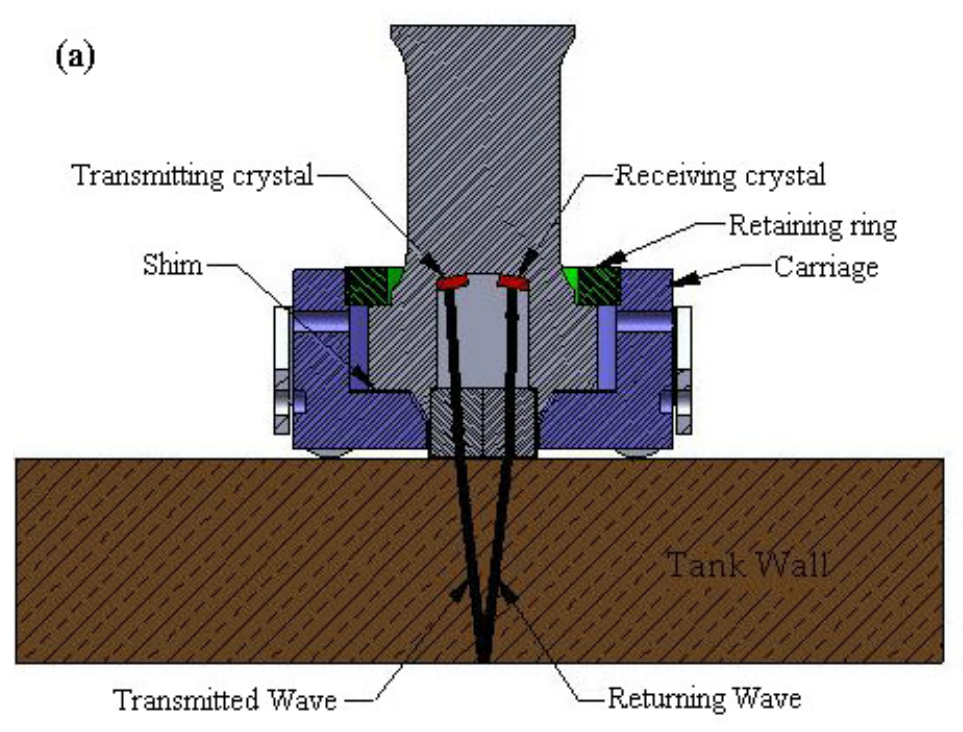

(b)

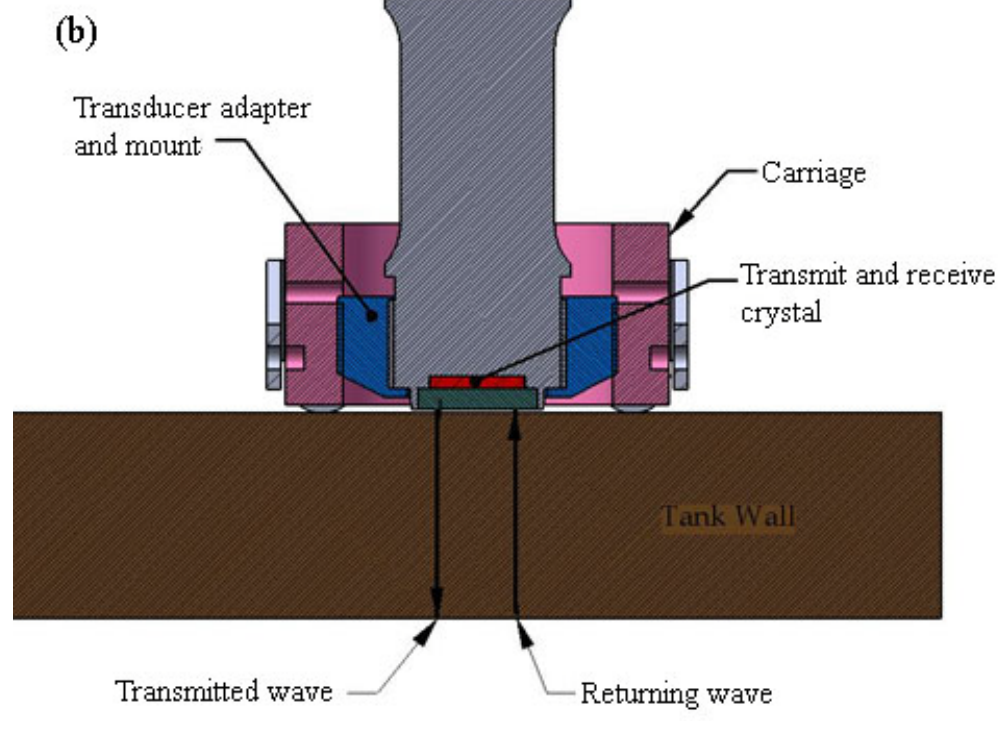

Figure 4.31. Ultrasonic Transducers: (a) dual-element and (b) single-element

\subsubsection{Data Acquisition Methods and Evaluation of Data}

\subsubsection{Initial Laboratory Evaluation}

The laboratory measurement setup consisted of a Ritex broadband receiver, BR-640A; a Ritex square-wave pulser, SP-801A; a Ritex diplexer when using a single-element transducer; and a LeCroy WaveRunner 64Xi, 600-MHz oscilloscope. The measurement mode of the oscilloscope was used to 
determine the time to the first positive peak of the signal of interest. Multiple back-wall echoes through the specimen under evaluation were measured and a part thickness calculated from an average of the multiple return echoes.

As an initial test for the laboratory setup, a 2-foot $\times 2$-foot flat plate with a nominal thickness of 0.881 was measured first for velocity in the plate and then for thickness values at five point locations. As part of the plate velocity determination, the plate thickness was first measured with a micrometer at several points. Approximately five micrometer readings at five points were made. The velocity of sound in the plate was determined from the measured time intervals between multiple back-surface echoes and the previously determined plate thicknesses obtained from the multiple micrometer readings. The plate velocity was determined to be 0.233 inch/ $\mu$ sec.

Given the plate velocity, the plate thickness was then ultrasonically measured. To do this, the time intervals between multiple back-surface echoes at five point locations on the plate were measured. Up to five back-surface echo measurements were recorded at each position and the process was repeated giving up to ten time-interval recordings per plate position. Plate thicknesses at each of the five positions were calculated from an average of these time-interval measurements and the plate velocity. This process was performed for five transducers - three single-element and two dual-element probes. The error in plate thickness measurements is listed in Table 4.11 for each of the five plate locations and for each of the five probes that were evaluated. The two GE probes were supplied by AREVA personnel. Note that the GE dual probe is used in DST tank inspections. Other probes were available in the laboratory and were added to the study for additional comparisons between single- and dual-element probe consistency. The largest error occurred with the 5-MHz single-element probe and is approximately 0.002 inch, as shown in the right column. All other probes had even less error. This data show that there is no advantage in using a single-element probe for thickness measurements. Both GE 5-MHz probes performed comparably well and provided reproducible thickness measurements to within 0.001 inch of the known thickness.

Table 4.11. Laboratory Thickness Measurements on a Flat Plate

\begin{tabular}{cccccc}
\cline { 2 - 6 } & \multicolumn{5}{c}{ Error (inch) } \\
\hline Plate & GE 5-MHz & GE 5-MHz & 3.5-MHz & 4-MHz & 5-MHz \\
Position & Single & Dual & Single & Dual & Single \\
\hline 1 & 0.0008 & 0.0009 & 0.0006 & 0.0004 & 0.0019 \\
2 & 0.0007 & 0.0009 & 0.0002 & 0.0002 & 0.0018 \\
3 & 0.0005 & 0.0006 & 0.0002 & 0.0003 & 0.0016 \\
4 & 0.0008 & 0.0010 & 0.0010 & 0.0002 & 0.0017 \\
5 & 0.0003 & 0.0004 & -0.0001 & 0.0000 & 0.0016 \\
\hline
\end{tabular}

\subsubsection{Laboratory and P-scan Comparison}

The next test was to perform the same laboratory thickness measurement process on a step wedge with both GE probes and then evaluate the P-scan system on the step wedge with both probes. This would assess both the P-scan system performance as compared to a laboratory setup and the GE dualprobe performance as compared to a GE single-element probe performance. A 1-inch-thick steel wedge 
with steps at 0.1-inch increments was evaluated in this test. This step-wedge standard is used in the calibration procedure for the DST inspections.

For the laboratory setup, the velocity in the wedge material was determined from the 1.0008- and 0.4005 -inch steps. The velocity was found to be $0.0232 \mathrm{inch} / \mathrm{\mu sec}$. Next the $0.9009-, 0.8010-, 0.7009-$, 0.6009 -, and 0.5008-inch step thicknesses were measured with both the dual- and single-element GE 5-MHz probes. The measurements are listed in Table 4.12 and the errors listed in Table 4.13. This laboratory study shows that the single-element probe has a maximum error of 0.001 inch and the dualelement probe a maximum error of 0.002 inch. The average error difference between probes is 0.0004 inch. This difference between the two probes is insignificant and certainly would not justify a new scanning procedure based on a single-element probe inspection.

The P-scan system was also used to measure the step-wedge thicknesses with both dual- and singleelement probes. The system was calibrated on the 1.0- and 0.4-inch steps as with the laboratory system. Thickness measurement values and error are shown in Table 4.12 and Table 4.13. The P-scan produces similar results to the laboratory system and also shows that the single transducer with an average error of 0.0013 inch and the dual probe with an error of 0.0012 inch generate nearly equal thickness values.

In summary, a brief evaluation of the performance difference of a dual-element ultrasonic transducer as compared to a single-element probe in thickness-measurement capability has shown no difference. Specifically, the dual-element probe currently used to measure wall thickness in the DSTs was compared to a single-element probe of the same style. Both probes are 5-MHz contact transducers manufactured by GE. Data show an average error in thickness measurements of approximately 0.001 inch with either the laboratory measurement system or the P-scan system, regardless of probe type - single or dual. Specific measurements show that an error of up to 0.003 inch is possible.

Table 4.12. Laboratory and P-scan Thickness Measurements on a Step Wedge

\begin{tabular}{ccccc}
\hline \multirow{2}{*}{$\begin{array}{c}\text { Step } \\
\text { Thickness } \\
\text { (inch) }\end{array}$} & \multicolumn{2}{c}{ Laboratory Measurement (inch) } & \multicolumn{2}{c}{ P-scan Measurement (inch) } \\
\cline { 2 - 5 } & GE 5-MHz & GE 5-MHz & GE 5-MHz & GE 5-MHz \\
Single & Dual & Single & Dual \\
\hline 0.9009 & 0.9004 & 0.9002 & 0.901 & 0.899 \\
0.8010 & 0.8004 & 0.8002 & 0.799 & 0.800 \\
0.7008 & 0.7004 & 0.7000 & 0.700 & 0.700 \\
0.6009 & 0.6001 & 0.6001 & 0.600 & 0.600 \\
0.5008 & 0.4997 & 0.4998 & 0.498 & 0.502 \\
\hline
\end{tabular}


Table 4.13. Error in Laboratory and P-scan Thickness Measurements

\begin{tabular}{ccccc}
\cline { 2 - 5 } & \multicolumn{4}{c}{ Error (inch) } \\
\hline Step & Laboratory Measurement (inch) & P-scan Measurement (inch) \\
\cline { 2 - 5 } Thickness & GE 5-MHz & GE 5-MHz & GE 5-MHz & GE 5-MHz \\
(inch) & Single & Dual & Single & Dual \\
\hline 0.9009 & 0.0005 & 0.0007 & 0.0001 & 0.0019 \\
0.8010 & 0.0006 & 0.0009 & 0.0020 & 0.0010 \\
0.7008 & 0.0006 & 0.0009 & 0.0009 & 0.0009 \\
0.6009 & 0.0008 & 0.0008 & 0.0009 & 0.0009 \\
0.5008 & 0.0011 & 0.0020 & 0.0028 & 0.0012 \\
\hline Average & 0.0007 & 0.0011 & 0.0013 & 0.0012 \\
\hline
\end{tabular}




\subsection{Mockup/Tank Studies}

Two studies were performed both on a mockup plate and on field tanks. The first was a point study that compared stationary and the usual crawler UT measurements. The second was a variability study that examined potential differences/variability between operators, instruments, and transducers. They are discussed respectively in the next two sections.

\subsection{Mockup/Tank Point Studies}

A point study was performed on both a mockup and on the walls of both of tanks 241-AW-103 and 241-AW-105. The point studies compare stationary measurements to those made with a moving crawler and scanning bridge. The intent is to help understand the relationship between stationary measurements and scanning measurements and which approach more accurately represents the true wall thickness. The somewhat unexpected directional phenomenon of lift-off was encountered in the associated data analysis, and that topic is discussed here as well.

\subsubsection{Data Acquisition Methods and Evaluation of Data}

Figure 5.1 represents a15-inch wide vertical UT wall-thickness inspection path. On the mockup plate the vertical extent of the path was about 3.5 feet; on Plate 3 of tanks 241-AW-103 and 241-AW-105, this was about 8 feet instead.

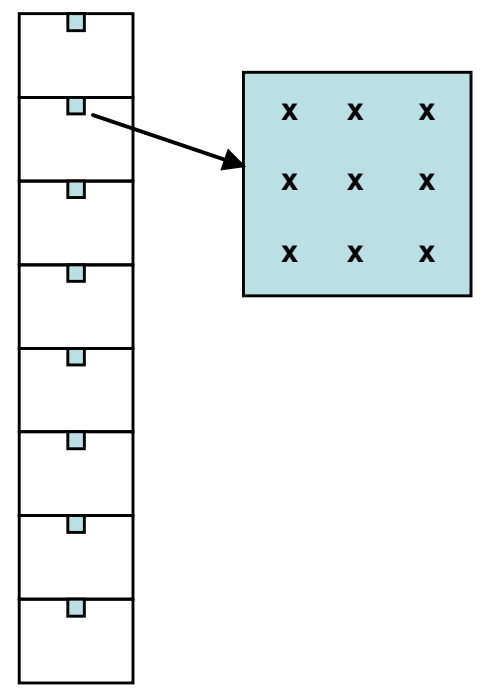

Figure 5.1. Inspection Path and Location of Point Measurements

As indicated in the figure, subsequent analyses split the paths into 15 inch $\times 12$ inch sections, although the full 12 inches was not available for the bottom image on the mockup. In tank wall thickness inspections, the minimum, average, and maximum wall thicknesses are typically reported for each such image. 
Each smaller, blue-shaded square within a UT image represents a 3-inch square area for which wall thicknesses were estimated using two different approaches. The first approach is from the subset of approximately $7000+$ pixels within the square from the usual UT inspection scan data. The second approach generates measurements at the x's within these smaller squares, that is, the locations of additional stationary indexing measurements. The 3-inch area was located as close as could be reasonably accomplished to the top center of each original UT image. In other words, the top 3-inch square is at the very top center of the entire path, with each additional 3-inch square then located an additional 12 inches lower.

The nine individual wall thicknesses from each 3-inch square will be estimated from the stationary measurements and be averaged to obtain the average thickness of the entire 3-inch square area. From the scan data, nine 1-inch square sections will have the x's in the figure as their approximate center point. The average wall thickness over these 1-inch sections will be computed and compared to the stationary values from the $\mathrm{x}$ locations.

When such 1-inch sections were being identified in the pixel data, a pattern in the wall thicknesses between the rows of pixels was noticed. The pixel rows were grouped by the last column and plotted in Figure 5.2. These figures represent the average column thickness over the entire 8-foot column length of the associated vertical path. The blue points are from the rows that would be labeled "small," the green points are from those that would be labeled "small repeated," and the red points are from those that would be labeled "large" based on the above pattern. As can be seen, the red points from the larger rows are biased considerably higher than the blue and green points, especially on the right side of the plots.

These phenomena were discussed with the Level III inspectors. They said the four/six pattern was known by them and understood. It occurs due to hardware/software characteristics. As was suspected, the red points are caused by lift-off of the transducer when the direction of the scanner is reversed at the right edge of the scan plots shown in Figure 4.29. It gradually settles back down on the plots as the scanner moves left across the plots.

The averages over the entire 8 feet of scan show this more clearly in Figure 5.3. The color plots in Figure 5.2 are averaged vertically to obtain the top plot in Figure 5.3 for Tank 241-AW-105. The red liftoff points increase the measured wall thickness dramatically over the first few pixels on the right side of the plot. Then as the scanner moves further to the left on the plot, the "herky-jerky" motion results in a gradual settling of the transducer back to flat against the wall surface, but it takes about 12 to 13 inches for the red points to return to the level of the blue and green points. And to the left of this point, a much smaller lift-off phenomenon impacts the blue and green points with the turn in direction back to the right, making their thickness slightly more than the red for a short distance. Table 5.1 shows the last 8 columns and about the first 30 rows of a Tank 241-AW-105 12-inch $\times 15$-inch UT image. The top row indicates the horizontal location of the columns from the center of the image at 0.0. The next column "Mean" is the row mean across the entire 15-inch row. The "Diff's" column gives the differences between the row above and the adjacent row. A plus/minus sequence was noticed in the Diff's column, but it is periodically interrupted. Consider the Mean column and compare it to the final "Magnitude" column. The mean column starts with a large value followed by a smaller one, which is then approximately repeated. Then comes a sequence of four large/small rows with the last small one again approximately repeated. Next comes a sequence of six large/small rows with the last small one again approximately repeated. This four/six pattern is repeated throughout the entire 8-foot length of this scan of Tank 241- 
AW-105, which was done for the point study associated with it. The same pattern appeared in Tank 241AW-103 and the mockup scan inspections as well as in other UT inspection data.

The green and blue points offer the better estimates of wall thickness. The Level III inspectors indicated the red points are not used in their analyses that generate the 12 -inch $\times 15$-inch image minima, maxima, and average thickness. This was indeed observed by the authors when their visual analysis approach was demonstrated.

In the corresponding Tank 241-AW-103 and mockup plots in Figure 5.3, the more significant lift-off occurs in the opposite direction. The Level III inspector indicated this can indeed happen instead due to fixture changes. The magnitude of the lift-off wall thickness bias (the vertical distance between the red points and blue/green points) is only about one-half what it was for Tank 241-AW-105, from a maximum there of about 0.040 -inch, down to about 0.020-inch.
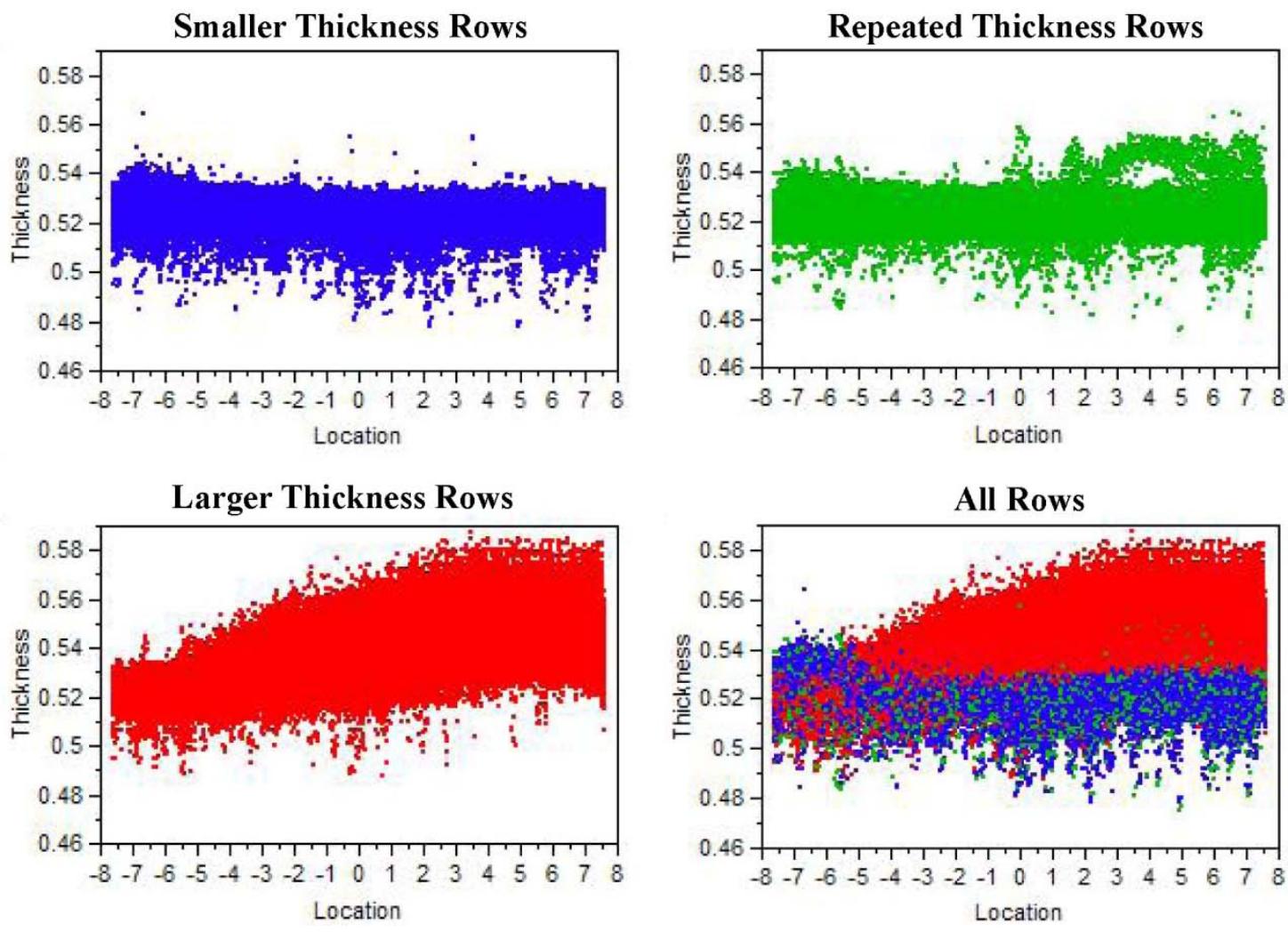

Figure 5.2. AW-105 Average Column Wall Thicknesses 
Tank AW-105 8-ft Strip Averages

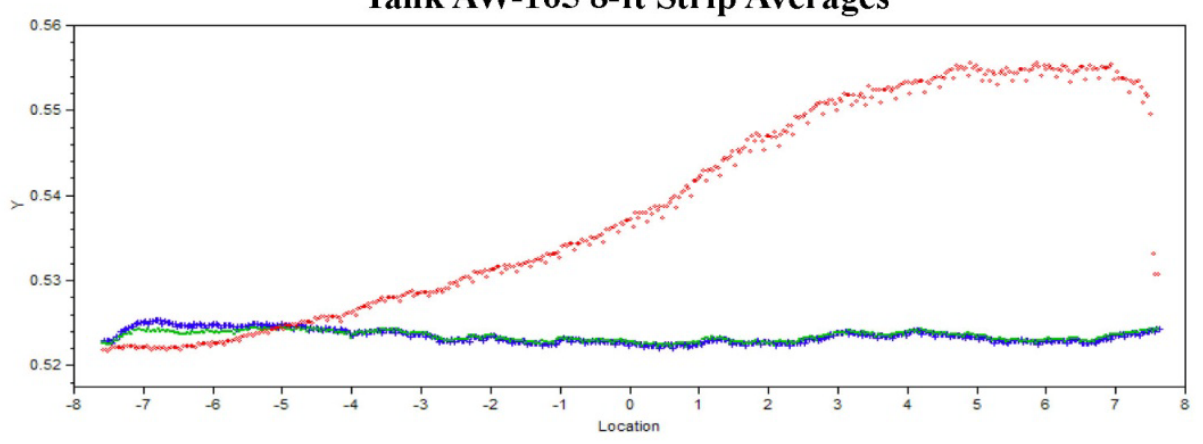

Tank AW-103 8-ft Strip Averages

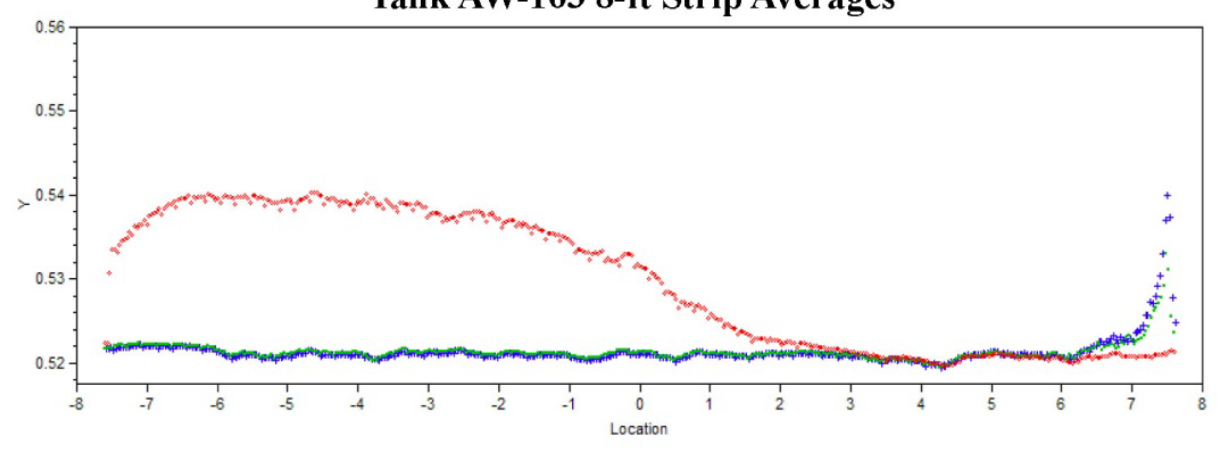

Mockup 4-ft Strip Averages

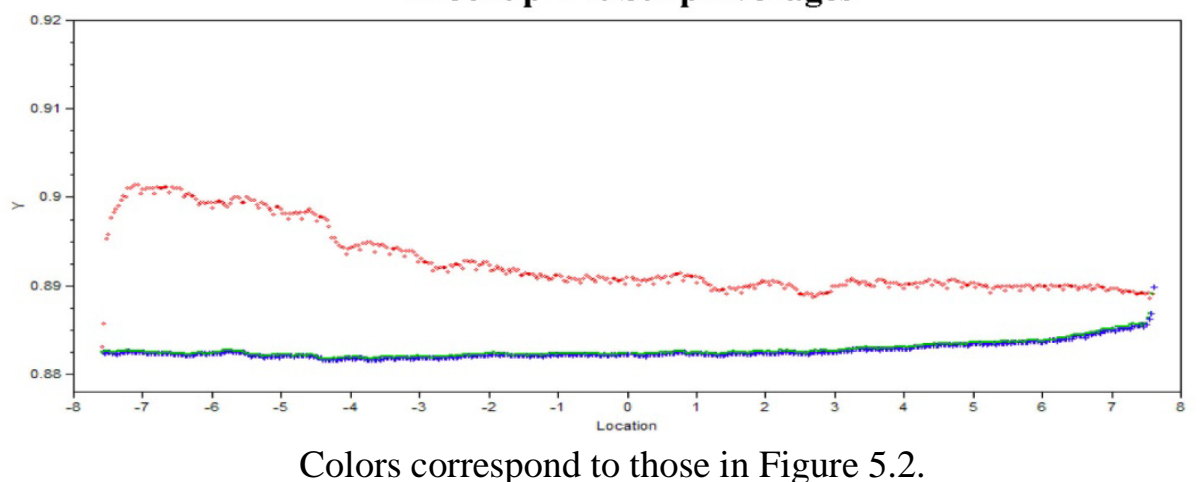

Figure 5.3. Average Wall Thicknesses (in inches)

The authors' initial concern was that the red points were resulting in over-estimated UT image average or maximum wall thicknesses in typical tank inspections; little impact would be felt for the corresponding minima. However, the Level III inspector's approach indeed uses little of the red-point information. But caution needs be exercised if all pixel values are averaged in computer applications, as was expected to be the case in this special point study. Then the average thicknesses would be overestimated, and that is precisely what first happened to the authors in these point-study analyses. 
Table 5.1. A Top Corner of Tank 241-AW-105 Image Pixels

\begin{tabular}{|c|c|c|c|c|c|c|c|c|c|c|}
\hline 7.36 & 7.395 & 7.43 & 7.465 & 7.5 & 7.535 & 7.57 & 7.605 & Mean & Diff's & Magnitude \\
\hline 0.536 & 0.533 & 0.535 & 0.539 & 0.542 & 0.518 & 0.515 & 0.515 & 0.5355 & & large \\
\hline 0.515 & 0.515 & 0.515 & 0.515 & 0.515 & 0.514 & 0.513 & 0.514 & 0.5143 & 0.0212 & small \\
\hline 0.514 & 0.514 & 0.513 & 0.514 & 0.514 & 0.513 & 0.513 & 0.514 & 0.5132 & 0.0011 & small repeated \\
\hline 0.539 & 0.542 & 0.530 & 0.545 & 0.541 & 0.519 & 0.515 & 0.515 & 0.5365 & -0.0233 & large \\
\hline 0.515 & 0.515 & 0.514 & 0.514 & 0.514 & 0.513 & 0.512 & 0.513 & 0.5136 & 0.0230 & small \\
\hline 0.550 & 0.545 & 0.547 & 0.536 & 0.533 & 0.516 & 0.515 & 0.515 & 0.5389 & -0.0254 & large \\
\hline 0.514 & 0.514 & 0.514 & 0.514 & 0.514 & 0.514 & 0.514 & 0.514 & 0.5136 & 0.0253 & small \\
\hline 0.513 & 0.513 & 0.514 & 0.514 & 0.514 & 0.514 & 0.515 & 0.515 & 0.5136 & 0.0000 & small repeated \\
\hline 0.543 & 0.540 & 0.544 & 0.550 & 0.558 & 0.525 & 0.522 & 0.522 & 0.5394 & -0.0259 & large \\
\hline 0.513 & 0.515 & 0.515 & 0.515 & 0.515 & 0.516 & 0.516 & 0.515 & 0.5133 & 0.0261 & small \\
\hline 0.535 & 0.534 & 0.533 & 0.539 & 0.533 & 0.522 & 0.518 & 0.518 & 0.5396 & -0.0263 & large \\
\hline 0.515 & 0.515 & 0.515 & 0.515 & 0.515 & 0.515 & 0.515 & 0.515 & 0.5134 & 0.0263 & small \\
\hline 0.534 & 0.544 & 0.532 & 0.539 & 0.536 & 0.521 & 0.517 & 0.517 & 0.5397 & -0.0263 & large \\
\hline 0.515 & 0.515 & 0.515 & 0.515 & 0.515 & 0.515 & 0.514 & 0.515 & 0.5133 & 0.0263 & small \\
\hline 0.515 & 0.515 & 0.515 & 0.515 & 0.515 & 0.515 & 0.516 & 0.516 & 0.5136 & -0.0002 & small repeated \\
\hline 0.542 & 0.539 & 0.538 & 0.534 & 0.535 & 0.529 & 0.529 & 0.529 & 0.5402 & -0.0267 & large \\
\hline 0.515 & 0.515 & 0.517 & 0.518 & 0.518 & 0.517 & 0.516 & 0.516 & 0.5134 & 0.0268 & small \\
\hline 0.540 & 0.539 & 0.533 & 0.529 & 0.534 & 0.528 & 0.522 & 0.522 & 0.5399 & -0.0265 & large \\
\hline 0.516 & 0.516 & 0.518 & 0.519 & 0.520 & 0.520 & 0.519 & 0.519 & 0.5133 & 0.0267 & small \\
\hline 0.517 & 0.517 & 0.518 & 0.518 & 0.519 & 0.518 & 0.519 & 0.517 & 0.5135 & -0.0003 & small repeated \\
\hline 0.535 & 0.531 & 0.527 & 0.528 & 0.524 & 0.526 & 0.520 & 0.520 & 0.5382 & -0.0247 & large \\
\hline 0.516 & 0.516 & 0.517 & 0.517 & 0.517 & 0.518 & 0.518 & 0.517 & 0.5137 & 0.0245 & small \\
\hline 0.529 & 0.524 & 0.524 & 0.522 & 0.525 & 0.522 & 0.521 & 0.521 & 0.5392 & -0.0255 & large \\
\hline 0.516 & 0.516 & 0.516 & 0.516 & 0.516 & 0.516 & 0.515 & 0.515 & 0.5140 & 0.0252 & small \\
\hline 0.534 & 0.532 & 0.526 & 0.527 & 0.528 & 0.526 & 0.520 & 0.520 & 0.5384 & -0.0243 & large \\
\hline 0.515 & 0.515 & 0.515 & 0.515 & 0.515 & 0.516 & 0.516 & 0.515 & 0.5137 & 0.0247 & small \\
\hline 0.515 & 0.515 & 0.515 & 0.515 & 0.516 & 0.517 & 0.516 & 0.515 & 0.5137 & 0.0000 & small repeated \\
\hline
\end{tabular}

For the stationary measurement indicated by the x's in Figure 4.7, some effort was expended to make sure the crawler was flat against the mockup/tank wall surface. This was more difficult to do for Tank 241-AW-105 due to its rougher wall surface. This also explains why in the Figure 4.7 plots, the greater red point difference is shown for Tank 241-AW-105; the rougher wall causes more lift-off, and it takes a longer time for it to flatten out than in Tank 241-AW-103. Note in Tank 241-AW-103 a brief, more extreme lift-off is shown in the opposite direction for the blue/green points. For the mockup, again the red point bias is more persistent, now across the entire width of the plot.

So in the mockup point-study comparisons of the four sets of nine segments in the blue squares to the corresponding nine stationary measurements, the "red" biased points were included in the initial analyses. This led to the left section of Table 5.2. Results are shown for each of the four images indicated previously in the 3.5-foot version of Figure 4.7, and each of these images is split into the nine segments.

The left half and top section of Table 5.2 gives the average results obtained when working with all pixel rows; that is, green, blue, and red points as described earlier in association with Figure 4.7. The right half and top section does not include the red pixel rows in the computations of the averages. Smaller thicknesses are thereby obtained in the right half of the table by omitting the high-biased red points. 
Table 5.2. Comparison Between Mockup Scan and Stationary UT Measurements

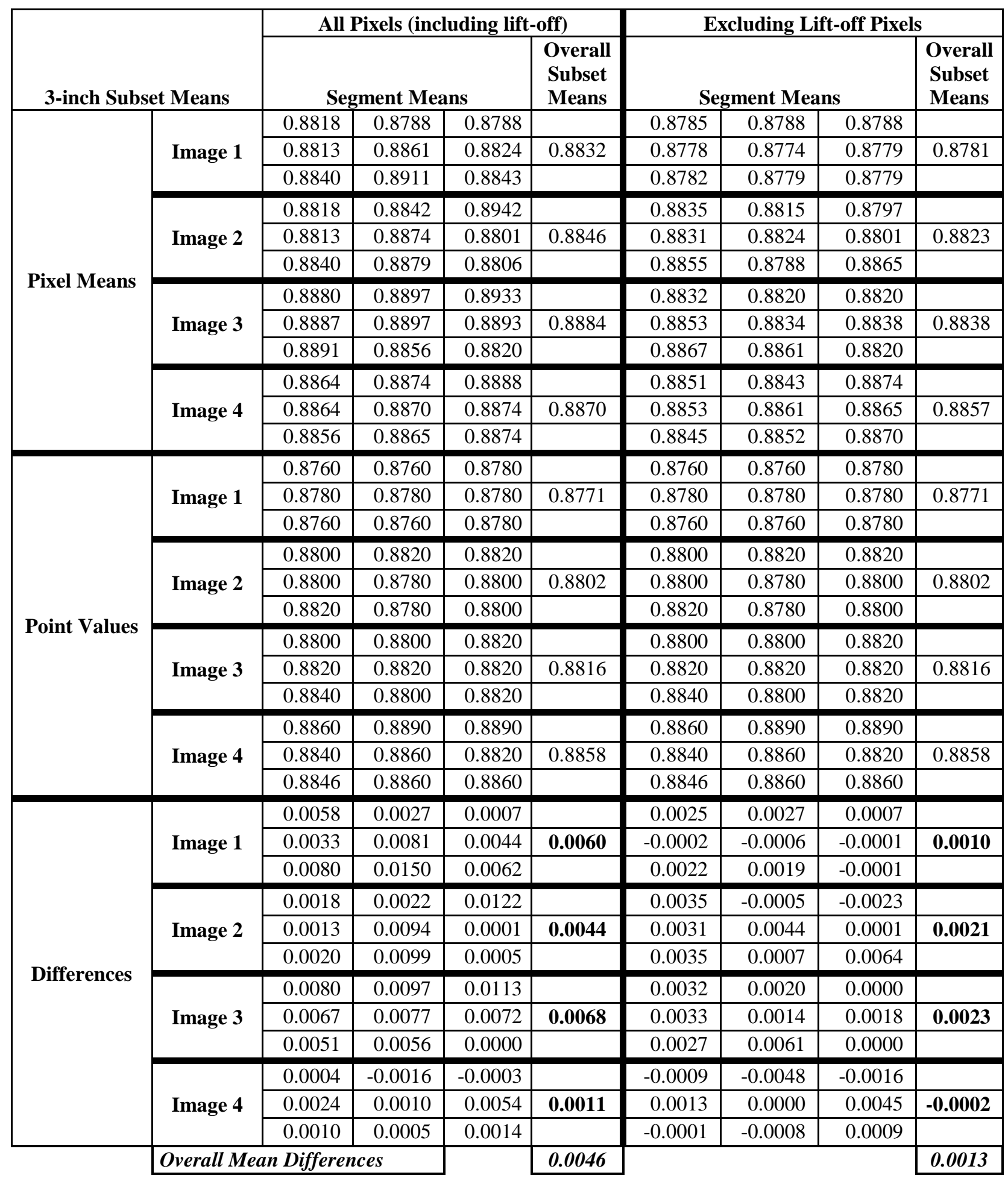

The middle sections of the table give the nine stationary point thicknesses, with the bottom section then giving the differences between the top and middle sections. The means of the nine-segment results are given to their right in each case, and at the bottom of the columns containing these "3-inch Subset" 
means is the mean over all four images. In the left half of the table, this is seen to be about 11 mils, which might have been considered an apparent difference in moving crawler and stationary measurements except for the now-acknowledged impact of the biased "red point" measurements. Note this is over only the top and middle 3 inches of each image and therefore results will incorporate the lift-off shown only in the middle 3 inches of the mockup plot in Figure 4.7.

This difference is 4.6 mils for the mockup. It will be seen to be greater for Tank 241-AW-105 and less for Tank 241-AW-103 in Table 5.3. These results correspond to the lift-off indications in Figure 4.7 for these three point studies.

When the red pixel points are instead omitted (right half of Table 5.2), the 4.6-mil difference for the mockup is reduced to 1.3 mils. So caution needs to be used when pixel measurements are used computationally for UT images. Lift-off can generate significant biases by reporting excessively large wall thickness. Such bias is dramatically reduced by excluding the red points from the analyses.

Overall the 4.6-mil bias caused by including the pixels represented by the red points was reduced to 1.3 mils, an insignificant quantity for indicating a potential difference between stationary and scan measurements. The analysis of bias reduction computations obtained by deleting the lift-off points have not been performed for the two tanks because this topic unexpectedly arose late in the data analyses associated with this report, and the rather involved computations were deferred until after the report draft was to be completed. However, the bias impact due to the red points was computed by including all pixels in the 3 -inch square in comparison to the nine stationary points. Refer again to Figure 4.7 to observe the red points targeted for possible omission.

The left and right sections of Table 5.3, for Tanks 241-AW-105 and 241-AW-103, respectively, are analogous to the bottom left section of Table 5.2; that is, the difference results between the moving scanner measurements and stationary measurements when all pixels are included, in particular the biased red points. Segments are the nine 1-inch squares within the entire 3-inch square subset of a full UT image. Now as shown, eight such images are available.

The final row indicates an 11.4-mil bias caused by the red points, averaged over the eight 3-inch squares for Tank 241-AW-105. The corresponding bias was 4.6-mil for the mockup, and these results relatively coincide with magnitude of the Figure 5.4 red-point biases. A little surprising is the only 0.9-mil bias for Tank 241-AW-103; from Figure 5.4, relative to the other two cases, a reduced bias would indeed be expected for Tank 241-AW-103, but possibly not as small as 0.9 mils. From Table 5.3, this small AW-103 bias is driven by the negative results (point measurements greater than the moving-crawler measurements) for the top images in the top right section of the table.

Recall these differences and the resulting biases apply to the average thickness only for the 3-inch squares within the images. Over entire 12 -inch $\times 15$-inch images, the biases would be even greater. While the "bias correction" computations attained for the mockup by omitting the red points was not yet done for Tanks 241-AW-103 and 241-AW-105, it would obviously considerably reduce the biases, possibly even leading to a negative bias for AW-103. 
Table 5.3. Scan and Point Averages for Tanks 241-AW-103 and 241-AW-105

\begin{tabular}{|c|c|c|c|c|c|c|c|c|c|}
\hline \multirow{2}{*}{\multicolumn{2}{|c|}{ 3-inch Subset Means }} & \multicolumn{4}{|c|}{ 241-AW-105 } & \multicolumn{4}{|c|}{ 241-AW-103 } \\
\hline & & \multicolumn{3}{|c|}{ Segment } & \multirow[t]{2}{*}{$\begin{array}{l}\text { Overall } \\
\text { Subset }\end{array}$} & \multicolumn{3}{|c|}{ Segment } & $\begin{array}{l}\text { Overall } \\
\text { Subset }\end{array}$ \\
\hline \multirow{24}{*}{ Differences } & \multirow{3}{*}{ Image 1} & 0.0088 & 0.0114 & 0.0058 & & -0.0092 & -0.0039 & -0.0088 & \\
\hline & & 0.0086 & 0.0092 & 0.0061 & 0.0063 & -0.0049 & -0.0040 & -0.0019 & -0.0049 \\
\hline & & 0.0047 & 0.0004 & 0.0013 & & -0.0031 & -0.0033 & -0.0049 & \\
\hline & \multirow{3}{*}{ Image 2} & 0.0077 & 0.0153 & 0.0154 & & -0.0021 & -0.0021 & -0.0013 & \\
\hline & & 0.0163 & 0.0105 & 0.0127 & 0.0134 & -0.0026 & -0.0031 & -0.0078 & -0.0056 \\
\hline & & 0.0135 & 0.0118 & 0.0173 & & -0.0162 & -0.0072 & -0.0082 & \\
\hline & \multirow{3}{*}{ Image 3} & 0.0058 & 0.0147 & 0.0157 & & 0.0001 & -0.0014 & -0.0002 & \\
\hline & & 0.0127 & 0.0127 & 0.0199 & 0.0142 & 0.0006 & -0.0033 & -0.0010 & -0.0025 \\
\hline & & 0.0150 & 0.0141 & 0.0170 & & -0.0077 & -0.0037 & -0.0057 & \\
\hline & \multirow{3}{*}{ Image 4} & 0.0060 & 0.0098 & 0.0108 & & 0.0045 & 0.0040 & 0.0036 & \\
\hline & & 0.0136 & 0.0092 & 0.0129 & 0.0101 & 0.0007 & 0.0050 & 0.0017 & 0.0032 \\
\hline & & 0.0102 & 0.0066 & 0.0117 & & 0.0039 & 0.0045 & 0.0012 & \\
\hline & \multirow{3}{*}{ Image 5} & 0.0105 & 0.0130 & 0.0181 & & 0.0048 & 0.0002 & 0.0020 & \\
\hline & & 0.0119 & 0.0149 & 0.0175 & 0.0137 & 0.0036 & 0.0015 & 0.0025 & 0.0031 \\
\hline & & 0.0100 & 0.0135 & 0.0143 & & 0.0059 & 0.0050 & 0.0025 & \\
\hline & \multirow{3}{*}{ Image 6} & 0.0132 & 0.0115 & 0.0126 & & 0.0057 & 0.0060 & -0.0001 & \\
\hline & & 0.0100 & 0.0104 & 0.0132 & 0.0118 & 0.0088 & 0.0066 & 0.0019 & 0.0045 \\
\hline & & 0.0122 & 0.0105 & 0.0124 & & 0.0083 & 0.0047 & -0.0012 & \\
\hline & \multirow{3}{*}{ Image 7} & 0.0114 & 0.0157 & 0.0148 & & 0.0068 & 0.0016 & -0.0011 & \\
\hline & & 0.0123 & 0.0150 & 0.0154 & 0.0139 & -0.0013 & 0.0002 & $\begin{array}{l}-0.0008 \\
\end{array}$ & -0.0025 \\
\hline & & 0.0096 & 0.0152 & 0.0157 & & 0.0052 & -0.0138 & -0.0190 & \\
\hline & \multirow{3}{*}{ Image 8} & 0.0050 & 0.0055 & 0.0084 & & 0.0143 & 0.0118 & 0.0050 & \\
\hline & & 0.0048 & 0.0088 & 0.0082 & 0.0078 & 0.0148 & 0.0142 & 0.0108 & 0.0116 \\
\hline & & 0.0089 & 0.0106 & 0.0098 & & 0.0120 & 0.0106 & 0.0109 & \\
\hline & \multicolumn{3}{|c|}{ n Differences } & & 0.0114 & & & & 0.0009 \\
\hline
\end{tabular}

It appears that little difference exists between the stationary and scan measurements, although the liftoff phenomenon and its impact clearly has to be considered if the actual pixel measurements are used computationally to estimate wall thickness.

A final view is shown in Figure 5.4 of the mean results per image for the two tanks. The red scan curves here still include the biased pixel measurements. If they were omitted, the red curves would more closely resemble the blue curves.

One last observation is made in this section regarding Figure 5.4. Along the horizontal axis, every sixth point is slightly lower than the surrounding points. This again was explained by Level III inspectors as a result of the hardware/software configuration and the pixel size used. It has only minimal impact on thickness measurements, being 1 to 2 mils less for the biased red points and considerably less for the more accurate blue and green points. 

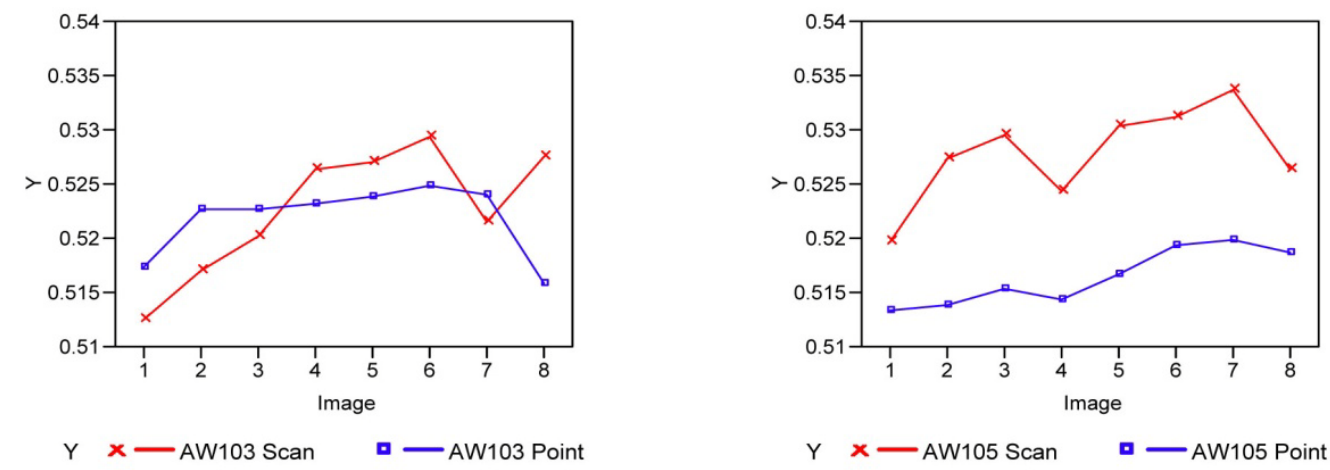

Figure 5.4. Image Means for Tanks 241-AW-103 and 241-AW-105

Based on the analysis above, the predictable and repeatable offset in the wall-thickness data was observed each time the transducer direction was reversed at the end of a scan path. The most likely cause of these positional shifts is a combination of two sources; the first is the accumulation of small amounts of slack in each of the various pivot points and mounting points in the system, the second is instability in the transducer mount/positioner. The result being that each time the direction of transducer movement changes, the position and orientation of the transducer changes a small amount. That is to say "the transducer and the mounting apparatus acquire a net tilt relative to the surface of interest.” The solution to this two-fold error will address these characteristics separately.

In the case of accumulated error in the linkage and associated joints, a series of experiments using calibration standards to fully understand this phenomenon and how it relates to the calibration process should be performed. It is felt that it may be necessary to modify the calibration process to include the entire physical apparatus and to quantify this shifting characteristic. In addition, improved design elements and/or material specifications to introduce more rigidity and consistency in the apparatus to this physical system should be considered.

In the case of the transducer mount/positioner, PNNL designed and fabricated a prototypical apparatus that used fewer parts and resulted in a much more rigid, stable, and reproducible mounting scheme. Figure 5.5 shows the original configuration assembled and in parts.

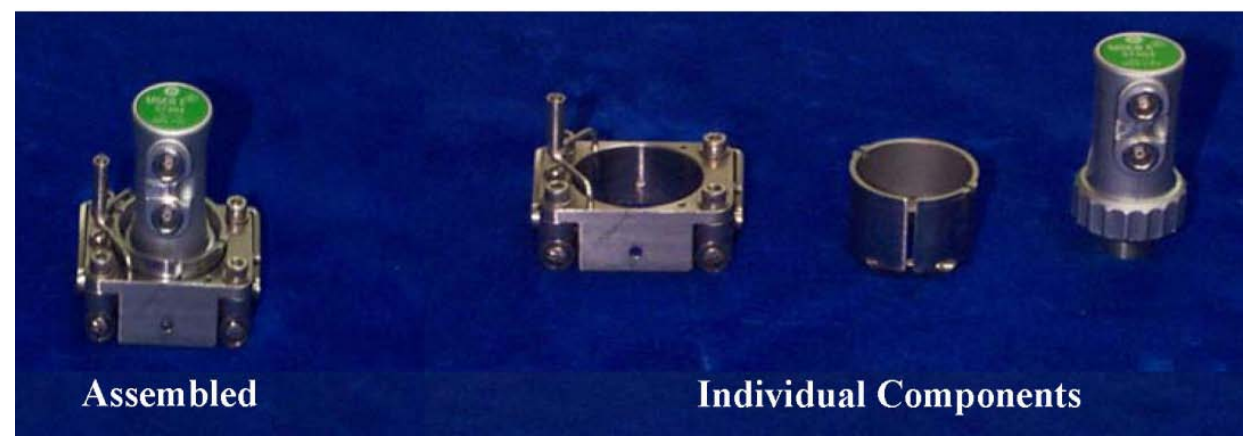

Figure 5.5. Original Transducer and Holder Assembly 
Figure 5.6 is a computer model of these same components to allow for cross-sectional and detailed views. Note the detail view illustrating the gaps between the transducer/sleeve and the sleeve/carriage. These gaps are subject to torque applied to the set screws during assembly. Note that the associated set screws apply localized pressure and can potentially become a pivot point allowing movement of components during testing. Note also that transducer position relative to the surface of interest is controlled solely by sliding the sleeve in its loose bore and then tightening a single transverse set screw.

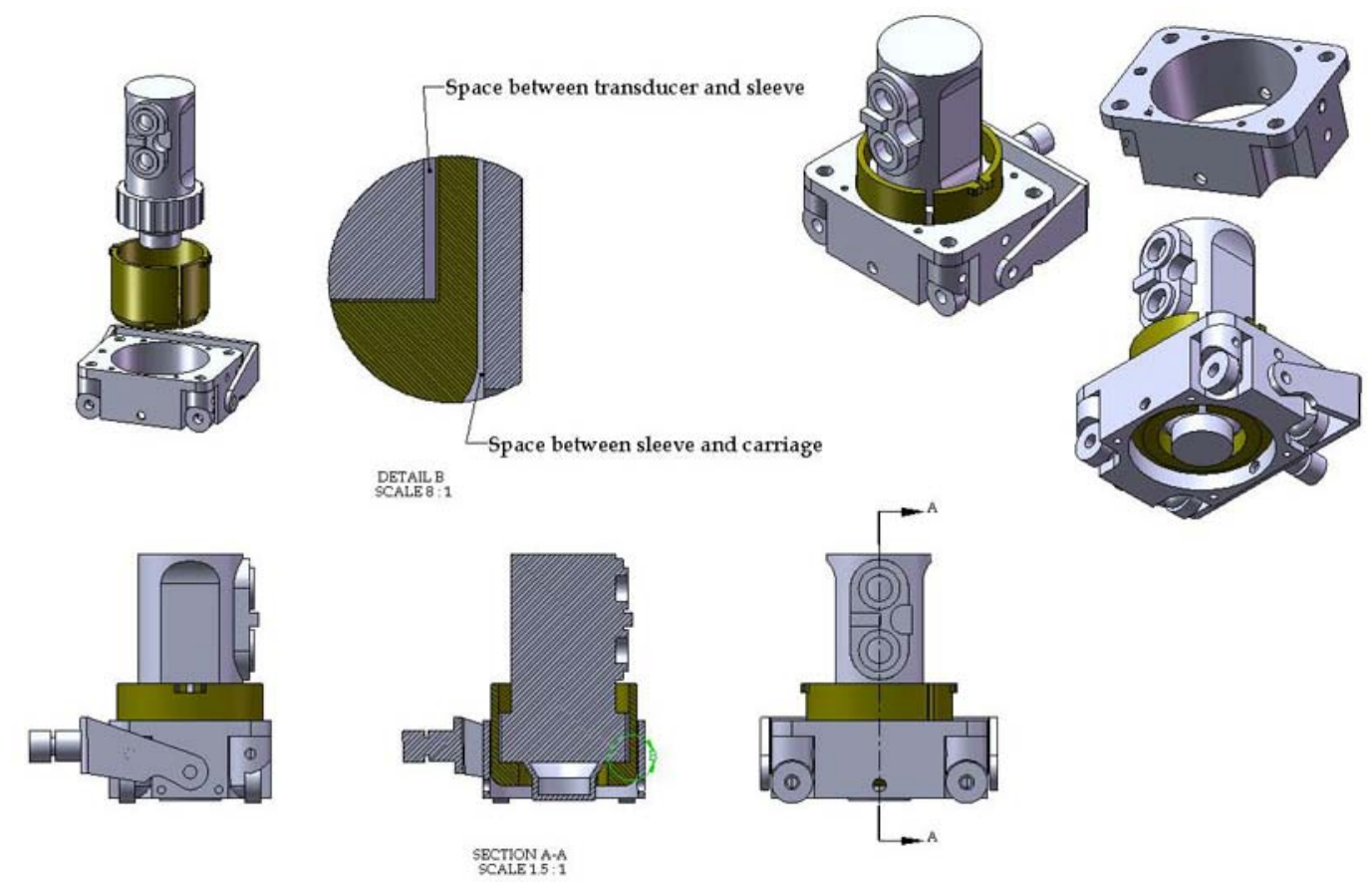

Figure 5.6. Graphic Representation of the Original Transducer and Holder

Note that this arrangement uses two components to mount the transducer and that it relies on two separate clamping actions to hold the transducer in position. The transducer is first mounted into a sleeve and clamped in place by a single screw, which clamps the sleeve at its bottom (see Figure 5.7), resulting in a localized clamping effect about a more or less planar region near the bottom of the transducer. Next, the transducer/sleeve assembly is positioned in the carriage and located with a single set screw resulting in a potential pivot point about which the assembly can rotate as forces on its face change direction during scanning or calibration activities. We believe that a simpler, more robust, and reliable system of transducer mounting can be developed using a "Clamping Ring" type of device. We have constructed two prototype systems as seen below.

Figure 5.7 shows the single-ring design, which would be faster and simpler to assemble and deploy but a bit less flexible in adapting to minute variations in transducer geometry. This system would use a simple shim to compensate for transducer geometry variations.

Figure 5.8 shows the double-ring design which would be a bit more complicated to assemble, adjust, and deploy. This double-ring apparatus would be much better suited to laboratory studies as it would be capable of minute and precise adjustments of transducer position during testing without disassembly. 

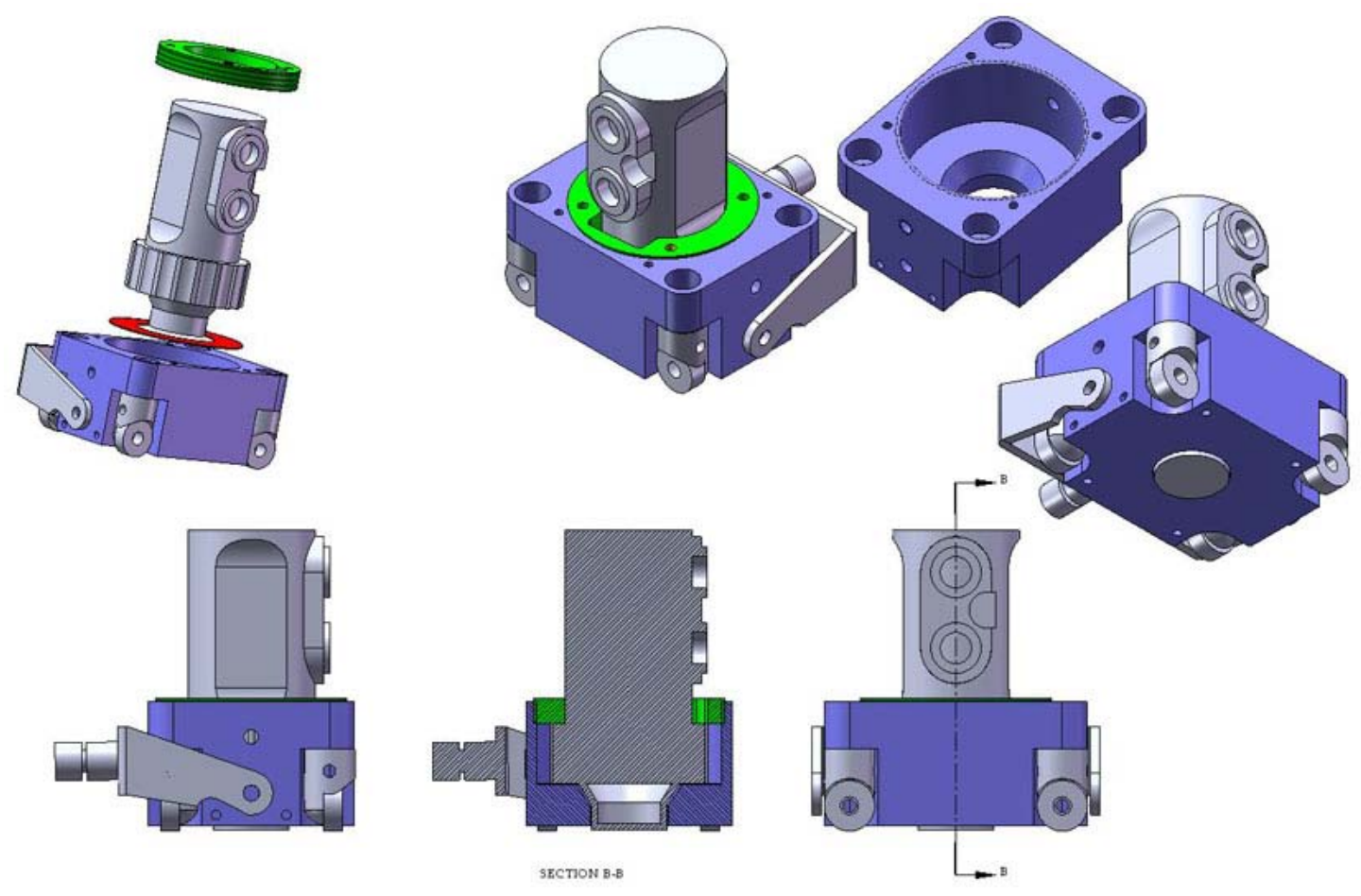

Figure 5.7. Single-Ring Design - Easy to Assemble and Deploy

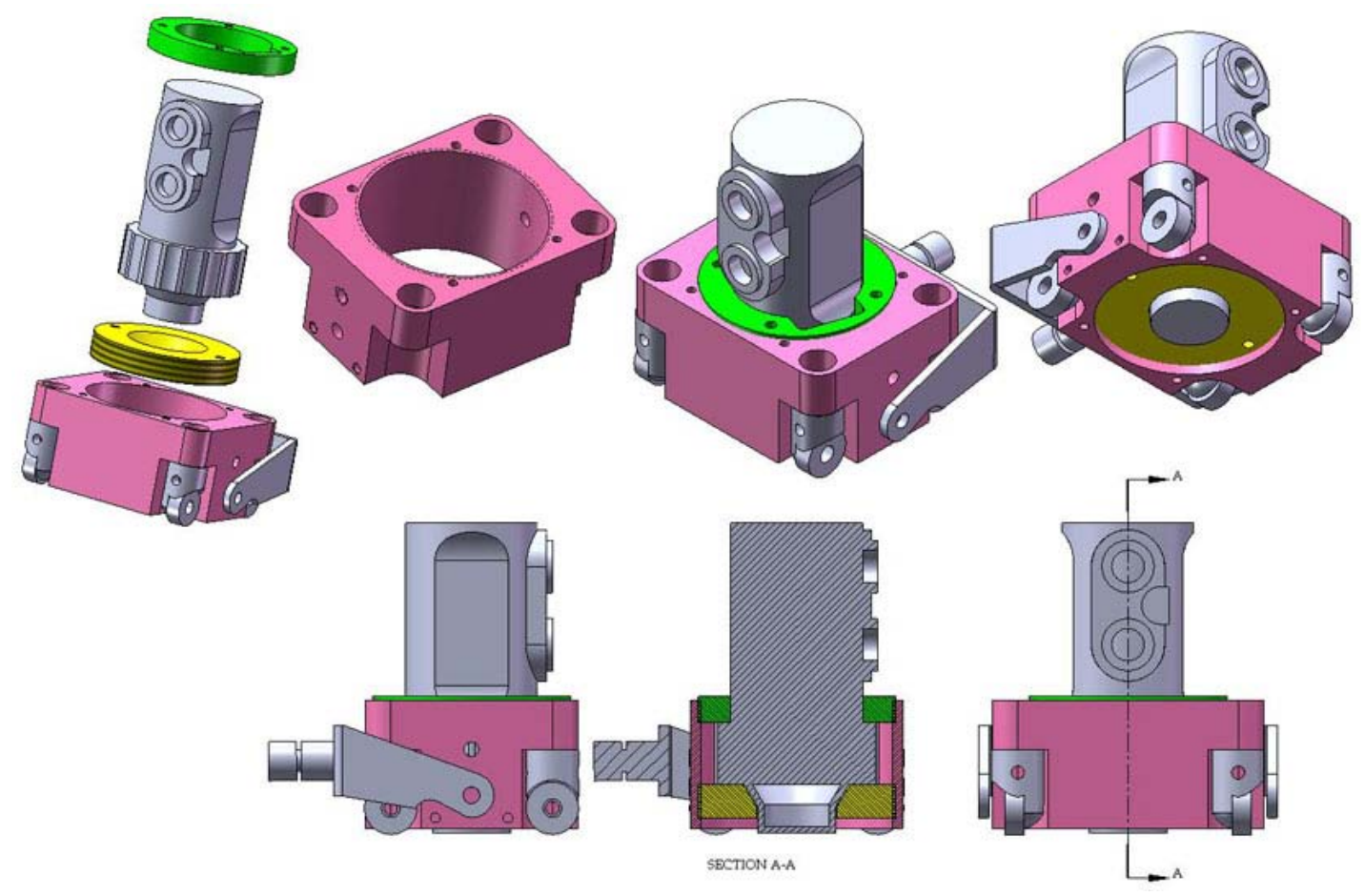

Figure 5.8. Double-Ring Apparatus - Suited to Laboratory Applications 
Note that both the single- and double-ring apparatuses would borrow heavily from existing hardware design. This borrowing would allow us to utilize much of the hardware currently used and thereby significantly reduce costs associated with fabrication. However, to maintain this apparatus as a highprecision positioner, the associated hardware (e.g., wheels) must also be fabricated to a high precision.

To explain these two new designs in more detail, the following information is provided:

- In the single-ring design, the position of the transducer would be determined by a brass shim of known thickness. This shim would be placed between the bottom of the carriage and the transducer and the single locking ring tightened from the top via a spanner wrench (refer to Figure 5.10 for details).

- In the double-ring design, the position of the transducer is determined by the position of the lower lock ring, which can be adjusted over a range of positions using the same spanner. After the lower lock ring has been positioned, the transducer is installed and again held in place by the upper lock ring. If this position is found to be incorrect, it is a simple matter to reposition the transducer using the spanner to loosen or tighten the two lock rings as appropriate (see Figure 5.10 for details).
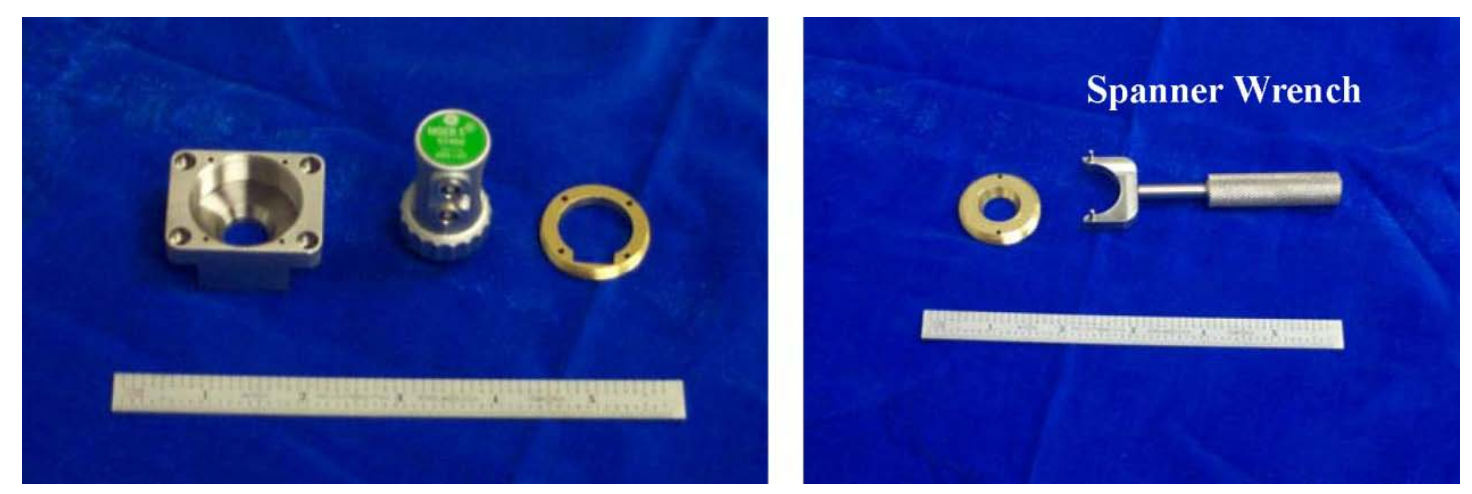

Figure 5.9. Components of the Fixed Position Apparatus and Associated Spanner Wrench
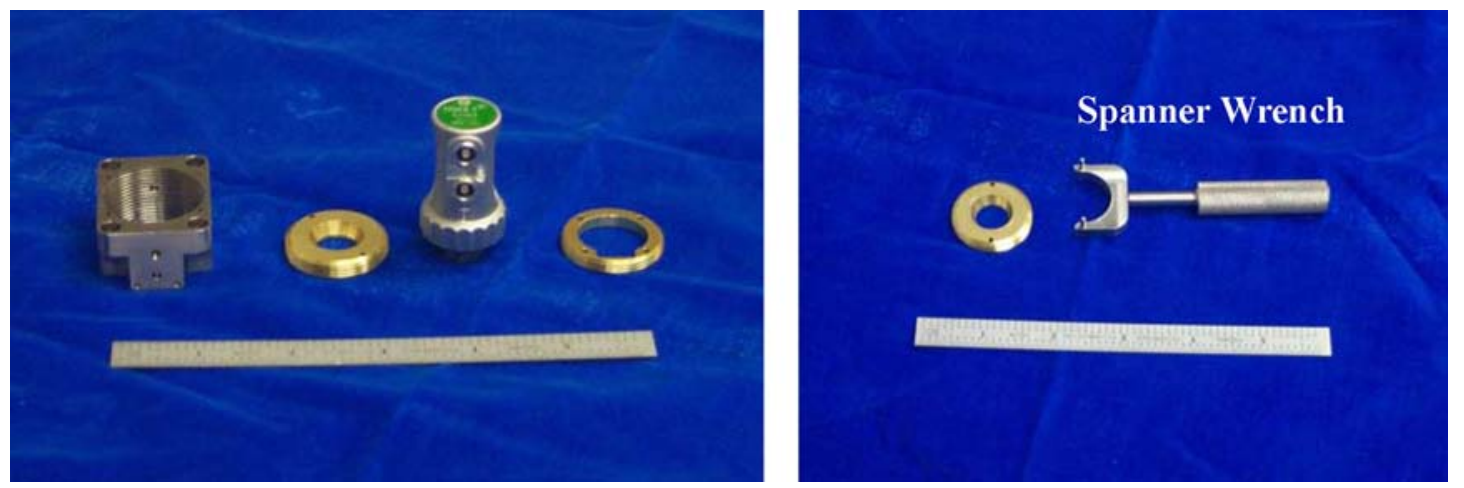

Figure 5.10. Components of the Adjustable Position Apparatus and Associated Spanner Wrench 


\subsection{Mockup/Tank Variability Studies}

To assure that the UT examination team from AFS provided consistent, repeatable data in a field operation, variability studies on both a mockup and during actual field operations were developed by PNNL. These studies examined potential variability between operators, instruments, and transducers by having different combinations of these factors each generate a UT measurement path on a mockup plate and on actual tank wall plates in tank 241-AW-103.

\subsubsection{Data Acquisition Methods and Evaluation of Data}

Vertical paths were inspected on a mockup plate and in Plates 3 and 5 of tank 241-AW-103 by three operators using three instruments and three transducers. To use all such combinations of the three operators/instruments/transducers would have required 27 inspections of the paths, a prohibitively timeconsuming undertaking for either the mockup or tank. Instead a "statistically strategic" design is shown in Table 5.4 that allowed all three of those factors to be examined using only nine different vertical paths (on the mockup and in each of the two plates).

Table 5.4. Study Instrument/Transducer/Operator Combinations

\begin{tabular}{ccc}
\hline Instrument & Transducer & Operator \\
\hline A & 1 & W \\
A & 2 & J \\
A & 3 & B \\
B & 1 & B \\
B & 2 & W \\
B & 3 & J \\
C & 1 & J \\
C & 2 & B \\
C & 3 & W \\
\hline
\end{tabular}

On the mockup plate, a single 3-foot path area was first cleaned appropriately utilizing the current wire brush technique used in the field. (In the tank, a 5-foot path was measured in Plate 3 and 2 feet in Plate 5.) Then each experimental design combination, consisting of one each of the three operators, instruments, and transducers, generated a UT inspection of such paths. The most difficult of the three factors to change out was the instrument, so the first instrument was set up in the lab and all necessary scans completed with that instrument. Note that three runs were made with each instrument. When the nine runs were completed, each operator had made three runs using each transducer once and each instrument once.

Note that under this sequence of runs we have the problem that instrument differences could be caused by potential transducer wear because the first instrument gets the first run on each new transducer, the second instrument gets the second run for each transducer, and the third instrument gets the final runs for each transducer. Ideally this "confounding” with transducer wear would be avoided, but to do so would involve shuffling of instruments in and out of the lab and to and from the field, and that was not proposed. Level III inspectors suggested that the minimal 9 feet of scanning done with each transducer should result in minimal wear. 
The usual visual data analysis was performed on the resulting nine 3-foot vertical paths, thereby generating 27 minimum, average, and maximum UT image wall thicknesses, three per inspection combination. In Figure 5.11 the mockup means of the UT image averages are compared; units are inches throughout with the thickness values shown on the vertical axes. The vertical extents of the green diamonds for each of the levels within the operator, instrument, and transducer factors represent confidence intervals for the means. If they do not overlap vertically, they would be considered statistically different from each other. Here the least difference is shown between the three instrument means because the three diamonds are almost perfectly level. This overlap for instruments alleviates the concern about the wear on the transducers potentially introducing differences between instruments as was discussed earlier.
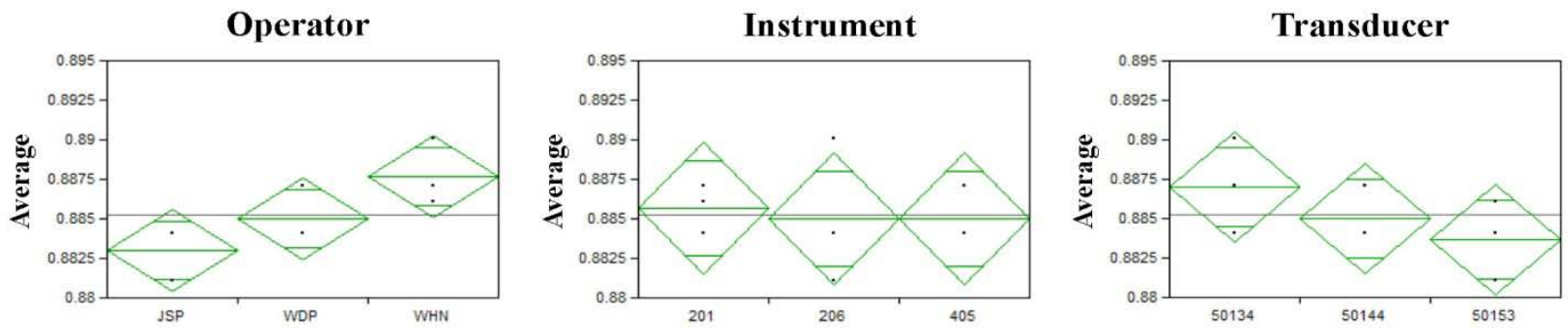

Figure 5.11. Mockup Variability Study Results

Table 5.5 lists the mockup means represented by the centers of the green diamonds in Figure 5.11. The significance value at the bottom of the Instrument column is quite large at 0.9510. Such significance values can range from 0.0 to 1.0 with smaller values indicating statistically significant differences; a decision level typically used is for the value being less than 0.05 suggesting the factor introduces significant differences. This is not at all the case for instrument with the large significance value and where the mean values differ by less than a mil. Differences between transducers are somewhat greater as indicated by the corresponding green diamonds in Figure 5.11 and the Table 5.5 mean values (mean differences up to just over 3 mils). Now, the significance level has dropped to 0.3209 , so still no statistically significant differences relative to the variability in the data are suggested between transducers.

The operator differences are somewhat greater however. Note for the green diamonds in Figure 5.11, the two on the ends just barely intersect with each other. This lack of overlap and the 0.0575 significance value in Table 5.5 suggest that relative to the variability in the data, the difference between operators is marginally statistically significant (mean differences are up to nearly 5 mil).

Table 5.5. Mockup Variability Study Means

\begin{tabular}{|c|c|c|c|c|c|}
\hline \multicolumn{2}{|c|}{ Operator Means } & \multicolumn{2}{|c|}{ Instrument Means } & \multicolumn{2}{|c|}{ Transducer Means } \\
\hline JSP & 0.8830 & 201 & 0.8857 & 50134 & 0.8870 \\
\hline WDP & 0.8850 & 206 & 0.8850 & 50144 & 0.8850 \\
\hline WHN & 0.8877 & 405 & 0.8850 & 50153 & 0.8837 \\
\hline \multicolumn{2}{|c|}{ Significance 0.0575} & \multicolumn{2}{|c|}{ Significance 0.9510} & \multicolumn{2}{|c|}{ Significance 0.3209} \\
\hline
\end{tabular}


The analogous results for the corresponding tank study are given in Figure 5.12 and Table 5.6. Here to eliminate the large impact of the different thicknesses between Plates 3 and 5 (0.5-inch and 0.75-inch, respectively), measurements are reported as the difference from nominal. Unlike the mockup case where operator was the greatest contributor to variability, operator now contributes the least. Very little difference is shown in the operator green diamonds in the figure, and the Table 5.6 mean values for operator differ by less than a mil.

The instrument and transducer difference would both be considered statistically significant due to their small significance levels in Table 5.6 and differing heights of the green diamonds in Figure 5.12. The instrument means differ by nearly $3 \mathrm{mil}$ and the transducer means by nearly 4 mil. The greater statistical significance of such tank measurement differences as compared to that for the mockup is partially due to the fact that greater amounts of data are available for the tank study (seven UT images rather than only three).
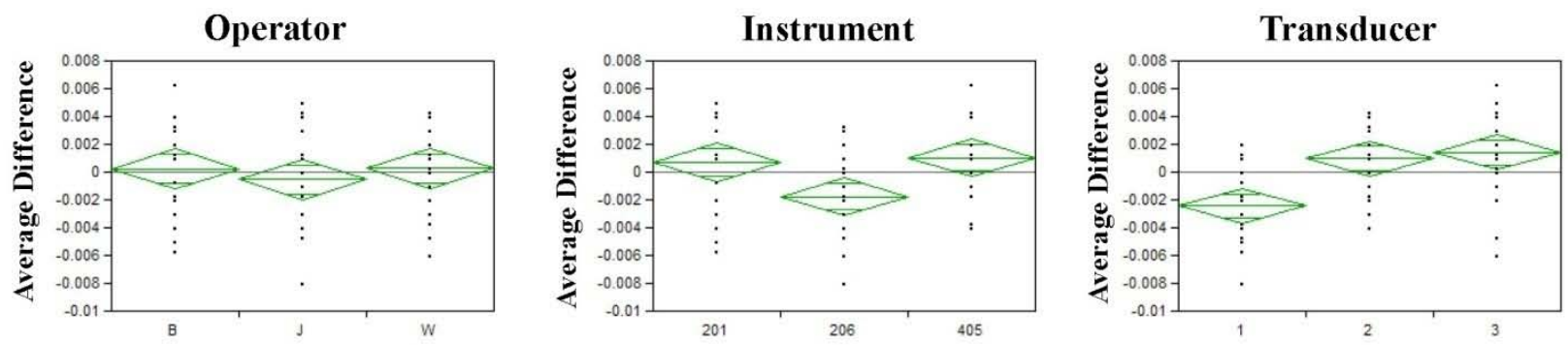

Figure 5.12. Tank Variability Study Results

Table 5.6. Tank Variability Study Means

\begin{tabular}{crlrcr}
\hline \multicolumn{2}{c}{ Operator Means } & \multicolumn{2}{c}{ Instrument Means } & \multicolumn{2}{c}{ Transducer Means } \\
\hline $\mathbf{B}$ & 0.0002 & $\mathbf{2 0 1}$ & 0.0007 & $\mathbf{1}$ & -0.0025 \\
$\mathbf{J}$ & -0.0005 & $\mathbf{2 0 6}$ & -0.0018 & $\mathbf{2}$ & 0.0010 \\
$\mathbf{W}$ & 0.0003 & $\mathbf{4 0 5}$ & 0.0010 & $\mathbf{3}$ & 0.0014 \\
\hline \multicolumn{2}{l}{ Significance } & 0.5379 & \multicolumn{2}{l}{ Significance 0.0017} & \multicolumn{2}{c}{ Significance $<0.0001$} \\
\hline
\end{tabular}

The results just discussed for the mockup and tank variability studies are presented in a different manner in Table 5.7 and Table 5.8. Variance components due to the three factors are examined. Statistical variances are given in the "Variance Component" column. The values for operator, instrument, and transducer are summed along with a "Within" variance value to get the total variance. For the mockup, "Within" variability would be the variability between the three values obtained for the three UT images in the 3-foot path, which is caused by the actual variability in the wall thickness of the mockup. For the tank plates, the "Within" variability is the changing difference from nominal thicknesses between and within the seven UT images.

The "Percent of Total" and the "Plot Percent" sections of the tables show what proportions of the variability in the data are due to the various components. For the mockup, the primary contributor at $60 \%$ is the operator with minimal amounts for transducer and within (changing plate thickness). No variability 
at all is attributed to the instruments. For the tank, the primary contributor at $52.5 \%$ is the "Within" variability. This variability is caused by the differing plate thicknesses even after the nominal thickness is subtracted. Lesser amounts are then due to transducer and instrument. And now no variability at all is attributed to the operators.

Table 5.7. Mockup Variability Study Results

\begin{tabular}{|c|c|c|c|c|}
\hline Component & $\begin{array}{l}\text { Variance } \\
\text { Component }\end{array}$ & $\begin{array}{c}\text { Percent of } \\
\text { Total }\end{array}$ & Plot Percent & $\begin{array}{l}\text { Square Root } \\
\text { (Variance } \\
\text { Component) }\end{array}$ \\
\hline Instrument & $0.00 \mathrm{E}+00$ & 0.0 & $\overline{\mathrm{E}}$ & 0 \\
\hline Transducer & 0.0000025 & 29.0 & E & 0.00158 \\
\hline Operator & 5.17E-06 & 60.0 & $\bar{\square}$ & 0.00227 \\
\hline Within & $9.44 \mathrm{E}-07$ & 11.0 & 5 & 0.00097 \\
\hline Total & 8.61E-06 & 100.0 & $\square$ & 0.00293 \\
\hline
\end{tabular}

Table 5.8. Tank AW-103 Variance Components

\begin{tabular}{lccccc}
\hline \multicolumn{1}{c}{ Component } & $\begin{array}{c}\text { Variance } \\
\text { Component }\end{array}$ & \% of Total & Plot \% & Sqrt (Var Comp) \\
\hline Instrument & 0.0000020 & 15.6 & & & 0.00143 \\
Transducer & 0.0000041 & 31.9 & & & 0.00204 \\
Operator & 0.0000000 & 0 & & & 0 \\
Within & 0.0000068 & 52.5 & & & 0.00261 \\
\hline Total & 0.0000130 & 100.0 & & & 0.00361 \\
\hline
\end{tabular}

The biggest change for the tank study, as compared to the mockup study, was the lack of variability due to operator, which was the primary contributor for the mockup study. Transducer showed more variability than instrument in both studies. Note the total variability standard deviation increased from the mockup study to the tank study only from 2.9 mil to 3.6 mil, and that increase was due primarily to the added within variability. (Note this total standard deviation is the square root of the total variance component, and not the sum of the individual standard deviations.) When only the three measurement factors (instrument, transducer, and operator) are considered, adding their variance components and taking the square root to get their combined standard deviation, then the mockup and tank measurement standard deviations are, respectively, $2.7 \mathrm{mil}$ and $2.5 \mathrm{mil}$. So slightly less measurement variability was shown in the tank than for the mockup.

A two sigma measurement uncertainty range over instrument/transducer/operator is therefore about \pm 5 mil in either case. No explanation is offered here as to why the operator differences were more substantial in the mockup study than in the tank study. 


\subsection{Conclusions}

Variations noted in the data between the first inspection series and the second inspection series initiated this study.

Since measurement inception in 1997, nine waste tanks have been examined twice through FY 2009 and were used as the basis information in performing these analyses. Several different studies were conducted, and the results are presented in this report which addresses three key areas. The first area concerns the different types of evaluation that were used during data analysis that occurred in the initial scan years (1997-2001) and was considered a historical review. Secondly a series of studies were performed on laboratory mockups where the parameters could be controlled. Finally a couple of actual field studies were performed on waste tanks 241-AW-103 and 241-AW-105. The conclusions that resulted from these studies are addressed below. The first three conclusions are more general, but they are supported by the latter conclusions associated with the specific studies.

\section{General conclusions:}

- Precision: The UT measurement process is likely more precise (repeatable) than it's been given credit for, at least in the short term under consistent temperature conditions. Variability studies described in this report with multiple operators, instruments, and transducers, and thus multiple setups and calibrations, indicated that measurement results are repeatable within a two-sigma range to about \pm 5 mil.

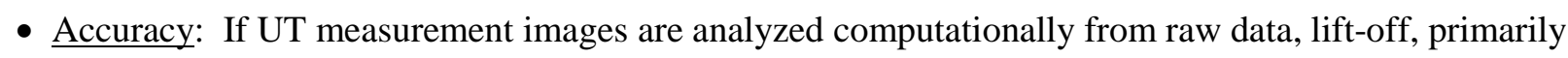
in one scanner direction, can cause overestimation of wall thickness, but the visual analysis method currently used is minimally impacted by this. An altered fixture should reduce such lift-off. However, temperature differences between couplant, tank wall, and calibration block can significantly impact measurement bias, even within the currently required differentials of no more than 25 degrees. Former analysis methods that used peak/edge analysis show this impact while a newly proposed multiple-echo method shows much less sensitivity to such temperature differentials.

- Corrosion conclusions: Comparing old to new inspections to determine wall corrosion for a particular tank is somewhat risky because specific and respective temperature conditions under the old and new inspections are unknown. For example, a hot-summer old inspection and cold-winter new inspection, or conversely, might have resulted in differing couplant, tank wall, and calibration block temperature relationships between the two inspections and thus altered accuracy characteristics. These differences would in turn lead to poor wall-thickness change estimates for the peak/edge analysis methods currently used. Using instead multiple echo analysis, currently under investigation, in subsequent consecutive inspections would appear to mostly eliminate such problems thereby facilitating improved old to new comparisons.

Specific conclusions:

- Peak, Edge, and Peak/Edge analysis of UT inspection scans for various tanks demonstrated how the particular type of analysis used for old inspections could be deduced. Measurement differences between the analysis methods are shown to be up to about 4.5 mils on the average. Such measurement differences should be used to adjust "old-minus-new” differences for tanks where 
different analysis methods were used in the old and new inspections. Peak/Edge is now the preferred approach and has been used consistently since about the 2002 timeframe. (Section 3.3)

- Baseline measurements were made on the two mockups used in these studies. Flat-barrel and pointbarrel micrometer measurements are maximum values over the size of the barrel tip, so point-barrel measurements were about 2.5 mils smaller on the average. No difference was indicated between PNNL and AFS point-barrel measurements. The manual UT values taken on the same mockup areas were in between micrometer values. The manual micrometer values averaged about 1.1 mils greater than the point-barrel measurements and about 1.4 mils less than the flat-barrel measurements. (Section 4.1)

- A wall-cleaning study on a mockup that scanned un-cleaned areas and areas cleaned using wire brush or flapper wheel showed no significant difference in UT image averages before and after cleaning. (Section 4.2) Therefore, the cleaning method did not introduce actual wall thickness or thickness measurement changes.

When mockup plates' baseline measurements using micrometers and manual UT were compared to subsequent scan measurements in the wall-cleaning and variability studies, the scan thickness measurements were about 12 mils less than the baseline measurements. (Section 4.2.2) While the specific cause of this difference was not identified, it could potentially be due to the manual UT and micrometer measurements being relatively unaffected by differing couplant, mockup, and calibration block temperatures. Such temperature differences can influence the UT scan measurements as described in the following bullets.

- A temperature study was conducted (Section 4.3) that kept the test block and couplant temperatures close together, but varied them in different combinations with varying calibration block temperatures. Results showed that having test block/water couplant temperature lower than the calibration block temperature led to under-estimating wall thickness. Conversely, having calibration block temperature lower than block/water couplant temperature led to over-estimating wall thickness. Having temperatures the same led instead to generally unbiased thickness measurement.

Under the operational requirement that tank wall and calibration block temperature be within $25^{\circ} \mathrm{F}$ of each other, the under-/over-estimation of wall thickness could still be as great as \pm 14 mils for UT image averages. Such temperature variation is, therefore, indicated to be a considerably larger contributor to UT measurement variability and/or bias than the measurement factors in the previous bullet. Based on these results, differing temperature combinations from old to new inspections could be a very significant source of measured wall-thickness differences, so keeping the calibration block/tank wall/couplant temperatures even closer together than the $25^{\circ} \mathrm{F}$ requirement is certainly desirable, if not essential, for meaningful comparisons of old and new inspection results.

- A second temperature study (Section 4.4) was conducted that kept the test block and calibration block temperatures close together but varied them in different combinations with varying couplant temperatures. Results showed that having couplant temperature less than the test block/calibration block temperature led to under-estimating wall thickness by as much as 35 mils, again a significant source of potential bias/variability. Conversely, having the test block/calibration block temperature less than couplant temperature, or having the temperatures the same, led to unbiased thickness estimation. Thus, couplant temperature should be kept at least as high as the tank wall and calibration block temperatures. 
A more comprehensive study that varies all three temperatures independently (test block, calibration block, and couplant), as in the operator/transducer/instrument study, would be useful.

- The previous temperature study results were obtained using peak/edge analysis as is currently used in field inspections. An alternative multiple-echo analysis approach was also used to evaluate the UT measurements from these temperature studies (Section 4.3.4 and 4.4.4). This alternative approach resulted in more than an order of magnitude reduction in the thickness changes observed. Thus, the multiple-echo approach showed much less sensitivity to such temperature changes. This alternative analysis approach should be investigated for field use.

- Other studies performed on mockups, including spring tension of transducer holders (Section 4.5), cable length (Section 4.6), and dual-element versus single-element transducers (Section 4.7), concluded that modifications of these components within the parameters analyzed would have little impact on the measurement values.

- Point studies were performed on a mockup plate and in Tanks 241-AW-103 and 241-AW-105 (Section 5.1). Three-inch-square areas of the plate and tank walls were examined using subsets of the usual scan pixel measurements. Nine fixed points were then measured from within the 3-inch areas with the scanner stationary. When the 7000+ pixels were examined for the 3-inch areas, persistent measurement difference patterns were observed for the tank and mockup scans, which were caused by transducer lift-off and scanner raster/step settings.

Subsequent discussion with inspection personnel indicated their awareness of such patterns. The inspection personnel explained how they account for the lift-off so that patterns do not have influence on the measurement analyses. In particular, the lift-off phenomenon from the scanner changing directions has dramatic effect on measurements, with generally every other row of pixel measurements being biased quite high. Again, this lift-off bias does not impact the current visual analysis approach used by the Level III inspectors. If personnel actually do computations on the pixel measurements, the impact of the lift-off phenomenon needs to be considered.

For the mockup plate, the average bias between the scan measurement of the centered 3-inch areas and the nine stationary points was 4.6 mils when all pixels were used, but reduced to 1.3 mils when the lift-off rows of pixels were not included. Due to rougher walls, the lift-off phenomenon was considerably greater in Tank 241-AW-105. The average bias for the 3-inch areas was then 11.4 mils with only 0.9 mils for Tank 241-AW-103. The corrected values obtained by omitting the lift-off pixels were not computed for these latter two cases. The observed biases would be even greater for the entire 12-inch $\times 15$-inch images than for the 3-inch squares. Without the lift-off pixels included, little difference is expected between the scan and stationary measurements. Fixture re-design is being performed that would reduce or eliminate the lift-off phenomenon.

- UT image measurement variability studies on operators, instruments, and transducers were performed through repeated scans of a mockup plate and Tank AW-103 (Section 5.2). In the tank study, the primary source of variation was between tank locations while this was a minimal source of variability for the mockup plate. Among the measurement factors, for the mockup, the primary contributor to variability was the operator followed by the transducer with essentially no variability between instruments. However, in the tank study, the most variability was due to transducer, followed by instrument, with essentially none due to operator. The differing results are rather surprising. When only the measurement factors are considered and not the location differences, a combined one standard deviation variability for the mockup plate was 2.7 mils and for the tank 2.5 mils, so slightly 
less measurement variability was demonstrated in the tank study. Two-sigma ranges for these three combined measurement factors are thus about \pm 5 mils. 


\subsection{References}

Birks AS, RE Green Jr. and P McIntire. 1991. Nondestructive Testing Handbook, Second Edition: Volume 7, Ultrasonic Testing. American Society for Nondestructive Testing, Columbus, Ohio.

Perdrix M, JC Baboux and F Lakestani. 1980. "Theoretical and Experimental Study of the Influence of the Couplant Layer on the Response of a Broadband Ultrasonic Transducer.” J. Phys. D: Appl. Phys., 13:185-194.

Boomer, KD. 2007. Double-Shell Tank Integrity Program Plan. RPP-7574, Revision 2. CH2M Hill Hanford Group, Inc., Richland, Washington. 
7.2 


\section{Distribution}

No. of

Copies

4 Washington River Protection Solutions

$\begin{array}{ll}\text { Herbert S. Berman } & \text { RS-58 } \\ \text { Kayle D. Boomer } & \text { H6-19 } \\ \text { Christopher A. Burke } & \text { R3-26 } \\ \text { Jim L. Castleberry } & \text { R3-26 }\end{array}$

No. of

Copies

\section{Internal Distribution}

Pacific Northwest National Laboratory P.O. Box 999

Richland, WA 99352

$\begin{array}{ll}\text { AF Pardini } & \text { K5-26 } \\ \text { JT Munley } & \text { K5-17 } \\ \text { SL Crawford } & \text { K5-26 } \\ \text { DR Weier } & \text { K6-08 } \\ \text { ML Watkins } & \text { K5-26 } \\ \text { Information Release } & \text { (PDF) }\end{array}$




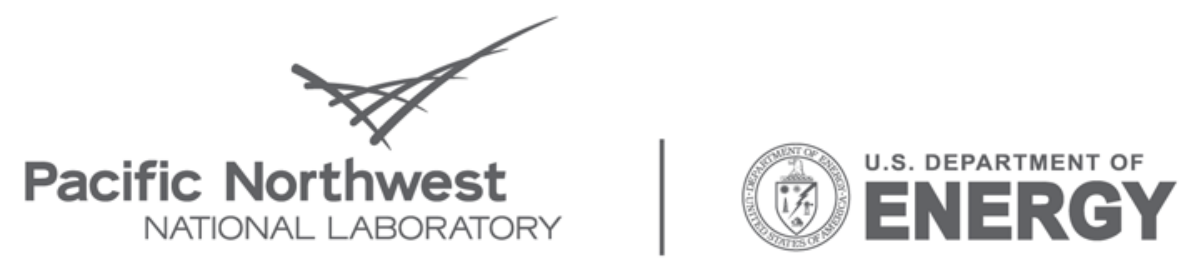

Proudly Operated by Battelle Since 1965

902 Battelle Boulevard

P.O. Box 999

Richland, WA 99352

1-888-375-PNNL (7665)

www.pnl.gov 